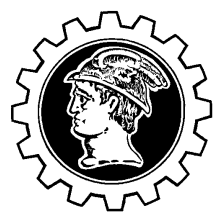

UNIVERSIDADE DE SÃO PAULO

FACULDADE DE ECONOMIA, ADMINISTRAÇÃO E

CONTABILIDADE

DEPARTAMENTO DE ECONOMIA

PROGRAMA DE PÓS GRADUAÇÃO EM TEORIA ECONÔMICA

AGLOMERAÇÃO E DESENVOLVIMENTO: EVIDÊNCIAS PARA MUNICÍPIOS BRASILEIROS

Daniel Silva Junior

Orientador: Prof. Dr. Carlos Eduardo Soares Gonçalves

SÃO PAULO 
Prof $^{\mathrm{a}}$.Dr ${ }^{\mathrm{a}}$. Suely Vilela

Reitor da Universidade de São Paulo

Prof.Dr.Carlos Roberto Azzoni

Diretor da Faculdade de Economia, Administração e Contabilidade.

Prof.Dr.Joaquim José Martins Guilhoto

Chefe do Departamento de Economia

Prof.Dr.Dante Mendes Aldrighi

Coordenador do Programa de Pós-Graduação em Economia 
DANIEL SILVA JUNIOR

\section{AGLOMERAÇÃO E DESENVOLVIMENTO: EVIDÊNCIAS PARA MUNICÍPIOS BRASILEIROS}

Dissertação apresentada ao Departamento de Economia da Faculdade de Economia, Administração e Contabilidade da Universidade de São Paulo como requisito para a obtenção do título de Mestre em Economia.

Orientador: Prof. Dr. Carlos Eduardo Soares Gonçalves 
Dissertação defendida e aprovada no Departamento de Economia da Faculdade de Economia, Administração e Contabilidade da Universidade de São Paulo - Programa de Pós-Graduação em Economia, pela seguinte banca examinadora:

Silva Junior, Daniel

Aglomeração e desenvolvimento: evidências para municípios brasileiros

/ Daniel Silva Junior. -- São Paulo, 2007.

$104 \mathrm{p}$.

Dissertação (Mestrado) - Universidade de São Paulo, 2007

Bibliografia.

1. Desenvolvimento econômico 2. Aglomerações urbanas 3. Econometria I. Universidade de São Paulo. Faculdade de Economia, Administração e Contabilidade II. Título.

CDD -338.9 
À minha família

Por todo o apoio dado ao longo destes anos. 


\section{AGRADECIMENTOS}

Agradeço a Deus, por sua proteção em todos esses anos.

À CNPQ pelo suporte financeiro prestado a execução dessa dissertação .

Ao departamento de economia da Universidade de São Paulo, na figura de seus funcionários, sempre competentes e dispostos a ajudar, e de seus professores, que com sua competência me ajudaram a compreender melhor o mundo das ciências econômicas. Em especial aos meus orientadores Danilo Camargo Igliori e Carlos Eduardo Gonçalves, que sempre demonstraram paciência, compreensão e vontade de ajudar, sem vocês este trabalho nunca seria finalizado.

Aos meus amigos do IPE, pela amizade e companheirismo durante essa jornada. Em especial, gostaria de agradecer aos ingressantes no mestrado de 2005: Gustavos (os dois), Tiagos (os dois), Marcos (um só, o Cidão), Raul, Emilio (que apesar de ser Corintiano, Argentino e Comunista é uma boa pessoa), Priscila (miss teoria econômica 2005), Rojas, Mário, Maria, Camila, Vanessa (capitã do lendário time de vôlei da FEA), Daniela (desenhista, costureira, jogadora de vôlei, ambientalista, agricultora, economista e cidadã de Jundy-city), Mariane (seu caderno deveria passar ao domínio público), Renata, Bisinha (Rafael) e João Paulo; a Bruno Rocha - obrigado pela matriz W - e a todos os meus companheiros de caminhada diária ao bandejão: JP, Sakura, Zé, Tio Toninho, Gilmar, Gervásio (Seu Rezende) e o Cidão (o Marcos), que abandona a primavera em NY para nos acompanhar nesse ritual - desculpem-me se esqueci alguém.

Finalmente, agradeço minha família. As minhas irmãs Andréia e Jussara, ao meu praticamente irmão Alan, as minhas avós Ana e Almerinda, as minhas tias Marinalva e Dejanira, meus primos André, Reinaldo e Solange (quase irmãos) e acima de tudo, agradeço a minha mãe Maria, que mesmo não estando mais nesse mundo, continua sempre presente em meu coração. Devo tudo a vocês. 
Toda cidade é um tipo de associação, e toda associação é estabelecida tendo em vista algum bem (pois os homens sempre agem visando a algo que consideram ser um bem). 


\section{RESUMO}

Esta dissertação investiga o impacto da aglomeração sobre o desempenho econômico dos Municípios Brasileiros entre 1970 e 2000. Para tanto, foram estimadas equações de crescimento combinadas com modelos econométricos espaciais. Os resultados indicam que a aglomeração teve efeito positivo sobre o crescimento econômico, sem indícios claros de congestionamento. Além disso, também foram encontrados sinais de externalidades positivas e spillovers de educação vindos de áreas vizinhas. Os resultados reforçam a necessidade de se considerar os efeitos espaciais quando se procura entender o desenvolvimento econômico no Brasil. 


\begin{abstract}
This paper investigates the impact of agglomeration economies on economic performance of Brazilian municipalities between 1970 and 2000. In order to achieve that, we estimate growth equations adopting standard spatial econometric models. The results indicate that agglomeration has positive impacts on economic development without clear indication of congestion effects. Moreover, we also found evidence of positive spatial externalities and educational spillovers coming from neighboring areas. The results reinforce the need for considering spatial effects when aiming to understand the economic development in Brazil.
\end{abstract}




\section{SUMÁRIO}

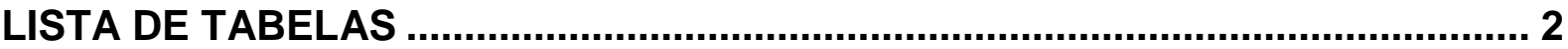

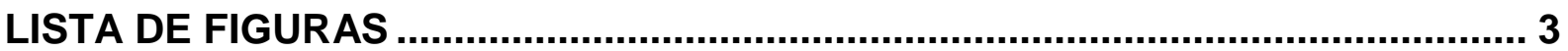

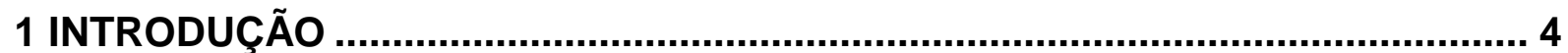

2 REVISÃO DE LITERATURA...................................................................... 8

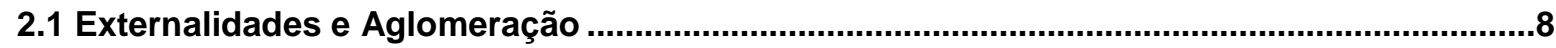

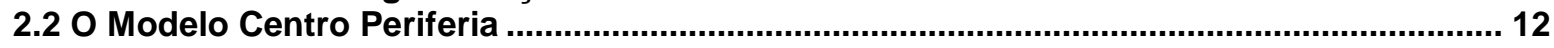

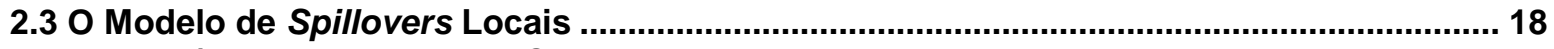

2.3.1 Hipóteses do Modelo de Spillovers Locais ................................................................... 19

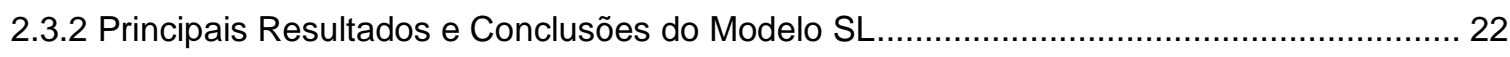

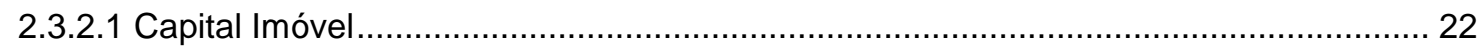

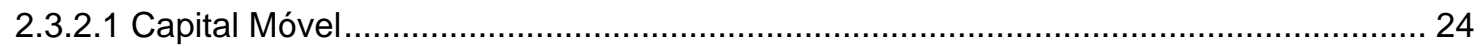

2.3.3 Considerações Sobro o Principais Resultados e Conclusões do Modelo SL....................... 27

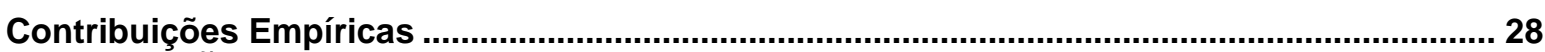

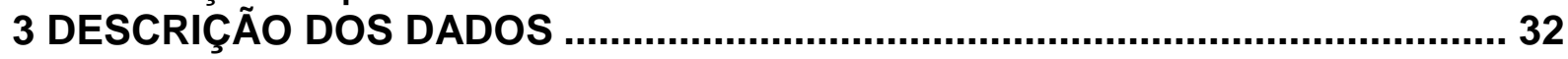

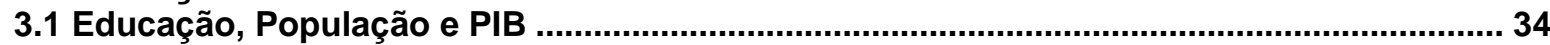

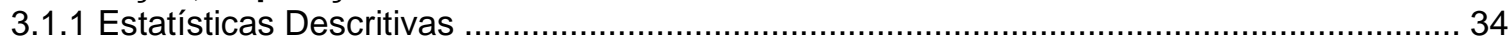

3.1.2 Curvas de Lorenz, Índice de Gini e Análise Visual ....................................................... 40

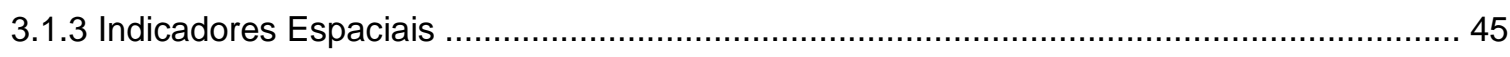

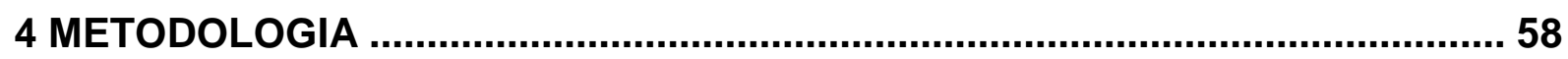

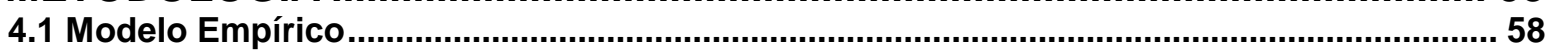

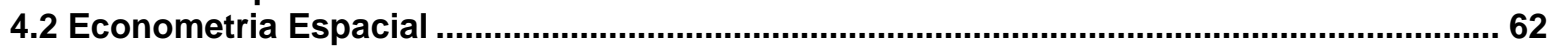

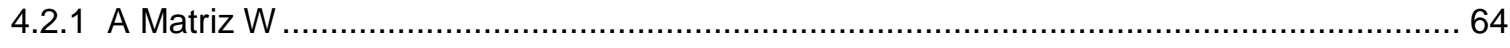

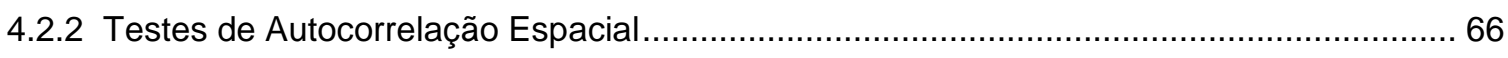

4.2.3 Abordagem Alternativa da Autocorrelação Espacial................................................... 68

5 RESULTADOS ..................................................................................... 71

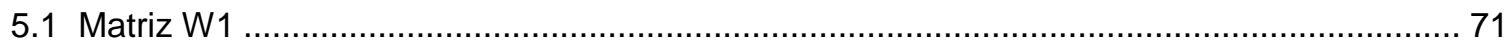

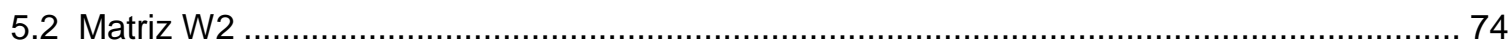

5.3 Correção não Paramétrica da Variância ………............................................................. 76

5.4 A Exclusão das Regiões Norte e Centro Oeste ............................................................ 80

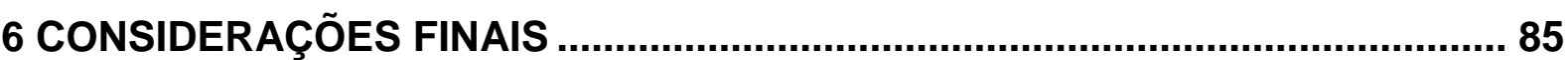

REFERÊNCIAS ............................................................................................. 88 


\section{LISTA DE TABELAS}

Tabela 3.1 - Número de AMCs por Região.................................................... 33

Tabela 3.2 - Tamanho médio das AMCs (Média por Região) ............................... 34

Tabela 3.3 - Infra-Estrutura Domiciliar (1970) ................................................... 34

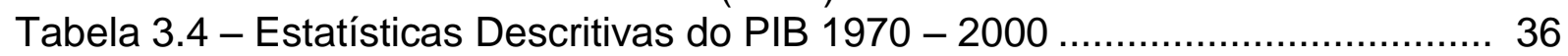

Tabela 3.5 - Estatísticas Descritivas da População 1970 - 2000 ........................... 37

Tabela 3.6 - Estatísticas Descritivas da Escolaridade 1970 - 2000 ...................... 38

Tabela 3.7 - Evolução do Índice de Gini .......................................................... 42

Tabela 3.8 - Teste I de Moran para Autocorrelação Espacial - Educação .............. 48

Tabela 3.9 - Teste I de Moran para Autocorrelação Espacial - PIB ....................... 48

Tabela 3.10 - Teste I de Moran para Autocorrelação Espacial - População ........... 48

Tabela 3.11 - Valores Extemos do Moran Local - Escolaridade 1970 .................... 54

Tabela 3.12 - Valores Extemos do Moran Local - Escolaridade 2000 .................... 54

Tabela 3.13 - Valores Extemos do Moran Local - Crescimento da Escolaridade 1970

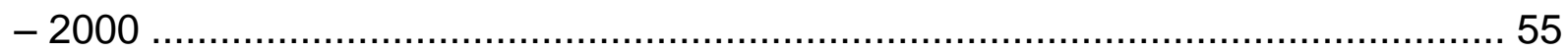

Tabela 3.14 - Valores Extemos do Moran Local - PIB 1970 ................................. 55

Tabela 3.15 - Valores Extemos do Moran Local - PIB 2000 ................................. 55

Tabela 3.16 - Valores Extemos do Moran Local - Crescimento do PIB 1970-2000. 56

Tabela 3.17 - Valores Extemos do Moran Local - População 1970 ....................... 56

Tabela 3.18 - Valores Extemos do Moran Local - População 2000 ....................... 56

Tabela 3.19 - Valores Extemos do Moran Local - Crescimento da População 2000

Tabela 5.1 - Crescimento do PIB Municipal Total - W1 ........................................ 74

Tabela 5.2 - Crescimento do PIB Municipal Total - W2 ................................... 76

Tabela 5.3 - Crescimento do PIB Municipal Total ............................................ 78

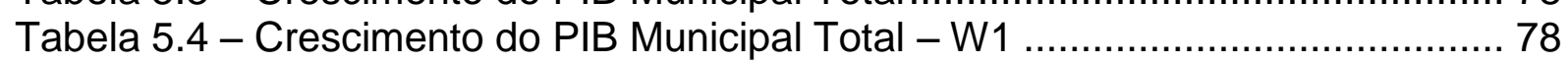

Tabela 5.5 - Crescimento do PIB Municipal Total - W2 .................................. 79

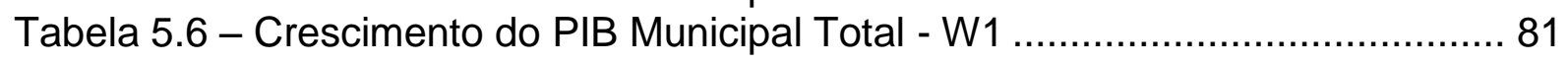

Tabela 5.7 - Crescimento do PIB Municipal Total - W2 ................................. 82

Tabela 5.8 - Crescimento do PIB Municipal Total ........................................... 83

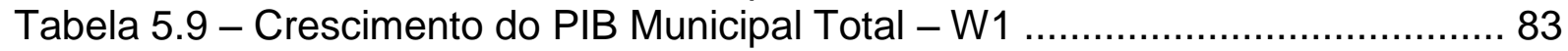

Tabela 5.10 - Crescimento do PIB Municipal Total - W2 .................................. 84 


\section{LISTA DE FIGURAS}

Figura 2.1 - Diagrama Tomahawk ……………….................................... 16

Figura 2.2 - Diagrama Esquemático do Modelo de Spillovers Locais ..................... 21

Figura 3.1 - Evolução do PIB ..................................................................... 39

Figura 3.2 - Evolução da População ............................................................ 39

Figura 3.3 - Evolução da Educação ………………....................................... 39

Figura 3.4 - Curva de Lorenz - PIB …………….................................... 41

Figura 3.5 - Curva de Lorenz - População ………….................................... 41

Figura 3.6 - Curva de Lorenz - População - Educação ……………………....... 41

Figura 3.7 - Densidade Geográfica do PIB - 1970 ……................................... 42

Figura 3.8 - Densidade Geográfica do PIB - 2000 ........................................ 43

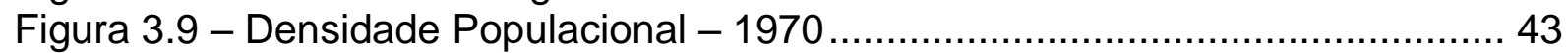

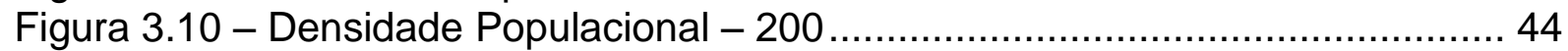

Figura 3.11 - Valores Densidade Educacional - 1970 ..................................... 44

Figura 3.12 - Valores Densidade Educacional - 2000 ................................... 45

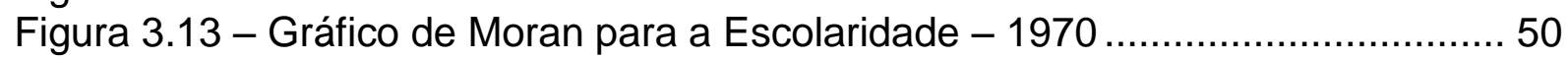

Figura 3.14 - Gráfico de Moran para a Escolaridade - 2000 ............................... 50

Figura 3.15 - Gráfico de Moran para o Crescimento da Escolaridade 1970-2000 ... 50

Figura 3.16 - Gráfico de Moran para o PIB - 1970 ……..................................... 51

Figura 3.17 - Gráfico de Moran para o PIB - 2000 ......................................... 51

Figura 3.18 - Gráfico de Moran para o Crescimento do PIB 1970-2000 ................ 51

Figura 3.19 - Gráfico de Moran para a População - 1970 ................................... 52

Figura 3.20 - Gráfico de Moran para a População - 2000 ................................. 52

Figura 3.21 - Gráfico de Moran para o Crescimento da População 1970-2000....... 52 


\section{Introdução}

Durante o fim do século dezoito e inicio do século dezenove a Europa experimentou uma elevação na taxa de crescimento. Simultaneamente, verificamos a concentração da população e das atividades econômicas em determinadas regiões. A taxa de urbanização cresceu de modo acelerado e formaram-se diversos distritos industriais que se mantém até os dias de hoje (Baldwin e Martin (2004)). Embora dramático, o exemplo da revolução industrial ilustra de modo claro a idéia expressa por Fujita e Thisse (2002), “a aglomeração é a contraparte espacial do crescimento econômico ${ }^{1 \%}$.

Uma série de fatores pode ser apontada como causadora dessa forte relação entre crescimento e aglomeração. A concentração facilita a geração e transmissão de conhecimento (spillovers), promove a formação de um mercado de trabalho eficiente e economiza custos de transporte a consumidores e produtores. Embora essas idéias sejam antigas, Marshall (1920) já as apontava como responsáveis pela formação de distritos industriais, somente a partir da década de 90, com o surgimento da Nova Geografia Econômica (NGE), elas começam a ser incorporadas de maneira explicita na modelagem econômica.

O modelo centro periferia (CP), proposto por Krugman (1991 a,b), é o marco inicial da NGE, que pode ser descrita como uma linha de pesquisa que utiliza as idéias a respeito de externalidades e imperfeições de mercado (concorrência monopolistíca) para criar modelos que se insiram dentro de padrões aceitos pela teoria econômica e que sejam capazes de captar as forças econômicas responsáveis pela distribuição das atividades econômicas (Igliori 2001).

Embora representem um grande avanço do ponto de vista teórico, os modelos da NGE apresentam algumas limitações, sobretudo no que diz respeito ao crescimento econômico e a obtenção de modelos analiticamente tratáveis. Essas deficiências deram origem ao modelo de spillover locais (SL), apresentado em Martin e Ottaviano (1999) e Baldwin et al. (2001), que procura unir as idéias de crescimento endógeno propostas por Romer (1986 e 1990) com as

\footnotetext{
1 "agglomeration can be thought as the territorial counterpart of economic growth"
} 
externalidades e imperfeições de mercado oriundas da NGE. Este modelo sugere que a aglomeração apresenta um efeito positivo sobre o processo de desenvolvimento econômico.

Paralelamente ao desenvolvimento da teoria, os métodos quantitativos para o estudo de questões espaciais também avançaram na última década. Dentro dessa evolução, duas linhas de pesquisa se destacam. A primeira delas, iniciada por Kelejian e Prucha (1998 e 1999), utiliza métodos de GMM, ao invés de Máxima Verossimilhança, para estimação dos modelos tradicionais de econometria espacial ${ }^{2}$. No entanto, esse tipo de GMM espacial mantém hipóteses paramétricas sobre a estrutura de dependência espacial presente na população. Conley (1999), por outro lado, rompe com essas hipóteses ao descrever um estimador de GMM não paramétrico para a correção da dependência espacial.

Empiricamente, evidências da existência de externalidades foram encontradas em vários estudos empíricos. O trabalho de Ciccione e Hall (1996), por exemplo, analisa a relação entre concentração das atividades econômicas, medida através do número de trabalhadores por área, e a produtividade média do trabalho em counties americanos. Ciccione (2002) promove um estudo semelhante em cinco países da Europa (França, Alemanha, Espanha, Itália e Reino Unido) no nível de nuts $3^{3}$. Em ambos os artigos, encontra-se relação positiva entre aglomeração e produtividade do trabalho.

Testes indiretos, principalmente através da detecção de spillovers, também fornecem evidências da existência de efeitos positivos da aglomeração sobre o desenvolvimento. $O$ trabalho de Jaffe et al. (1993) é um dos pioneiros nessa área. Com dados americanos sobre patentes, os autores concluem que os spillovers de conhecimento não são totalmente locais, eles podem se estender além da vizinhança imediata. Um trabalho mais recente, Keller (2002), mostra que os spillovers estão se tornando mais globais com o passar do tempo, mas “tecnologia é em grande parte local, não global, pois os benefícios advindos dos spillovers declinam com a distância"».

\footnotetext{
${ }^{2}$ Uma síntese dos modelos tradicionais de econometria espacial pode ser encontrada em Anselin (1988).

3 Nuts significa "Nomenclatura de Unidades Territoriais para Estatísticas" em Francês. O nível 3 corresponde a menor área disponível para análise.

4 "technology is to a substantial degree local, not global, as the benefits from spillovers are declining with distance"
} 
No entanto, os efeitos benéficos oriundos da concentração econômica não são inesgotáveis, a concentração elevada pode trazer resultados indesejados, conhecidos como efeitos de congestionamento. Estas externalidades negativas podem ser representadas por diversos fatores, tais como dificuldade de provisão de serviços públicos, aumento excessivo do custo da mão de obra e do valor dos aluguéis (Solow 1973, Henderson 2000 e Duranton e Puga 2001). Dessa forma, espera-se que aglomeração apresente um efeito benéfico sobre o desenvolvimento até um determinado ponto, a partir do qual se torna um problema para o crescimento econômico.

A discussão acima sugere a existência de um nível ótimo de concentração econômica, o que levanta questões a respeito da promoção de políticas públicas: Como garantir que a economia trabalhe em seu nível ótimo? Qual deve ser a atitude do governo em relação às aglomerações? Incentiva-las ou não?

Do ponto de vista teórico, Henderson (1974) e Becker e Henderson (1999) mostram que, se o mercado imobiliário funcionar perfeitamente e houver autonomia fiscal em cada localidade, o tamanho das cidades será eficiente do ponto de vista econômico, caso contrário, haverá tendência a super-concentração.

Uma outra linha de pesquisa argumenta, no entanto, que as instituições políticas tenderam a promover a concentração econômica acima do ponto ótimo (Renaud (1981), Henderson (1988), Ades e Glaeser (1995)). Isto se deve ao fato das políticas públicas beneficiarem cidades com maior número de habitantes e com maior poder econômico, o que distorce a decisão dos agentes a respeito do local escolhido para morar. Contudo, isso pode não ocorrer na prática, Au e Henderson (2006) mostra que as restrições a migração existentes na China fazem com que grande parte das cidades tenha tamanho inferior ao ótimo.

Com base nas questões políticas suscitadas nos últimos parágrafos, pode-se afirmar de forma inequívoca que a compreensão da relação entre desenvolvimento e aglomeração é de vital importância para a promoção do bem estar da população. Dentro desse contexto, este trabalho irá contribuir para o aumento do conhecimento sobre o tema, através do estudo do desenvolvimento econômico dos municípios brasileiros entre anos de 1970 e 2000. 
A dissertação está estrutura em 6 capítulos, incluindo esta introdução. O capítulo seguinte revisa a moderna literatura sobre aglomeração e sua ligação com o desenvolvimento econômico. O terceiro capítulo descreve de modo detalhado a base de dados utilizada no estudo. O quarto capítulo mostra a estratégia de análise. Nele é apresentado uma equação estimável capaz testar as principais implicações trazidas pela teoria econômica, além de promover uma discussão acerca dos conceitos fundamentais da econometria espacial. $\mathrm{O}$ quinto capitulo exibe os resultados. Por fim, o sexto capitulo fornece as principais conclusões obtidas. 


\section{Revisão de Literatura.}

Aglomerações humanas existem desde a pré-história. Bairoch (1985) argumenta que agrupamentos humanos começam a emergir em várias partes do mundo após a revolução do neolítico, como conseqüência do crescimento do excedente agrícola. Embora um tanto impreciso, esse ponto no tempo representa o início de uma trajetória de urbanização crescente, que continua a ocorrer nos dias atuais. Entre 1950 e 1995 a proporção de pessoas vivendo em cidades subiu de 30\% para 45\% (United Nations, 1994), e estima-se que este número chegará a 50\% em 2008 (World Watch Institute, 2007).

Mais difícil que descobrir a origem das cidades, ou ainda constatar seu crescimento, é explicar de modo claro os motivos que levam a sua formação, permanência e crescimento ao longo do tempo. Tais razões podem ser filosóficas, como os apontados por Aristóteles em "Política", religiosas - Jerusalém e Meca podem ser tidas como exemplos - geográficas ou ainda, podese argumentar que as cidades são frutos de meros acidentes históricos.

Não se deve negar que os motivos destacados acima desempenham um papel importante na formação das cidades. No entanto, conforme apontado por (Huriot e Thisse, 2000), existem princípios gerais, comuns a todas as aglomerações, que podem ser compreendidos com ajuda da teoria econômica. Esses princípios gerais são a base dessa dissertação, e os avanços teóricos obtidos nessa área são tratados no restante dessa seção.

\subsection{Externalidades e Aglomeração}

A formação de aglomerações, desde pequenas cidades até grande megalópoles como São Paulo e Tóquio, esta relacionada a existência de externalidades, que representam forças econômicas capazes de tornar tais lugares atrativos.

O trabalho de Marshall (1920) pode ser tomado como um ponto de partida no estudo da relação entre externalidades e formação de aglomerações. Nesse livro, o autor procura explicar a formação dos distritos industriais, tendo por base a Inglaterra do final do século 
XIX. Deve-se observar, porém, que Marshall não faz uso explícito dos termos externalidade e retornos crescentes de escala, ao invés disso, o autor empregam a palavra "economia" para referir-se ao aumento de produtividade originado de uma dada forma de organização industrial ${ }^{5}$.

Seguindo Fujita e Thise 2000, dividimos as economias Marshallianas em quatro grupos. O primeiro deles refere-se às chamadas economias internas, ou retornos crescentes de escala. $\mathrm{O}$ segundo tipo de economias diz respeito a formação de um mercado de trabalho especializado e a produção de conhecimento, frutos da acumulação de capital humano e das interações sociais (Fujita e Thise 2000). A disponibilidade de insumos necessários à produção (produtos intermediários) aparece como outro beneficio gerado pela aglomeração. Finalmente, Marshall destaca a infra-estrutura presente nos distritos industriais como uma externalidade positiva gerada pela aglomeração. Nota-se que enquanto o primeiro tipo de economia depende de cada empresa isoladamente, os demais necessitam da concentração de atividades econômicas e da formação de arranjos institucionais nas imediações de cada firma.

Trabalhos posteriores continuaram a enfatizar a função das externalidades na formação das aglomerações. Scitovsky (1954) propõe a divisão das externalidades em duas categorias: pecuniárias e tecnológicas. A primeira categoria ocorre quando o bem-estar de um consumidor ou as possibilidades de produção de uma firma são afetados diretamente pela ação de outro agente na economia. Merece atenção o uso do termo "diretamente" que significa fora de sistemas de preço (Mas-Colell et al. 1995). Por outro lado, externalidades pecuniárias ocorrem quando as atividades de um agente impactam a utilidade de um agente ou as possibilidades de produção de uma firma através de mecanismos de preços (Fujita e Thise, 2000).

As externalidades pecuniárias são essenciais em atividades econômicas relacionadas à produção (Fujita e Thise, 2000). Tomando o exemplo utilizado por Ottaviano e Thisse (2001), externalidades pecuniárias ocorrem em certa localidade se a entrada de novas firmas aumenta o mercado local através da demanda extra que elas geram.

\footnotetext{
${ }^{5}$ Uma discussão acerca da organização industrial proposta por Marshall pode ser encontrada em Igliori 2001.
} 
Externalidades tecnológicas, por sua vez, estão relacionadas a atividades de criação e de desenvolvimento tecnológico, sendo dessa forma os motores do crescimento econômico (Fujita e Thise, 2000; Glaeser et. al. 1992). Esse tipo de externalidade ocorre basicamente devido a difusão de conhecimento. Nesse sentido, a comunicação entre indivíduos que dividem interesses comuns pode ser um insumo para a criatividade (Lucas, 1988). Deve-se ressaltar que, mesmo com o avanço dos meios de comunicação, os processos de transferência de conhecimento são amplamente beneficiados pela proximidade, pois, conforme observado por Feldman (1994), “o conhecimento atravessa corredores e ruas mais facilmente que continentes e oceanos"

Um ponto importante acerca das externalidades tecnológicas é que embora sua função no crescimento das cidades seja fundamental, não há consenso na literatura acerca do seu mecanismo de atuação. Glaser et al. (1992) destaca três diferentes correntes econômicas que procuram explicar como se difunde o conhecimento dentro de uma aglomeração. A primeira delas, conhecida como Marshall-Arrow-Romer (MAR) - devido aos trabalhos de Marshall (1920), Arrow (1962) e Romer (1986) - destaca a importância de spillovers entre empresas de um mesmo setor. De acordo com essa corrente, a concentração de um determinado tipo de indústria dentro de uma cidade ajuda o crescimento do setor, e portanto, da cidade como um todo. Além disso, essa linha de pensamento também defende que o monopólio é melhor que a competição para o crescimento econômico, isso ocorre devido ao maior controle de informação conseguido pelo monopólio, o que permite à empresa internalizar as externalidades, facilitando a inovação e o crescimento.

Porter (1990) concorda com MAR acerca da importância de spillovers especializados na estimulação do crescimento, porém discorda acerca da importância do monopólio na geração de inovação. Porter (1990) enfatiza que a competição entre empresas é que causa o desenvolvimento tecnológico, pois empresas que vivem em ambientes altamente competitivos necessitam de inovação constante, caso contrário podem ser obrigadas a fechar.

A posição de Jacobs $(1969,1984)$ por outro lado, contraria totalmente as afirmações de MAR. Em primeiro lugar, a autora acredita que a diversidade de indústrias em uma dada localidade é o grande fator gerador de inovação. Em outras palavras, Jacobs postula que a fertilização

\footnotetext{
6 "Knowledge traverses corridors and streets more easily than continents and oceans"
} 
cruzada entre os diferentes setores é o grande motor da geração de conhecimento, e portanto do crescimento das cidades. Jacobs também destaca que a competição, e não o monopólio, é o fator essencial para a ocorrência de inovação: "monopólios gratuitamente ferem as cidades e suprimem aquilo que suas economias são capazes de alcançar....Preços extorsivos, embora sejam quase certamente danosos, são a menor desvantagem dos monopólios, pois os monopólios evitam alterar os métodos de produção, os produtos e os serviços ${ }^{7 \%}$.

Testes empíricos realizados por Glaeser et al. (1992) são favoráveis as posições de Jacobs, pois encontram evidências de que os diversos setores industriais crescem a taxas menores em cidades em que são super-representados. Além disso, um determinado setor, em uma dada cidade, cresce a taxas maiores se o tamanho médio de suas firmas for abaixo do tamanho médio nacional das empresas desse setor. Um estudo semelhante, conduzido por Henderson et al. (1995), encontra evidências tanto da presença de externalidades MAR quanto da presença de externalidades apontadas por Jacobs. Um ponto interessante acerca desse estudo é que o tipo de externalidade predominante depende da natureza do setor. Indústria "maduras" tendem a apresentar externalidades do tipo MAR, enquanto setores de alta tecnologia apresentam evidências de externalidades semelhantes as apresentadas por Jacobs.

Embora a discussão acima ressalte apenas externalidades positivas - no sentido de que incentivam a concentração econômica - externaliades (pecuniárias ou tecnológicas) também podem ser negativas, servindo dessa forma como uma força de dispersão que impede a concentração de todas as atividades econômicas em um único ponto no espaço. Externalidades negativas podem aparecer sob diversas formas, tais como congestionamentos, alto custo de aluguel, dificuldade na provisão de serviços públicos e violência (Solow, 1973, Henderson, 2000 e Duranton e Puga, 2001).

Deve-se notar que as externalidades descritas acima não são de modo algum excludentes. Na verdade, aglomerações são formadas por ambos os tipos de externalidades, geralmente atuando de maneira conjunta (Fujita e Thise, 2000). No entanto, determinados aglomerações são mais bem explicadas através da predominância de um ou outro tipo de externaliade. (O’Flaherty, 2005), por exemplo, afirma que a formação do Vale do Silício na Califórnia esta

\footnotetext{
7 "monopolies gratuitously harm cities and suppress what their economies are capable of achieving ...Extortionate prices, harmful though they most certainly are, are the least of disadvantages of monopolies, for monopolies forestall alternate methods, products and services"
} 
fortemente relacionada a difusão de conhecimento entre empresas do local, ou seja as externalidades tecnológicas conseguem explicar esse tipo de aglomeração de modo satisfatório. Ottaviano e Thise (2001), por outro lado, destacam a relevância das externalidades pecuniárias na explicação de aglomerações inter-regionais tais como o “Cinturão Manufatureiro" nos EUA ou o "Hot Banana” na Europa.

Embora a existência de aglomerações seja uma constatação trivial, e os motivos básicos para a existência desse fenômeno, conforme discutidos acima, sejam intuitivos. A questão da formação das cidades esteve fora do mainstrean da teoria econômica até a década de 1990 com o surgimento da Nova Geografia Econômica ${ }^{8}$. Tal ausência pode ser creditada a dificuldade de se criar modelos econômicos que incorporem a presença de externalidades e retornos crescentes de escala.

No entanto, a partir do trabalho inicial de Krugman (1991), diversos modelos foram construídos com o intuito de compreender as relações entre espaço e economia. No restante dessa seção, estudaremos dois deles: o modelo Centro-Periferia (CP) e o modelo de Spillovers Locais (SL). Essa escolha esta centrada nas características particulares de cada um deles. O modelo CP é inovador, responsável pela inauguração da Nova Geografia Econômica e serve como referência para modelos posteriores. O modelo de SL, por sua vez, é pioneiro no estudo das relações entre crescimento e aglomeração, destacando a presença de externalidades tecnológicas na geração de inovação e desenvolvimento econômico.

\subsection{O Modelo Centro Periferia}

Proposto por Krugman (1991 a,b) o modelo CP é a espinha dorsal da NGE. Basicamente, este modelo se propõe a estudar as possíveis causas de divergência econômica entre duas regiões fisicamente idênticas. Conforme veremos, um dos grandes méritos desse modelo é o uso de

\footnotetext{
${ }^{8}$ Essa afirmação merece duas qualificações. Primeiro, conforme destacado por Huriot and Thisse (2000), a formação de cidades estava presente nos primórdios da Ciência Economica, pode-se tomar como exemplo o trabalho de Cantilon (1755). Portanto, o termo "mainstrean” representa apenas a moderna economia neoclássica, não toda a história da ciência econômica. Segundo, Huriot e Thisse (2000) situam a inclusão da economia urbana ao mainstrean da teoria econômica na década de 1970. Preferimos colocar esse acontecimento na década de 1990, devido a grande repercussão da NGE no meio acadêmico. Um levantamento da história da economia urbana pode ser vista em Baumont and Huriot (2000).
} 
uma estrutura simples - sob o aspecto das idéias econômicas envolvidas - para tratar o complexo problema da distribuição espacial das atividades econômicas. A explicação sobre o modelo CP nessa seção é informal e intuitiva, as demonstrações e detalhes técnicos podem sem obtido em Baldwin et al. (2003), Krugman (1991 a, b) e Fujita et al. (1999).

Dentro do modelo, cada região apresenta dois setores produtivos, inicialmente idênticos em tecnologia e em número de trabalhadores. O primeiro deles é o setor tradicional, geralmente tratado como agricultura, cuja produção ocorre dentro de padrões Walrasianos de concorrência perfeita e retornos constantes. O segundo setor, normalmente tratado como setor manufatureiro, segue o padrão Dixit-Stiglitz (1977) de concorrência monopolística e retornos crescentes. Os trabalhadores não podem mudar de setor, similarmente, as empresas e os trabalhadores da agricultura não se deslocam entre as regiões. De modo contrário, os trabalhadores e a empresas do setor manufatureiro apresentam livre mobilidade entre as regiões, sendo assim os responsáveis pela dinâmica do modelo. Outra diferença entre os dois setores é forma de escoar a produção. Enquanto a agricultura está livre de custos de transporte e vende o seu produto com o mesmo preço nos dois mercados, a manufatura está sujeita a um tipo especial de custo conhecido como "iceberg costs" (idéia proposta por Samuelson, 1952), o que significa que para vender uma unidade de produto em outra região o produtor deve embarcar $\tau>1$ unidades.

Tomando como base o trabalho de Baldwin et al.(2003), pode-se descrever a lógica de funcionamento do modelo $\mathrm{CP}$ de modo simples. Basicamente, três forças são responsáveis pela alocação espacial das atividades econômicas no modelo. A primeira força é o "acesso ao mercado", ela descreve a tendência de firmas monopolistas localizarem sua produção no maior mercado e exportar para o mercado menor. Em seguida, temos o efeito "custo de vida", que representa o fato de que os produtos tendem a ser mais baratos na região com maior produção industrial, pois os consumidores desta região deverão importar uma menor quantidade de bens e, dessa forma, economizar os custos de transporte. Por fim, tem-se o efeito de "congestionamento do mercado" que reflete o fato de que indústrias que atuam em ambientes não competitivos preferem se localizar em regiões com menor número de competidores. Em resumo, as duas primeiras forças atuam no sentido de incentivar a aglomeração, enquanto a terceira delas promove a dispersão das atividades econômicas. 
Deve-se destacar que os dois efeitos de aglomeração - acesso ao mercado e o custo de vida reforçam-se mutuamente, desencadeando um processo de causalidade circular. Pode-se visualizar esse fato a partir de um mundo simétrico, dividido em duas regiões, Norte e Sul. Ambas as regiões são idênticas em relação ao número de trabalhadores e quantidade de empresas instaladas. Finalmente, imagine que esse equilíbrio é quebrado por um trabalhador que parte da região Sul e instala-se na região Norte. Dado que os trabalhadores gastam sua renda localmente, o mercado do Norte torna-se maior e, por conseguinte, o mercado do Sul diminui. Devido ao efeito "acesso ao mercado", algumas firmas no Sul terão incentivos para se mudar para o Norte. Essa mudança, por sua vez, torna o salário nominal no Norte mais atrativo que o mesmo salário nominal no Sul devido o efeito "custo de vida", o que estimula novas migrações.

O processo de causalidade circular, que pode levar a concentração de todas as atividades econômicas em uma dada região, sofre o contrapeso da terceira força presente no modelo, o "congestionamento de mercado". Continuando com o exemplo exposto no parágrafo anterior, a migração de firmas do Sul para o Norte torna mais forte a competição entre as empresas nessa última região, devido aos "custos de congestionamento". A maior competição no Norte obriga as empresas dessa região a pagar menores salários nominais para evitar lucros negativos. Dessa forma, o Norte deixa de ser tão atrativo para os trabalhadores.

Torna-se claro que a configuração espacial desse mundo hipotético irá depender da relação entre as forças de aglomeração e de dispersão presentes no modelo. Se os efeitos "acesso ao mercado" e "custo de vida" sobrepujarem o efeito "congestionamento de mercado", haverá apenas um equilíbrio estável, com todas as empresas e trabalhadores localizados em uma das duas regiões (aglomeração catastrófica ou equilíbrio Centro Periferia). Caso contrário, o mundo simétrico será o equilíbrio estável, e os eventuais choques sofrerão correção imediata dentro do modelo.

A intensidade das forças de aglomeração e dispersão - e portanto a resolução do modelo depende do custo de transporte. Em primeiro lugar, deve-se notar que as todas as forças do modelo perdem intensidade como a diminuição dos custos de transporte (Baldwin et al., 2003, Krugman 1991 a, b e Fujita et al. 1999). Tomemos inicialmente o efeito "congestionamento de mercado", sem custo de transporte essa força não existe, pois a competição entre firmas não depende da região em que elas se localizam, uma vez que ela pode cobrar o mesmo preço 
nos dois mercados. No outro extremo, caso o preço de transporte seja muito alto, o "congestionamento de mercado" atinge o seu auge, dado que uma alteração no número de empresas baseadas em uma determinada região apresenta um forte impacto na competição por consumidores e, portanto nos salários (Baldwin et al., 2003, Krugman 1991 a, b e Fujita et al. 1999).

Um padrão similar é visto quando tratamos das forças de aglomeração. Em um mundo livre de custos de transportes, o efeito "custo de vida" desaparece, pois não existe diferença no índice de preços das duas regiões. O mesmo vale para o "acesso ao mercado", sem custo de transporte as empresas são indiferentes entre se localizar em uma ou em outra região. No entanto, esse cenário muda se tivermos custos de transporte muito altos. Nesse caso, a parcela de produtos produzidos localmente tem grande impacto no índice total de preços (Baldwin et al., 2003, Krugman 1991 a, b e Fujita et al. 1999). Da mesma forma, o "acesso ao mercado" ganha relevância com custos de transporte elevados - as empresas irão preferir se localizar nos maiores mercados, obtendo assim maior receita.

Apesar de ter o mesmo sentido, o comportamento das forças de aglomeração e de dispersão frente ao custo de transporte é diferente. De modo mais específico, pode-se dizer que a força de dispersão é maior que as de aglomeração quando os custos de transporte são muito altos. No entanto, de acordo com as hipóteses do modelo, a redução nos custos de transporte enfraquece a força de dispersão mais rapidamente que as de aglomeração. Portanto, uma diminuição gradativa dos custos de transporte leva a um ponto, conhecido como break-point, no qual as forças de aglomeração superam a força de dispersão.

Tecnicamente, o "break point" é definido como o ponto no qual o equilíbrio simétrico deixa de ser estável. Esse ponto contrasta com o "sustain point", que determina o nível de custo de transporte no qual o equilíbrio com todas as empresas localizadas em uma determinada região, ou equilíbrio Centro Periferia, passa a ser estável. Robert-Nicoud (2002) prova que o "sustain point" ocorre com um custo de transporte maior que o "break point", o que significa que para um determinado intervalo de custos de transporte existe mais de um equilíbrio é estável.

As relações entre os diversos equilíbrios de longo prazo do modelo $\mathrm{CP}$ e o custo de transporte são sintetizadas na figura 2.1, conhecida como diagrama tomahawk. $\mathrm{O}$ eixo das ordenadas 
mostra a Proporção de firmas instaladas na região Norte, enquanto o eixo das abscissas apresenta a facilidade de comércio, 0 significa custos de transporte infinitos e 1 custos iguais a zero (Baldwin et al., 2003, Krugman 1991 a, b e Fujita et al. 1999). Os equilíbrios estáveis são representados pelas linhas grossas e escuras. Nota-se que equilíbrios simétricos são estáveis para níveis de facilidade de comércio abaixo de B (break point), enquanto os equilíbrios do tipo centro periferia são estáveis para valores entre $S$ (sustain point) e 1. Entre os pontos $\mathrm{S}$ e $\mathrm{B}$, tanto o equilíbrio simétrico quanto o assimétrico são estáveis. De maneira complementar, as linhas pontilhadas do gráfico representam os equilíbrios instáveis do modelo.

Figura 2.1 - Diagrama Tomahawk

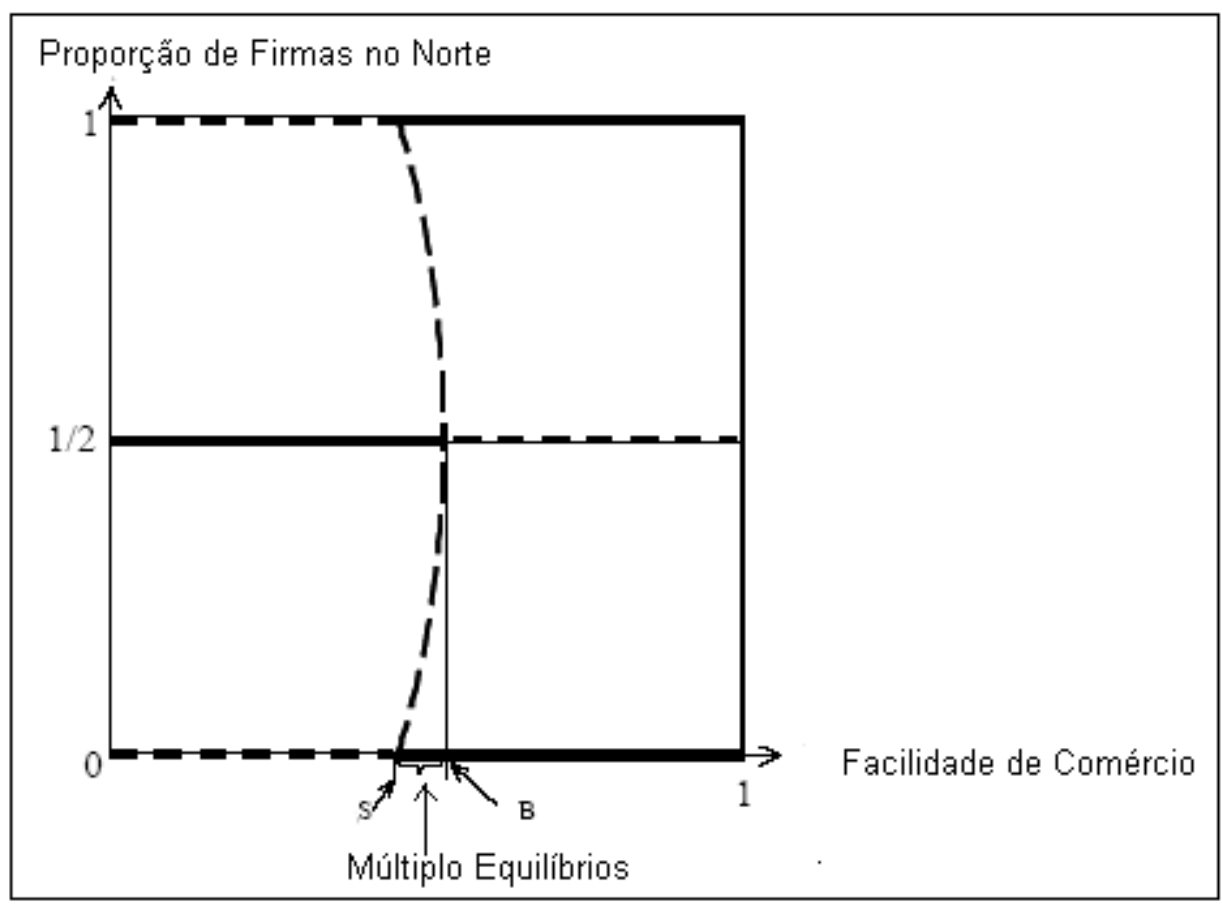

Fonte: Baldiwn et al. (2003)

Mesmo na ausência de formalização, três das principais características do modelo centro periferia tornam-se clara a partir da exposição acima. A primeira delas é a assimetria endógena, que significa a diminuição constante dos custos de transporte entre duas regiões inicialmente simétricas pode levar a assimetrias regionais (Baldwin et al., 2003, Krugman 1991 a, b e Fujita et al. 1999). A segunda característica é conhecida como histerese local, isto ocorre quando o custo de transporte é tal que o modelo comporta múltiplos equilíbrios. Nesse caso, pode-se dizer que a história importa. Suponha, por exemplo, que a economia tem inicio em uma situação em que praticamente toda a indústria esta localizada em uma determinada região, nesse caso, ela irá se mover para o equilíbrio assimétrico e irá permanecer lá 
indefinidamente. No entanto, como o equilíbrio simétrico também é estável, a economia poderia estar em outra situação se a história tivesse inicio em outro ponto. Finalmente, temos a aglomeração catastrófica, que significa que o custo de transporte abaixo do ponto do "break point" pode levar a concentração total da economia: todas as empresas e trabalhadores localizados em uma única região.

O modelo CP tem como grande mérito a incorporação de externalidades e retornos crescentes de escala em sua construção. As três forças utilizadas no modelo são apenas três formas diferentes de externalidades pecuniárias. Os retornos crescentes, por sua ver, aparecem nas funções de produção das empresas. Com esse arcabouço simples, Krugman consegue, baseado apenas em princípios econômicos, explicar de modo satisfatório a formação de aglomerações.

No entanto, mesmo com todos esses avanços, o modelo apresenta duas deficiências significantes. A primeira é a alta complexidade matemática do modelo, que impede a obtenção de soluções analíticas para as principais variáveis endógenas do modelo. Todas as soluções do modelo devem ser obtidas através de simulações computacionais, o que dificulta o uso do modelo CP para a formulação de políticas públicas ${ }^{9}$. Outro problema é a incapacidade do modelo de lidar com o fenômeno do crescimento, o modelo CP apenas trata do deslocamento de operários e empresas entre duas regiões, não comportando a possibilidade de criação de capital e, portanto de crescimento.

A seguir, será exposto o modelo de Spillovers Locais (SL) que consegue resolver estas duas principais carências apresentadas pelo modelo CP. Ou seja, o modelo SL apresenta soluções analíticas para suas variáveis endógenas e lida de modo explicito com a questão do crescimento. Devido a forte ligação entre esse modelo e a questão empírica estudada nesta dissertação, a próxima sessão apresentará um maior nível de formalização.

\footnotetext{
${ }^{9}$ Baldwin et al. (2003) argumenta que modelos analiticamente tratáveis são melhores para a formulação de políticas públicas. No entanto, muitos autores, sobretudo os proponentes da complexidade na economia, acreditam que soluções numéricas não são inferiores as analíticas em nenhum aspecto.
} 


\subsection{O Modelo de Spillovers Locais}

A grande inovação teórica trazida pelo modelo SL é a inclusão das externalidades tecnológica como fonte de crescimento. A importância desse tipo de externalidade sobre a formação e crescimento das cidades é um consenso dentro da Economia Urbana ${ }^{10}$, no entanto a inclusão desse elemento tende a ser evitada em razão da dificuldade de modelagem (Krugman 1995). O modelo SL, de modo elegante, promove a combinação de alguns elementos do modelo $\mathrm{CP}$ com os modelos de crescimento endógeno propostos por Romer (1986 e 1990), formando assim um modelo onde a difusão do conhecimento é um fator primordial para o crescimento econômico das cidades.

A descrição do modelo feita nessa seção esta baseada em Baldwin et. al.(2003) e em Baldwin e Martin (2004), que apresentam uma explicação intuitiva das idéias econômicas, bem como dos aspectos formais, presentes no modelo SL. Deve-se destacar, contudo que a primeira versão do modelo é apresentada em Martin e Ottaviano (1999), trabalho que marca o surgimento de um modelo semelhante ao $\mathrm{CP}$, porém com crescimento endógeno.

O crescimento econômico é marcado pela acumulação de capital, este definido de forma ampla pode significar capital físico, humano ou tecnologia (acumulo de conhecimento). Os tradicionais modelos de crescimento exógeno (Solow, 1956 e Ramsey, 1928) são baseados na acumulação de capital físico, que por hipótese apresenta retornos decrescentes. Dessa forma, a crescimento econômico de longo prazo estará restrito ao crescimento populacional e ao progresso tecnológico, ambos exógenos. De maneira distinta, os modelos de crescimento endógeno procuram se concentrar na acumulação de conhecimento, admitindo, de forma bastante plausível, que a criação de conhecimento não apresente retornos decrescentes.

De modo específico, o modelo SL escapa da armadilha dos retornos decrescentes ao supor que o preço da criação de capital tecnológico cai conforme a quantidade de capital na economia aumenta. Isto se deve à existência de uma curva de aprendizado na economia, na qual as inovações recentes dependem das idéias passadas. Dessa forma, a experiência

\footnotetext{
${ }^{10}$ Por exemplo, ver Fujita e Thise (2000); Glaeser et. al. (1992) e O’Flaherty (2005).
} 
adquirida nas inovações passadas facilita o desenvolvimento de inovações no presente (Baldwin et. al., 2003).

\subsubsection{Hipóteses do Modelo de Spillovers Locais}

O mundo é formado por duas regiões - região Norte e região Sul - ambas simétricas em termos de preferências, tecnologias e custos de transporte. Cada região possui três setores produtivos. O primeiro deles produz bens tradicionais e homogêneos, denotados por $\mathrm{T}$, e segue os princípios Walrasianos de concorrência perfeita e retornos constantes de escala. $\mathrm{O}$ custo desse setor é de uma unidade de trabalho (L) para cada unidade de produto T. O segundo setor é composto por manufaturas, ele é um setor de mercadorias diferenciadas (M), e sua produção ocorre sob as hipóteses de concorrência monopolistica, conforme proposto por Dixit-Stiglitz (1977). O custo fixo nesse setor é mensurado pelo capital (K). Casa empresa no setor de manufaturas necessita de uma unidade de capital para entrar em funcionamento. Como estamos trabalhando com capital tecnológico, pode-se dizer que cada nova variedade necessita de uma nova "idéia" para ser produzida. Além do custo fixo, esse setor também necessita de trabalho para sua produção ( $\mathrm{a}_{\mathrm{M}}$ unidade de trabalho para cada unidade de produto), de tal forma que a função custo é dada por $\pi+w a_{M} x_{i}$, em que $\pi$ é a taxa de retorno do capital, w é o salário e $\mathrm{x}_{\mathrm{i}}$ é o produto total de cada firma. $\mathrm{O}$ terceiro setor é o setor produtor de capital, que também obedece aos princípios Walrasianos de concorrência perfeita e retornos constantes de escala. Cada unidade de capital é construída com a $\mathrm{a}_{\mathrm{I}}$ unidades de trabalho. Como cada nova variedade necessita de uma unidade de capital para ser criada, o número total de variedades no mundo é igual ao estoque de capital: $\mathrm{K}^{\mathrm{w}}=\mathrm{K}+\mathrm{K}^{*}$, em que $\mathrm{K}^{\mathrm{w}}, \mathrm{K}$ e K* são, respectivamente, o estoque de capital no Mundo, no Norte el no Sul (variáveis regionais são especificadas sem asterisco quando trata-se do Norte e com asterisco quando trata-se do Sul). O número de firmas localizadas no Norte e no sul é representado por $\mathrm{n}$ e $\mathrm{n}^{*}$ respectivamente. Como cada variedade é produzida por uma firma diferente, temos que: $\mathrm{K}^{\mathrm{W}}=\mathrm{n}+\mathrm{n}^{*}$. Seguindo Baldwin e Martim (2004) não estamos considerando a existência de depreciação, uma vez que sua introdução não altera os resultados de modo significativo ${ }^{11}$.

\footnotetext{
${ }^{11}$ Ver Baldwin et. al. (2003) para um modelo com inclusão da depreciação.
} 
Em relação ao trabalho, supõe-se que este é homogêneo, imóvel entre as regiões e sem crescimento ao longo do tempo, de tal forma que toda a dinâmica do modelo fica por conta do capital.

Os custos de transporte entre as regiões variam conforme o setor. No setor tradicional não existem custos de transporte, as empresas vendem seus produtos ao mesmo preço em ambos os mercados. Por outro lado, o setor manufatureiro apresenta "iceberg costs" idênticos ao descrito na subseção anterior. Quanto ao setor produtor de capital, duas possibilidades são consideradas: perfeita mobilidade do capital (sem custos de transporte) e impossibilidade de transferência de capital entre as regiões. O esquema de funcionamento do modelo é descrito na figura 1 .

As externalidades tecnológicas do modelo aparecem no setor I, o produtor de capital. Seguindo Romer (1990) e Grossman and Helpman (1991), assume-se que a economia apresenta uma curva de aprendizagem, ou, em outras palavras, admite-se que o custo de produção de novo capital $\left(\mathrm{a}_{\mathrm{I}}\right)$ cai conforme o estoque de capital da economia aumenta. Hipótese que pode ser sustentada com base na natureza de bem público apresentada pelo conhecimento. De modo formal, para a região Norte essas hipóteses podem ser resumidas como:

$$
F=a_{I} ; \quad a_{I}=\frac{1}{K^{W} A} ; \quad \mathrm{A}=\mathrm{s}_{\mathrm{n}}+\lambda\left(1-\mathrm{s}_{\mathrm{n}}\right), 0 \leq \lambda \leq 1
$$

Sendo F o custo marginal de produção do capital (na figura 1 pode ser visto que o valor dos salários foi igualado a 1 , isso faz com que o custo marginal seja igual a $a_{I}$ ) e $s_{n}$ a proporção de firmas localizadas no Norte. Deve-se notar que devido a simetria, as equações do Sul são idênticas as do Norte, apenas adicionando-se asteriscos nas variáveis que $\mathrm{F}, \mathrm{a}_{\mathrm{I}}$ e A (invertendo-se a posição do $\lambda$ na equação dessa última). 
Figura 2.2 - Diagrama Esquemático do Modelo de Spillovers Locais

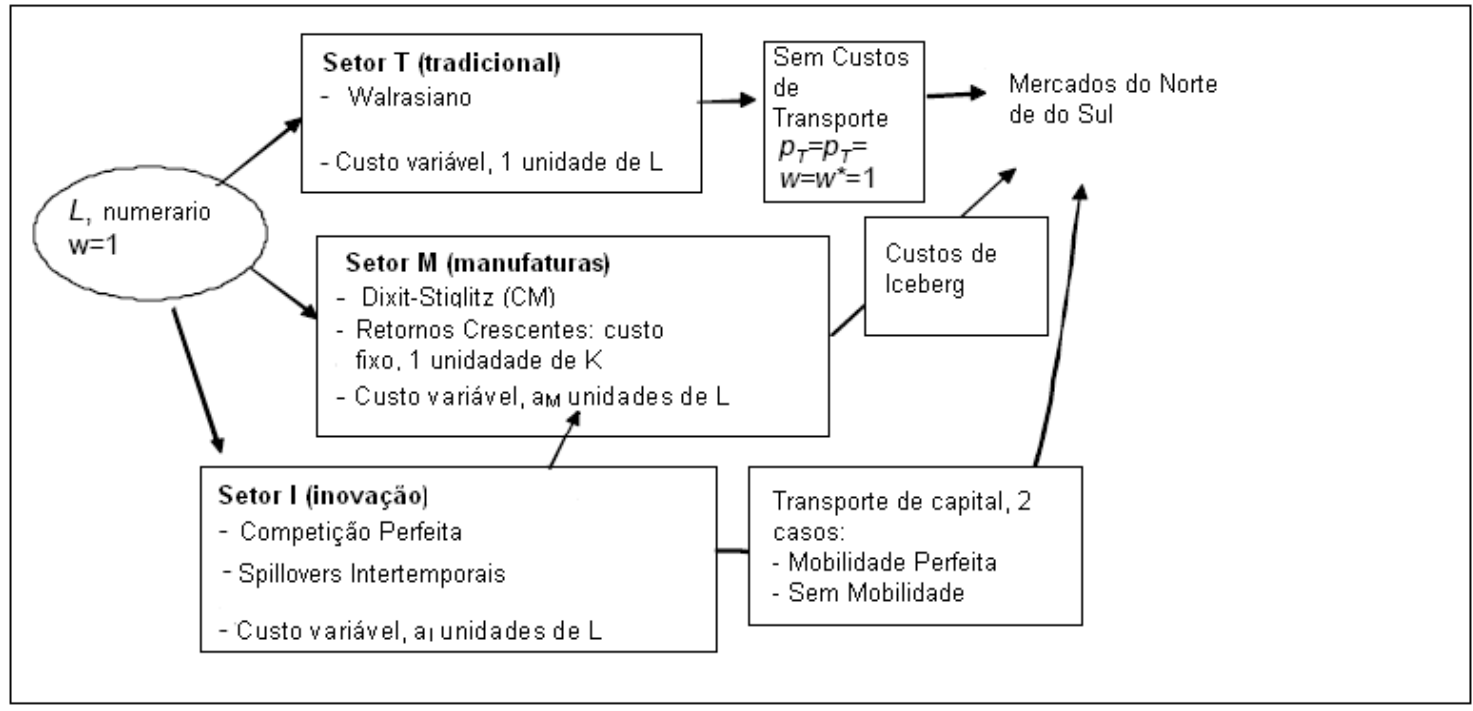

Fonte: Baldiwn e Martim (2004)

A equação (1) mostra uma característica importante do modelo LS. Caso $\lambda$ seja igual a 1 , temos o caso de spillovers globais ${ }^{12}$, nesse caso o conhecimento se difunde sem fronteiras pelo mundo e a proximidade não é importante para a transmissão de conhecimento. No entanto, se $\lambda$ for igual zero, as externalidades tecnológicas são puramente localizadas, e a informação tecnológica não cruza fronteiras. Evidências empíricas, sobretudo as apresentadas por Keller (2002), sugerem a distância limita, porém não impede a transmissão do conhecimento, o que indica que $\lambda$ deve situar-se em um valor intermediário entre 0 e 1 - o caso tratado nessa seção.

Adicionalmente, admiti-se que os agentes desse modelo vivem infinitamente e maximizam a seguinte função de utilidade,

$$
U=\int_{t=0}^{\infty} e^{-\rho t} \ln Q d t ; \quad Q=C_{T}^{1-\alpha} C_{M}^{\alpha} ; \quad C_{M}=\left(\int_{i=0}^{K+K^{*}} c^{1-1 / \sigma} d i\right)^{\frac{1}{1-1 / \sigma}}
$$

${ }^{12}$ De fato, esse modelo de spillovers globais é tratado de forma independente em Baldwin et. al (2003) e Baldwin et. al. (2004). No entanto, optamos por utilizar a versão localizada e apenas citar o modelo de spillovers globais como um caso especial. Além disso, o modelo com spillovers globais seria adequado para tratar de conhecimento de fácil codificação, que pode ser transportado a custo zero por todo o espaço (internet, por exemplo) 
Em que $\mathrm{C}_{\mathrm{T}}$ representa o consumo de bens tracionais e $\mathrm{C}_{\mathrm{M}}$ o consumo de bens industriais, $\alpha$ representa o parâmetro de uma função Cobb-Douglas e $\sigma>1$ é a elasticidade de substituição constante entre os produtos manufaturados. Essa função CES é o centro do modelo de competição monopolística proposto por Dixite e Stiglitz (1977).

\subsubsection{Principais resultados e conclusões do Modelo SL}

Nessa subseção, apenas expomos os principais resultados e conclusões do modelo SL sem demonstrá-los. A formalização desses resultados pode ser encontrada em Baldwin et. al. (2003, 2004). Seguindo estes autores, dividimos a análise em duas partes. A primeira é voltada para o modelo sem mobilidade de capital. A segunda, por outro lado, comenta os resultados do modelo com capital totalmente móvel.

\subsubsection{Capital Imóvel}

Com imobilidade do capital, a paisagem econômica do modelo é formada pela ação de três forças distintas. A primeira delas é a causalidade circular entre produção e consumo. Um aumento de lucro em uma região eleva o gasto na mesma região, o que por sua vez aumenta a quantidade de capital acumulado nesse local. $\mathrm{O}$ aumento na quantidade de capital na região eleva a renda permanente, o que gera expansão de mercado, e consequentemente, eleva os lucros das empresas. A segunda força é o congestionamento de mercado. Semelhante ao que ocorre no modelo $\mathrm{CP}$, essa força torna a região com mais empresas menos atraente a novos investimentos em virtude da forte concorrência das empresas locais. Finalmente, temos o efeito dos spillovers localizados, um aumento na porcentagem de firmas no Norte, por exemplo, diminui o custo de inovação no Norte e incentiva a criação de capital.

O comportamento das três forças do modelo pode levar a economia a um estado de aglomeração catastrófica. No entanto, aglomeração catastrófica não significa ausência total de empresas em uma das regiões como no modelo $\mathrm{CP}$, significa que uma das regiões pára de inovar e, portanto, põe fim o processo de instalação de novas indústrias, enquanto a outra continua o desenvolvimento tecnológico. Como estamos desconsiderando a depreciação, a região em que a inovação parou de ocorrer continua a ter indústrias funcionando em seu 
território, porém a participação dessas empresas no capital total da economia tende a zero com o passar do tempo.

De modo mais geral, a aglomeração catastrófica leva a formação de um circulo virtuoso no Centro e de um circulo vicioso na periferia. No centro ocorre aumento da participação das empresas dessa região sobre o capital total da economia, expansão do mercado e redução dos custos de inovação, o que induz a novos investimentos. Na periferia acontece o inverso, a mercado se contrai e o custo da inovação aumenta, acabando com o incentivo a inovar.

Assim como no modelo $\mathrm{CP}$, os custos de transporte são essências para determinar a ocorrência ou não de aglomeração catastrófica. Com custos de transporte muito elevados apenas o equilíbrio simétrico é estável. Porém, uma redução gradual nos custos de transporte, tudo o mais constante, faz com que o equilíbrio simétrico torne-se instável. O ponto em que isso ocorre é denominado "ponto catastrófico". Diminuindo ainda mais o custo de transporte chega-se a um ponto conhecido ponto cp (centro periferia), depois dele apenas o equilíbrio centro periferia (todas as empresas localizadas em uma única região) torna-se estável. Entre o ponto catastrófico e o ponto $\mathrm{cp}$, existe um intervalo de custos de transporte onde quatro equilíbrios são possíveis: dois equilíbrios Centro Periferia e dois outros equilíbrios assimétricos, porém não totalmente concentrados.

O fator de difusão de conhecimento $(\lambda)$ age como um potencializador dos efeitos do custo de transporte. Na ausência de spillovers locais $(\lambda=1)$, o ponto catastrófico não existe e o ponto $\mathrm{cp}$ está associado a um menor custo de transporte que estaria na presença de externalidades locais de produção $(0 \leq \lambda<1)$. Ou seja, a presença de spillovers locais torna a aglomeração catastrófica possível com maiores custos de transporte.

A possibilidade de aglomeração catastrófica faz com que o comportamento da taxa de crescimento econômico seja descontínuo. Suponha uma situação em que as indústrias são distribuídas entre as duas regiões (sem aglomeração catastrófica). Nesse caso, o custo de inovação é máximo, pois o desenvolvimento tecnológico ocorre nas duas regiões, e a taxa de crescimento econômico é crescente em $\lambda$. Isso muda quanto consideramos a situação da economia sob a presença de aglomeração catastrófica: toda a inovação fica concentrada na região com maior número de empresas, o que minimiza o custo de inovação e aumenta a taxa de crescimento da economia. 
Um resultado contra intuitivo do modelo, porém, sinaliza que essa disparidade no comportamento econômico das duas regiões pode ser benéfica para a periferia. Com a divergência regional caracterizada pelo equilíbrio centro-periferia, a região que se torna o centro, por exemplo o Norte, apresenta um aumento da renda real através da diminuição dos custos de transporte (não é necessário pagar custos de transporte pois todas as empresas tendem a se localizar nessa região) e do crescimento econômico. O Sul por sua vez sofre uma diminuição da renda real devido ao aumento na quantidade de bens importados, mas também é beneficiado pelo crescimento econômico.

O bem estar final da região Sul dependerá do equilíbrio entre os danos causados pelo aumento na quantidade de mercadorias importadas e pelos ganhos decorrentes do crescimento econômico. Pode-se mostrar que a resultante dessas forças dependerá do parâmetro $\alpha$ da função de utilidade (ver equação 2). Se $\alpha$ tiver um valor alto, os benefícios superam as perdas, de tal forma que a aglomeração catastrófica é benéfica mesmo para a região mais pobre. $\mathrm{O}$ inverso ocorre no caso de $\alpha$ baixo.

\subsubsection{Capital Móvel}

A mobilidade de capital confere algumas características interessantes ao modelo SL. Duas delas são essenciais para a compreensão dos resultados que veremos na seqüência. Primeiro, o capital pertencente aos moradores de uma região pode diferir da quantidade de capital instalada nessa região. Dessa forma, a localização do setor tecnológico no Norte, por exemplo, não impede que o Sul acumule capital. Além disso, como o único fator móvel é o capital, o lucro é sempre repatriado e gasto na região onde vive o detentor do capital. Esse repatriamento dos lucros corta a causalidade circular entre produção e gasto em uma mesma região, e dessa foram impede a formação de equilíbrio Centro-Periferia (todas as empresas localizadas em uma única região). Segundo, como as empresas de manufatura podem escolher onde se localizar, existe uma condição de não arbitragem que garante que o lucro das empresas seja o mesmo em ambas as regiões.

O primeiro resultado importante do modelo refere-se a localização do setor de desenvolvimento tecnológico. Uma vez que o capital pode fluir livremente entre as regiões, as 
empresas irão realizar todo o desenvolvimento tecnológico onde for mais barato, ou seja, na região que abrigar o maior número de empresas. Esse resultado está diretamente ligado a outra implicação desse modelo: quanto maior o nível de concentração das empresas de manufatura em uma região, maior será a taxa de crescimento econômico da economia como um todo. Dessa forma, a concentração das empresas é benéfica tanto à inovação quanto ao desenvolvimento econômico.

No entanto, o crescimento econômico nesse modelo não implica em maior concentração de renda (medida como porcentagem do dispêndio mundial). Na realidade, outro resultado do modelo mostra que a desigualdade de renda é função decrescente da taxa de crescimento econômico. Isso é fruto da queda do valor do capital associada ao crescimento econômico, que pode ser explicada de modo simples: aumento no crescimento econômico significa aumento no estoque de capital, ou de outra forma, maior número de variedades. Devido à estrutura concorrencial do modelo, esse crescimento na quantidade de variedades leva ao aumento da concorrência e consequiente queda no valor do capital. Esse efeito é mais acentuado na região mais rica (detentora da maior parte do capital), fazendo com que a economia diminua a desigualdade de renda entre as regiões.

Os elementos exógenos do modelo - custos de transporte e $\lambda$ - são também, indispensáveis para a compreensão da configuração espacial resultante desse modelo. O papel do custo de transporte pode ser bem compreendido através de um exemplo. Suponha inicialmente que o Norte apresenta uma parcela maior das empresas da economia, uma diminuição dos custos de transportes acarreta em um aumento da concentração de empresas na região Norte, o que implica em aumento na taxa de crescimento econômico, que por sua vez age no sentido de diminuir a desigualdade de renda entre as regiões. O efeito da queda do custo de transporte é, portanto, ambíguo. Por um lado, ele concentra a produção, por outro lado, diminui a disparidade de renda.

O segundo fator exógeno desse modelo é o parâmetro de difusão do conhecimento $\lambda$. Os resultados indicam que uma melhora na difusão do conhecimento (aumento de $\lambda$ ), eleva a taxa de crescimento. No entanto, o mecanismo envolvido nesse processo leva não somente a diminuição na desigualdade de renda, mas também na desigualdade locacional da produção. 
Os resultados acima indicam que a concentração é positiva para o desempenho da economia como um todo, uma vez que promove aumento na taxa de crescimento econômico. No entanto, também é necessário verificar se essa concentração possui um nível ótimo e se tal patamar é atingido dentro das hipóteses adotadas no modelo.

Para obter-se um resposta acerca do nível ótimo de concentração, duas distorções relacionadas a geografia dessa economia devem ser analisadas. Primeira, quando os investidores decidem em qual região suas empresas devem se localizar, eles não levam em conta o impacto dessa decisão sobre o custo de inovação da região em que o desenvolvimento tecnológico ocorre. Desse modo, o beneficio das externalidades positivas não é internalizado na decisão de alocação, resultando em baixa concentração. Segunda, a decisão de onde implantar a empresa gera impacto sobre a renda dos consumidores, que não podem se deslocar, que também não é internalizado pelos empresários, esse impacto não tem uma direção clara e por isso merece uma atenção especial.

$\mathrm{O}$ aumento de concentração da produção provoca três efeitos distintos sobre a renda das regiões. O primeiro é o efeito sobre o crescimento, ele é positivo nas duas regiões, pois como vimos um aumento na concentração acarreta aumento na taxa de crescimento econômico. $\mathrm{O}$ segundo efeito, por outro lado, é negativo para ambas as regiões. Ele representa a diminuição do valor da firma que ocorre pelo aumento do estoque total de capital na economia, e é mais intenso na região com maior concentração de empresas. Por fim, temos o efeito da concentração sobre o custo de transporte. O sinal desse efeito difere entre as regiões, ele é positivo na região com maior concentração - os consumidores dessa região pagarão menores custos de transporte - e negativo na região de menor concentração, pois os moradores deverão pagar maiores custos para adquirir as mercadorias manufaturadas.

A resultante dessas forças, quando analisadas sob as condições de equilíbrio de mercado, esta relacionada aos parâmetros exógenos do modelo. Se $\lambda$ for suficientemente pequeno, $o$ aumento da concentração será sempre positivo na região com maior concentração econômica. Na região menos industrializada, no entanto, o resultado total de um aumento na concentração depende também do valor dos custos de transporte. Caso $\lambda$ e os custos de transporte forem suficientemente pequenos, um aumento na concentração tem efeito positivo sobre a renda. Sob essas condições, o efeito do crescimento supera as perdas decorrentes da diminuição do valor do capital e do aumento nos custos de transporte. Conclui-se, portanto, que sob valores 
adequados das variáveis exógenas do modelo - spillovers suficientemente localizados e baixo custo de transporte - o nível de concentração de equilíbrio estará sempre abaixo do ótimo.

\subsubsection{Considerações sobre o Modelo SL}

Dentre as inovações trazidas pelo modelo SL, duas merecem atenção especial. Primeiro, as externalidades tecnológicas, na forma de spillovers, aparecem como as geradoras de crescimento econômico de longo prazo. Além disso, a geração do conhecimento depende da concentração espacial, uma vez que a difusão do conhecimento é limitada. Dessa forma, assume-se de modo explícito que a geografia impacta de modo significante o desenvolvimento econômico. Segundo, a concentração da produção tecnológica e industrial em um centro, pode ser benéfica para a região periférica - com ou sem mobilidade de capital - pois aumenta a taxa de crescimento econômico. Esse resultado apresenta uma implicação política: políticas públicas visando a igualdade regional podem resultar em perda de eficiência econômica.

Porém, o modelo apresenta algumas deficiências que limita seu uso para recomendações de política pública e para execução de testes empíricos. Em primeiro lugar, as forças de dispersão do modelo não conseguem captar certas nuances do mundo real. De fato, a única força de dispersão presente é o congestionamento de mercado decorrente da estrutura monopolistica à la Dixit-Stiglitz, incapaz, por exemplo, de captar o efeito do aumento do aluguel decorrente da concentração de empresas em uma determinada região.Essa deficiência impede que o modelo apresente a esperada relação na forma de "U" invertido entre aglomeração e crescimento. Segundo, a impossibilidade de deslocamento do trabalho coloca fora da análise um dos fenômenos mais interessantes da dinâmica regional: a migração de trabalhadores, em especial dos menos qualificados. Por fim, o modelo é por demais estilizado, o que dificulta a obtenção de equações estimáveis. Na verdade, não são conhecidos pelo autor trabalhos que obtenham equações estimáveis diretamente a partir do modelo SL.

Com base nessa discussão, pode-se dizer que o modelo SL fornece algumas hipóteses interessantes acerca da relação entre crescimento e aglomeração, e dessa forma, será útil nos testes empíricos dessa dissertação. Porém, elementos adicionais devem ser incorporados na 
análise econométrica para obter-se resultados mais esclarecedores a respeito do efeito da concentração sobre o desenvolvimento econômico.

\subsection{Contribuições Empíricas}

O crescimento econômico é um tema amplamente estudado na literatura econômica. Empiricamente, a maior parte dos estudos esta centrada no teste de convergência entre economias - predição originada nos trabalhos teóricos de Ramsey (1928) e Solow (1956).

A existência de convergência nos modelos de crescimento neoclássicos ocorre devido a hipótese de retornos marginais decrescentes do capital, e significa, basicamente, que quanto menor o PIB per capita de um país ou região em relação ao seu estado estacionário de longo prazo, maior é a taxa de crescimento econômico. Portanto, países pobres deveriam apresentar maiores taxas de crescimento econômico que países ricos.

No entanto, como os países alcançam diferentes estados estacionários, de acordo com sua taxa de poupança e de características particulares de sua função de produção, só se pode esperar convergência entre economias após todos os determinantes do estado estacionário terem sido controlados, ou em outras palavras a convergência não é absoluta, e sim condicional.

Dentre os inúmeros trabalhos realizados sobre convergência, merecem destaque Mankiw et al. (1992), que usando dados de 98 países encontraram evidências de convergência, embora esta seja bem lenta, e Barro e Sala-i-Martin (1991, 1992, 1995), que utilizaram dados de estados americanos e de regiões européias e japonesas, e obtiveram resultados semelhantes.

Deve-se destacar que o estudo da convergência condicional permitiu a análise da influência de diversos fatores sobre o crescimento econômico, como por exemplo, liberdade civis, distorções na taxa de câmbio e disponibilidade de crédito doméstico (Henderson, 2000), inclusos no modelo como variáveis de controle.

No entanto, a relação entre crescimento e aglomeração tem sido alvo de poucos trabalhos empíricos. Dentre estes, merece destaque Henderson (2000), que testa o efeito da taxa de 
urbanização sobre o crescimento. O autor utiliza dados de painel de diversos países (entre 80100 países dependendo da estimação) entre os anos de 1960 e 1995. Como principal resultado, o autor encontra uma relação em forma de " $U$ " invertido entre a taxa de urbanização e crescimento econômico.

Outras duas exceções são os trabalhos de Fingleton et al. (2003) e Bosker (2007). O primeiro deles testa o efeito da concentração geográfica sobre o crescimento do emprego em pequenas e médias empresas de alta tecnologia na Grã-bretanha. Assim como Henderson, os autores encontram uma relação não linear entre crescimento e aglomeração: a concentração do emprego sobre o crescimento econômico é benéfica até um determinado ponto, a partir do qual o excesso de concentração passa a ter efeito negativo sobre o crescimento do emprego. Bosker (2007) por sua vez, utiliza dados de 16 países europeus no nível de NUTS 2 para o período 1977-2002. O autor utiliza equações padrão de regressão - derivadas a partir de Solow (1956) - e encontra relação negativa entre o crescimento econômico e aglomeração (número de trabalhadores por área). Esse resultado sugere que os efeitos positivos da aglomeração foram superados pelos efeitos de congestionamento. Porém, esse resultado merece uma qualificação: Bosker considera a apenas a existência de relação linear entre aglomeração e crescimento, diferindo nesse ponto de Henderson (2000) e Fingleton et al. (2003).

Indiretamente, o trabalho de Quah (1996) sugere a existência de relação positiva ente aglomeração e crescimento. Estudando os cinco países da Coesão (Portugal, Grécia, Espanha e Irlanda), Quah descobre que os países com maior taxa de crescimento, e que, portanto convergiam em termos de renda per capita na direção ao restante dos países europeus (Portugal e Espanha) foram os que apresentaram maior divergência interna.

Além disso, posto que um dos principais mecanismos pelo qual a aglomeração afeta o crescimento é através da difusão de conhecimento, um teste indireto da influência aglomeração sobre o desenvolvimento pode ser realizado através da detecção de spillovers. Dentro dessa literatura, merecem destaque os trabalhos de Coe e Helpman (1995) e Coe et al. (1997). No primeiro trabalho, com dados de 21 países da OCDE mais Israel, os autores constroem medidas de estoque de pesquisa e desenvolvimento (P\&D) local, usando gastos acumulados em $\mathrm{P} \& \mathrm{D}$, e de $\mathrm{P} \& \mathrm{D}$ estrangeira, através da média do estoque de $\mathrm{P} \& \mathrm{D}$ dos parceiros comerciais ponderada pelo volume de comércio. Os resultados comprovam a 
existência de spillovers, e mostra que estes não são totalmente locais e nem totalmente globais. O segundo trabalho faz uma análise semelhante para 77 países em desenvolvimento, e encontram resultados parecidos em termos de abrangência dos spillovers, além de constatar que países em desenvolvimento se beneficiam significativamente da transferência de conhecimento de países desenvolvidos. Em ambos os trabalhos merece destaque a forma como a distância é incorporada a análise: a proximidade é medida pelo volume de comércio entre os países - quanto maior o volume de comércio, mais próximos são os países. Essa medida, contudo, acaba se refletindo em distância física, visto que o volume de comércio é uma função da distância.

Para o caso brasileiro, muitos estudos sobre desenvolvimento regional têm sido realizados desde a década passada. Ferreira (1996), Zini (1996) e Azzoni (1997) destacam-se como os precursores nessa área. Contudo, esses trabalhos estão totalmente voltados para a questão da convergência entre estados, além de não levar em conta o aspecto espacial do fenômeno. Coube a Magalhães et. al. (2000) produzir o primeiro estudo acerca de crescimento brasileiro levando em conta de modo explícito a influência do espaço. Novamente, o estudo estava focado na convergência entre estados. Analisando o período entre 1970 e 1995 os autores encontram evidência de convergência de renda entre os estados.

Um estudo mais recente, conduzido por Mossi et al. (2003) amplia a quantidade de ferramentas de econometria espacial utilizada por Magalhães et al. (2000) - além de analisar um período de tempo mais amplo (1939 - 1998). Porém, mantém como objetivo a análise da convergência entre os estados. Os resultados indicam a existência de dois clubes de convergência: o cluster rico, no Sul e Sudeste, e o pobre, no Nordeste. Mossi et al. (2003) explora a idéia da formação de clusters, através do uso de matrizes de transição e de kernels estocástico, e mostra que no Brasil existe a tendência de que um estado cercado por estados mais ricos (pobres) apresente um desempenho econômico superior (inferior) no período subseqüente.

Andrade et al. (2004) conduzem um trabalho sobre convergência em nível municipal entre os anos de 1970 e 1996 - para solucionar a questão do aumento do número de municípios ao longo do tempo, os autores usam como unidade de media áreas mínimas comparáveis (AMC) entre 1970 e 1996. Novamente, os resultados mostram que existe a formação de dois clubes 
de convergência entre as cidades brasileiras: um pobre, nas regiões Norte e Nordeste, e outro rico nas regiões Sul e Sudeste.

Da Mata et al. (2005) estuda os determinantes do crescimento das cidades brasileiras (em termos de população) entre 1970 e 2000. A principal descoberta dos autores é que um aumento na população rural, melhorias no transporte inter-regional e na qualidade da mão-deobra têm forte impacto no crescimento das cidades. De modo reverso, violência tem efeito negativo sobre o crescimento das cidades.

Deve-se destacar que Da Matta et al. (2005) encontram resultados condizentes com os esperados por essa dissertação, uma vez que os autores encontram evidências acerca da existência de externalidades positivas, que atuam como forças de aglomeração, e negativas, que agem como forças de dispersão.

A revisão dos estudos de crescimento no Brasil e no mundo mostra que existe uma carência de trabalhos analisando diretamente as relações entre aglomeração e desenvolvimento. Nas próximas seções, procuramos contribuir para a diminuição dessa lacuna através do estudo empírico do crescimento dos municípios brasileiros entre os anos de 1970 e 2000. 


\section{Descrição dos dados}

O banco de dados utilizado no trabalho consiste em uma série de informações referentes a áreas mínimas comparáveis entre 1970 e 2000 (AMC-70/00). Essas unidades de geográficas, delimitadas por Reis et. al. (2004), permitem a comparação intertemporal de variáveis econômicas e sociais em áreas fixas ao longo do período de interesse. De modo mais preciso, AMCs são o "conjunto mínimo de municípios que permite, de forma consistente, comparar uma mesma área ao longo do período" (Reis et. al. (2005)). Deve-se destacar que, no decorrer trabalho, os termos município e cidade são freqüentemente utilizados como sinônimos de AMC.

O número total de AMCs definidas por Reis et. al. (2004) é 3659. No entanto, 5 delas não foram utilizadas neste estudo pelo fato de apresentarem PIB negativo ${ }^{13}$. A tabela 3.1 mostra o número total de AMCs por região. Nota-se claramente a concentração de municípios nas regiões Sudeste e Nordeste, que conjuntamente possuem mais de $70 \%$ do total de cidades. O baixo número de AMCs na região Norte e Centro-Oeste evidência a perda de dinâmica interna de certas áreas, decorrente do uso de AMCs como unidade de estudo. Esse problema torna-se mais claro através do exemplo de Rondônia, que em 1970 possuía 2 municípios, hoje é constituída por 52, mas é representada por apenas uma área mínima comparável entre 1970 e 2000 (Andersen. et. al. (2002), p.37).

As informações foram obtidas no site do IPEADATA ${ }^{14}$, e contém os dados relativos ao PIB municipal, população, escolaridade média dos residentes com mais de 25 anos, área, latitude, longitude, número total de domicílios e número de domicílios com acesso a energia elétrica. A partir desses dados, foram construídas as variáveis crescimento e porcentagem de municípios com energia elétrica.

\footnotetext{
${ }^{13}$ Embora estranho, esse fato é plenamente compreensível quando verificamos que o PIB é um conceito de valor adicionado, não um estoque. A quebra na safra de um pequeno município com economia baseada na agricultura, por exemplo, pode fazer com que o PIB tenha valor negativo. Apesar disso, resolveu-se excluí-las da amostra pelo fato de usarmos como variável dependente o logaritmo do crescimento.

${ }^{14}$ Endereço eletrônico: www.ipeadata.gov.br
} 
As variáveis PIB municipal, população e educação constituem os elementos essenciais da análise devido a sua forte ligação com a teoria. Dessa forma, na próxima sessão deste capitulo, elas serão alvo de uma análise mais detalhada, que mostrará sua evolução espaçotemporal. As demais são brevemente descritas no restante dessa sessão.

As variáveis geográficas (área, latitude e longitude) desempenham um papel fundamental nesse trabalho. Sem a área não é possível medir a aglomeração, a latitude e a longitude tornam possível a construção da matriz $\mathrm{W}$, a qual será especificada detalhadamente no capítulo 4. Esse conjunto de variáveis é proveniente do censo de 2000.

A tabela 3.2 apresenta a área média das AMCs por região. Nota-se claramente que as regiões Norte e Centro-Oeste apresentam o maior tamanho médio das AMCs. A área média dos municípios no Norte, por exemplo, é quase 50 vezes maior que a área média dos municípios do Sudeste, fato que corrobora o problema da perda de dinâmica interna evidenciado anteriormente.

Um outro grupo extremamente importante é o das variáveis estruturais, composto pelo total de domicílios em cada cidade e pela quantidade de domicílios com água encanada. Elas permitem o controle adequado das condições iniciais dos municípios, que de acordo com o modelo desenvolvido no capítulo 4 é um dos fatores causadores do crescimento econômico. A fonte primária desses dados é o Censo demográfico de 1970.

A tabela 3.3 mostra a porcentagem média, por região, de domicílios com energia elétrica. Os dados mostram que a região Sudeste apresentava melhores condições estruturais no início da década de 70, mais de 60\% das residências tinham acesso a energia elétrica. Logo em seguida aparece a região Sul, com números próximos a estes. As demais regiões apresentam condições consideravelmente inferiores às apresentadas pelas regiões Sul e Sudeste.

Tabela 3.1 - Número de AMCs Por Região

\begin{tabular}{ccc}
\hline \hline Região & № & Porcentagem \\
\hline Norte & 108 & $2,96 \%$ \\
Nordeste & 1295 & $35,44 \%$ \\
Centro-Oeste & 257 & $7,03 \%$ \\
Sudeste & 1401 & $38,34 \%$ \\
Sul & 593 & $16,23 \%$ \\
\hline Brasil & 3654 & $100 \%$ \\
\hline
\end{tabular}

Fonte: IPEADATA e cálculos do autor 
Tabela 3.2

Tamanho Médio das AMCs (Média por Região)

\begin{tabular}{ccc}
\hline \hline Região & Média $\left(\mathrm{Km}^{2}\right)$ & Desvio Padrão \\
\hline Norte & 32685,53 & 62017,32 \\
Nordeste & 1187,02 & 2478,49 \\
Centro-Oeste & 7312,67 & 27725,46 \\
Sudeste & 655,83 & 1037,42 \\
Sul & 947,66 & 1830,31 \\
Brasil & 2306,34 & 14159,66 \\
\hline
\end{tabular}

Fonte: IPEADATA Cálculos do autor

Tabela 3.3 - Infra-estrutura Domiciliar (1970)

\begin{tabular}{ccc}
\hline \hline & \multicolumn{2}{c}{$\%$ Eletricidade } \\
\cline { 2 - 3 } Região & Média & Desvio Padrão \\
\hline norte & 23,58 & 16,08 \\
nordeste & 25,87 & 16,63 \\
Centro-Oeste & 33,60 & 18,90 \\
sudeste & 61,15 & 26,32 \\
sul & 58,42 & 21,90 \\
\hline Brasil & 45,15 & 27,49 \\
\hline
\end{tabular}

\subsection{Educação, População e PIB}

\subsubsection{Estatísticas Descritivas}

O valor do PIB municipal foi calculado pela equipe do IPEA para os anos de 1970, 1980, 1985, 1996. A metodologia envolvida nessa estimação pode ser encontrada em Reis et. al. (2004). Para o ano de 2000, o cálculo do PIB municipal coube ao IBGE, embora o IPEA seja o responsável por organizá-lo em AMCs. O valor dessa variável é medido em R \$ de 2000.

A segunda variável inclusa nessa analise exploratória de dados, população residente por município, é obtida a partir de dados censitários para os anos de 1970, 1980, 1991 e 2000. Para o ano de 1996 o valor foi obtido através de contagem da população. Deve-se destacar que os dados do Censo são fornecidos por municípios, a organização desses dados em AMCs dever ser creditada os pesquisadores do IPEA. 
A terceira variável analisada é a educação, utilizada como proxie de capital humano. A medida de educação é a média de anos de estudo dos adultos, definida como a divisão do somatório do número de anos de estudo de pessoas com mais de 25 anos pelo número total de residentes nessa faixa etária. A variável é fornecida pelo IPEA, e as informações metodológicas a respeito de seu cálculo podem ser obtidas no endereço eletrônico www.undp.org.br.

As estatísticas descritivas do PIB, da população e da escolaridade são apresentadas nas tabelas 3.4, 3.5 e 3.6 respectivamente. Juntamente com essas tabelas, as figuras $3.1,3.2$ e 3.3 mostram a evolução dessas variáveis durante as três ultimas décadas, em ambos os casos pode-se notar uma clara elevação no PIB, na população e na educação. O PIB nacional tem um salto de 285 bilhões em 1970 para 1100 bilhões em 2000. A população brasileira também apresentou um aumento considerável durante esse período, passando de pouco mais de 93 milhões para cerca 170 milhões. Do mesmo modo, a educação média do brasileiro sofre uma grande elevação, sendo o seu valor em 2000 mais do que o dobro do registrado em 1970.

Deve-se notar que em todas as regiões brasileiras o comportamento das variáveis foi similar, com apenas duas exceções consideráveis. A primeira é o PIB da região Sudeste, que cresceu acima da media nacional. A segunda exceção é a educação da região Centro Oeste, que se distanciou da escolaridade média da região Norte e Nordeste e se aproximou da região Sul. 
Tabela 3.4 - Estatísticas Descritivas do PIB 1970 - 2000

\begin{tabular}{|c|c|c|c|c|c|}
\hline & & 1970 & 1980 & 1996 & 2000 \\
\hline \multicolumn{6}{|l|}{ Norte } \\
\hline & Observações & 108 & 108 & 108 & 108 \\
\hline & Total & 6158226,96 & 22359985,20 & 35957066,40 & 48002306,40 \\
\hline & Média & 57020,62 & 207036,90 & 332935,80 & 444465,80 \\
\hline & Máximo & 1752364,00 & 6963402,00 & 12000000,00 & 16600000,00 \\
\hline & Mínimo & 672,57 & 3177,57 & 3623,93 & 7336,77 \\
\hline & Desvio Padrão & 225898,30 & 811489,80 & 1377401,00 & 1772177,00 \\
\hline \multicolumn{6}{|c|}{ Nordeste } \\
\hline & Observações & 1295 & 1295 & 1295 & 1295 \\
\hline & Total & 33333261,15 & 84469819,70 & 120396098,20 & 144073282,50 \\
\hline & Média & 25739,97 & 65227,66 & 92969,96 & 111253,50 \\
\hline & Máximo & 4041756,00 & 9631023,00 & 15900000,00 & 9862912,00 \\
\hline & Mínimo & 199,04 & $-49090,05$ & $-38666,51$ & 2639,95 \\
\hline & Desvio Padrão & 173817,40 & 432644,50 & 705773,30 & 585474,00 \\
\hline
\end{tabular}

Centro Oeste

$\begin{array}{lcccc}\text { Observações } & 257 & 257 & 257 & 257 \\ \text { Total } & 11024040,70 & 39277772,60 & 71769768,60 & 78992445,20 \\ \text { Média } & 42895,10 & 152831,80 & 279259,80 & 307363,60 \\ \text { Máximo } & 3600304,00 & 14100000,00 & 28900000,00 & 29600000,00 \\ \text { Mínimo } & 737,86 & 1493,64 & 2863,56 & 2394,39 \\ \text { Desvio Padrão } & 242393,30 & 942214,80 & 1936102,00 & 1962425,00\end{array}$

Sudeste

$\begin{array}{lcccc}\text { Observações } & 1401 & 1401 & 1401 & 1401 \\ \text { Total } & 186638698,20 & 440423403,60 & 554077146,90 & 636394443,00 \\ \text { Média } & 133218,20 & 314363,60 & 395486,90 & 454243,00 \\ \text { Máximo } & 55700000,00 & 110000000,00 & 141000000,00 & 127000000,00 \\ \text { Mínimo } & 659,05 & 1675,34 & 2340,90 & 3628,02 \\ \text { Desvio Padrão } & 1760493,00 & 3535567,00 & 4422566,00 & 3886649,00\end{array}$

Sul

$\begin{array}{lcccc}\text { Observações } & 593 & 593 & 593 & 593 \\ \text { Total } & 47582159,89 & 119917705,30 & 169286437,80 & 193514698,10 \\ \text { Média } & 80239,73 & 202222,10 & 285474,60 & 326331,70 \\ \text { Máximo } & 6458038,00 & 13800000,00 & 21800000,00 & 16300000,00 \\ \text { Mínimo } & 694,97 & 4381,76 & 5234,63 & 7968,99 \\ \text { Desvio Padrão } & 343392,60 & 845856,70 & 1389353,00 & 1135481,00\end{array}$

Brasil

\begin{tabular}{lcccc} 
Observações & 3654 & 3654 & 3654 & 3654 \\
Total & 284736342,24 & 706448647,80 & 951486618,60 & 1100977239,60 \\
Média & 77924,56 & 193335,70 & 260395,90 & 301307,40 \\
Máximo & 55700000,00 & 110000000,00 & 141000000,00 & 127000000,00 \\
Mínimo & 199,04 & $-49090,05$ & $-38666,51$ & 2394,39 \\
Desvio Padrão & 1107011,00 & 2250777,00 & 2884564,00 & 2550307,00 \\
\hline
\end{tabular}

Fonte: IPEADARA e cálculos do autor 
Tabela 3.5 - Estatísticas Descritivas da População 1970 - 2000

\begin{tabular}{|c|c|c|c|c|c|}
\hline & & 1970 & 1980 & 1996 & 2000 \\
\hline \multicolumn{6}{|l|}{ Norte } \\
\hline & Observações & 108.00 & 108.00 & 108.00 & 108.00 \\
\hline & Total & 3594594.24 & 5868101.16 & 10208409.48 & 11701432.80 \\
\hline & Média & 33283.28 & 54334.27 & 94522.31 & 108346.60 \\
\hline & Máximo & 633374.00 & 933280.00 & 1561448.00 & 1865901.00 \\
\hline & Mínimo & 2332.00 & 2096.00 & 4463.00 & 5255.00 \\
\hline & Desvio Padrão & 80262.35 & 133316.10 & 227520.00 & 263748.00 \\
\hline \multicolumn{6}{|c|}{ Nordeste } \\
\hline & Observações & 1295.00 & 1295.00 & 1295.00 & 1295.00 \\
\hline & Total & 28083421.80 & 34787973.50 & 44737031.15 & 47708797.15 \\
\hline & Média & 21686.04 & 26863.30 & 34545.97 & 36840.77 \\
\hline & Máximo & 1154717.00 & 1502013.00 & 2221500.00 & 2455143.00 \\
\hline & Mínimo & 874.00 & 1128.00 & 1435.00 & 1308.00 \\
\hline & Desvio Padrão & 55339.74 & 76790.71 & 109993.40 & 120014.30 \\
\hline \multicolumn{6}{|c|}{ Centro Oeste } \\
\hline & Observações & 257.00 & 257.00 & 257.00 & 257.00 \\
\hline & Total & 5072529.79 & 7545769.29 & 11549220.20 & 12793824.94 \\
\hline & Média & 19737.47 & 29360.97 & 44938.60 & 49781.42 \\
\hline & Máximo & 537492.00 & 1176908.00 & 1821946.00 & 2051146.00 \\
\hline & Mínimo & 1044.00 & 732.00 & 861.00 & 895.00 \\
\hline & Desvio Padrão & 48441.05 & 97485.20 & 163864.00 & 185588.20 \\
\hline \multicolumn{6}{|c|}{ Sudeste } \\
\hline & Observações & 1401.00 & 1401.00 & 1401.00 & 1401.00 \\
\hline & Total & 39850758.51 & 51737150.73 & 67000737.51 & 72412408.23 \\
\hline & Média & 28444.51 & 36928.73 & 47823.51 & 51686.23 \\
\hline & Máximo & 5924612.00 & 8493217.00 & 9839066.00 & 10400000.00 \\
\hline & Mínimo & 830.00 & 866.00 & 768.00 & 795.00 \\
\hline & Desvio Padrão & 201042.10 & 274761.00 & 317448.80 & 337130.00 \\
\hline \multicolumn{6}{|l|}{ Sul } \\
\hline & Observações & 593.00 & 593.00 & 593.00 & 593.00 \\
\hline & Total & 16490535.38 & 19027217.41 & 23509621.39 & 23509621.39 \\
\hline & Média & 27808.66 & 32086.37 & 39645.23 & 42332.73 \\
\hline & Máximo & 885545.00 & 1125478.00 & 1476253.00 & 1587315.00 \\
\hline & Mínimo & 1772.00 & 1080.00 & 1255.00 & 1338.00 \\
\hline & Desvio Padrão & 62332.34 & 82791.11 & 109876.70 & 118421.90 \\
\hline \multicolumn{6}{|l|}{ Brasil } \\
\hline & Observações & 3654.00 & 3654.00 & 3654.00 & 3654.00 \\
\hline & Total & 93091861.80 & 118966201.20 & 157005035.46 & 169719786.18 \\
\hline & Média & 25476.70 & 32557.80 & 42967.99 & 46447.67 \\
\hline & Máximo & 5924612.00 & 8493217.00 & 9839066.00 & 10400000.00 \\
\hline & Mínimo & 830.00 & 732.00 & 768.00 & 795.00 \\
\hline & Desvio Padrão & 132556.10 & 182626.70 & 219945.90 & 235679.20 \\
\hline
\end{tabular}

Fonte: IPEADARA e cálculos do autor 
Tabela 3.6 - Estatísticas Descritivas da Escolaridade 1970 - 2000

\begin{tabular}{|c|c|c|c|c|c|}
\hline & & 1970 & 1980 & 1991 & 2000 \\
\hline \multicolumn{6}{|l|}{ Norte } \\
\hline & Observações & 108 & 108 & 108 & 108 \\
\hline & Média & 1,19 & 1,75 & 2,55 & 3,57 \\
\hline & Máximo & 3,90 & 5,40 & 6,80 & 7,68 \\
\hline & Mínimo & 0,20 & 0,40 & 0,60 & 1,44 \\
\hline & Desvio Padrão & 0,56 & 0,82 & 1,10 & 1,20 \\
\hline \multicolumn{6}{|c|}{ Nordeste } \\
\hline & Observações & 1295 & 1295 & 1295 & 1295 \\
\hline & Média & 0,71 & 1,14 & 2,04 & 3,04 \\
\hline & Máximo & 4,00 & 5,60 & 6,89 & 7,72 \\
\hline & Mínimo & 0,00 & 0,10 & 0,40 & 1,34 \\
\hline & Desvio Padrão & 0,42 & 0,61 & 0,82 & 0,89 \\
\hline \multicolumn{6}{|c|}{ Centro Oeste } \\
\hline & Observações & 257 & 257 & 257 & 257 \\
\hline & Média & 1,26 & 2,11 & 3,43 & 4,45 \\
\hline & Máximo & 4,20 & 6,10 & 7,40 & 8,25 \\
\hline & Mínimo & 0,30 & 0,50 & 1,50 & 2,69 \\
\hline & Desvio Padrão & 0,54 & 0,72 & 0,81 & 0,79 \\
\hline \multicolumn{6}{|c|}{ Sudeste } \\
\hline & Observações & 1401 & 1401 & 1401 & 1401 \\
\hline & Média & 1,76 & 2,61 & 3,81 & 4,83 \\
\hline & Máximo & 5,60 & 7,20 & 8,80 & 9,26 \\
\hline & Mínimo & 0,10 & 0,30 & 0,80 & 1,78 \\
\hline & Desvio Padrão & 0,72 & 0,88 & 1,02 & 1,07 \\
\hline \multicolumn{6}{|l|}{ Sul } \\
\hline & Observações & 593 & 593 & 593 & 593 \\
\hline & Média & 1,97 & 2,89 & 4,06 & 5,03 \\
\hline & Máximo & 5,20 & 6,80 & 8,60 & \\
\hline & Mínimo & 0,50 & 1,00 & 1,90 & 2,87 \\
\hline & Desvio Padrão & 0,77 & 0,83 & 0,84 & 0,83 \\
\hline \multicolumn{6}{|l|}{ Brasil } \\
\hline & Observações & 3654 & 3654 & 3654 & 3654 \\
\hline & Média & 1,37 & 2,07 & 3,16 & 4,16 \\
\hline & Máximo & 5,60 & 7,20 & 8,80 & 9,65 \\
\hline & Mínimo & 0,00 & 0,10 & 0,40 & 1,34 \\
\hline & Desvio Padrão & 0,81 & 1,06 & 1,26 & 1,29 \\
\hline
\end{tabular}

Fonte: Cálculos do autor 
Figura 3.1 - Evolução do PIB

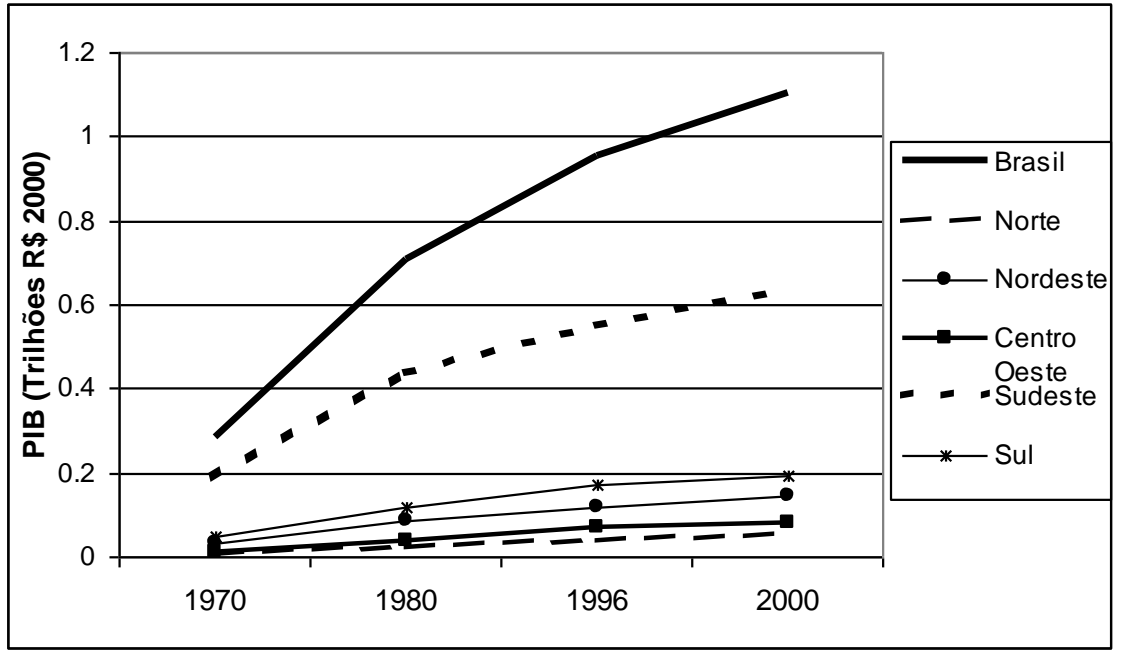

Fonte: IPEDATA e Cálculos do autor

Figura 3.2 - Evolução da População

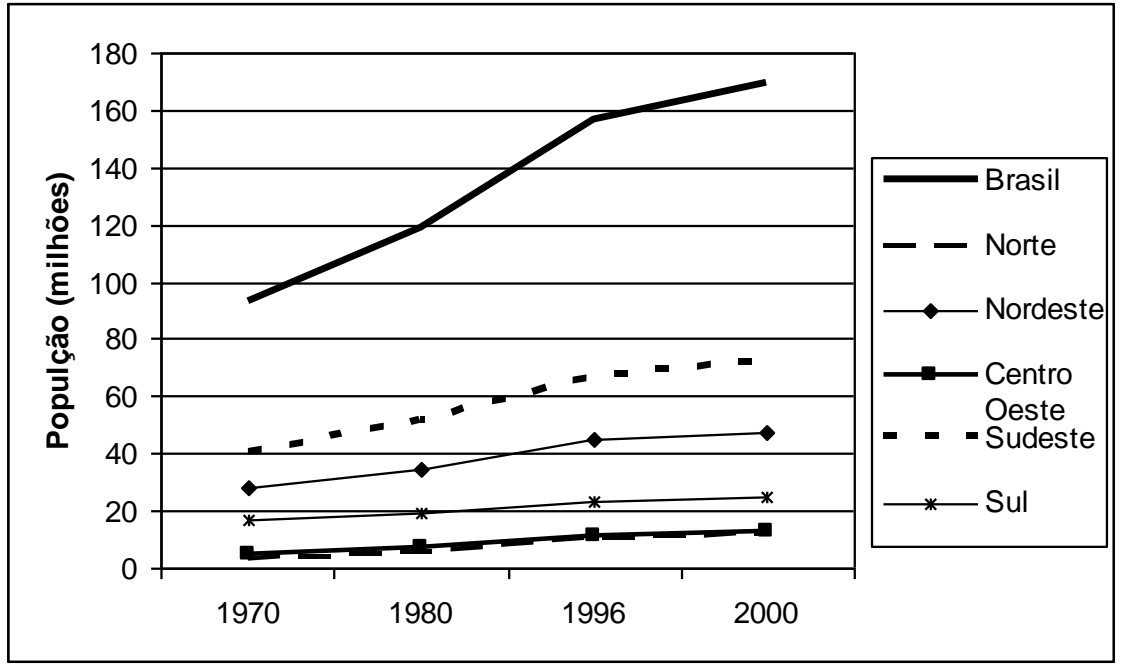

Fonte: IPEDATA e Cálculos do autor

Figura 3.3 - Evolução da Educação

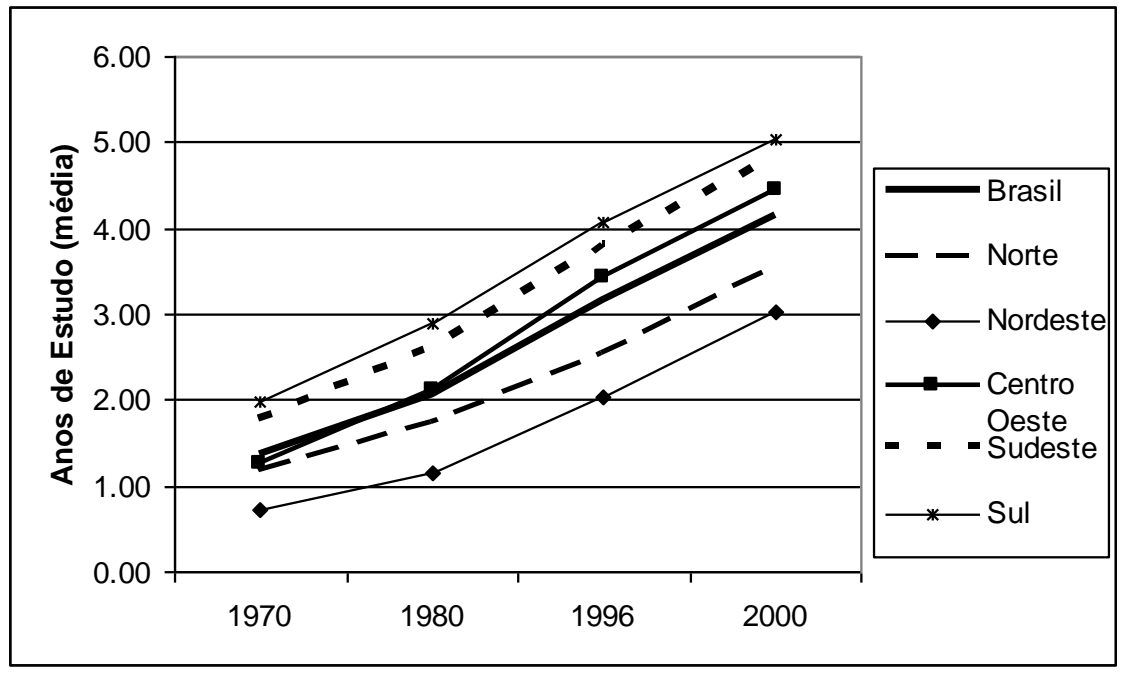

Fonte: IPEDATA e Cálculos do autor 


\subsubsection{Curvas de Lorenz, Índice de Gini e Análise Visual}

O movimento paralelo das variáveis das cinco regiões parece apontar para a manutenção das desigualdades regionais ao longo do período. Uma avaliação mais acurada dessa hipótese pode ser feita com o uso da Curva de Lorenz e do Índice de Gini.

As figuras 3.4, 3.5 e 3.6 mostram as curvas de Lorenz para o PIB, população e educação respectivamente. Os gráficos indicam que a desigualdade entre as cidades, em termos de PIB, manteve-se praticamente inalterada entre os anos de 1970 e 2000. A educação, por sua vez, sofreu redução ainda mais acentuada da desigualdade, a curva de Lorenz de 2000 é consideravelmente mais próxima a linha de $45^{\circ}$ que a curva de 1970 . Por outro lado, a concentração da população sofreu um nítido aumento nos últimos 30 anos. Esse mesmo resultado é expresso de outro modo através dos índices de Gini (tabela 2.7).

Uma terceira forma de acompanhar a evolução das variáveis é através de mapas de densidade elaborados pelo IPEADATA. O primeiro par de mapas (figura 3.7 e 3.8) mostra a densidade geográfica do PIB (medida em Reais de 2000 por quilômetro quadrado) para os anos de 1970 e 2000, as áreas mais escuras estão associadas a maior densidade econômica. Os dois gráficos são praticamente idênticos, as áreas mais escuras estão concentradas nas regiões Sul e Sudeste em ambos os anos. Esse fato coincide com o alto índice de Gini apresentado pelo PIB.

A densidade populacional, por sua vez, apresenta uma característica um pouco diferente daquela vista na densidade do PIB. Pode-se notar que no ano de 2000 ocorre um claro aumento no número de moradores Nordeste, as áreas escuras aumentaram de modo significativo em relação a 1970. Algo que não se verifica em relação a densidade econômica.

Por outro lado, a educação não apresentou tendência à concentração. As regiões escuras estão mais espalhadas pelos mapas (figuras 3.11 e 3.12), tanto em 1970 quanto em 2000. A mudança de escala, no entanto, dificulta uma avaliação espacial adequada com base no mapa. 
Figura 3.4 - Curva de Lorenz - PIB

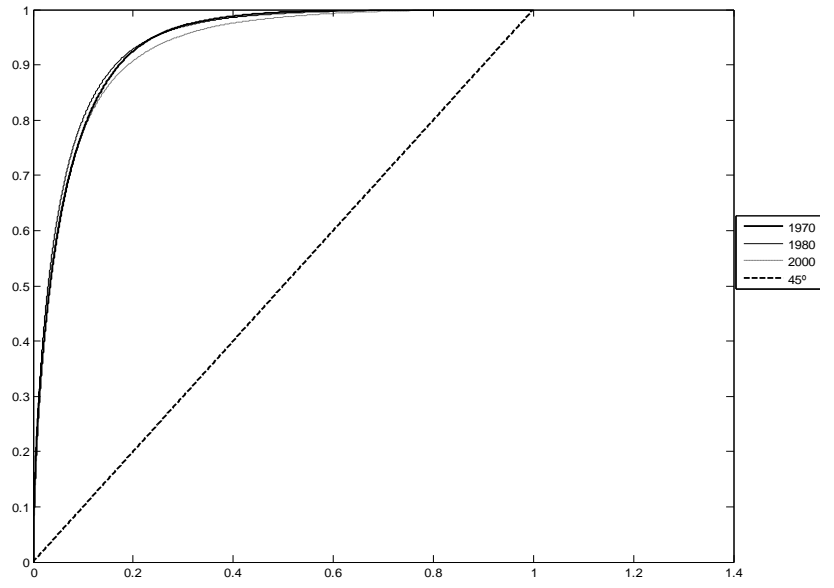

Fonte: Ipeadata eCálculos do autor

Figura 3.5 - Curva de Lorenz - População

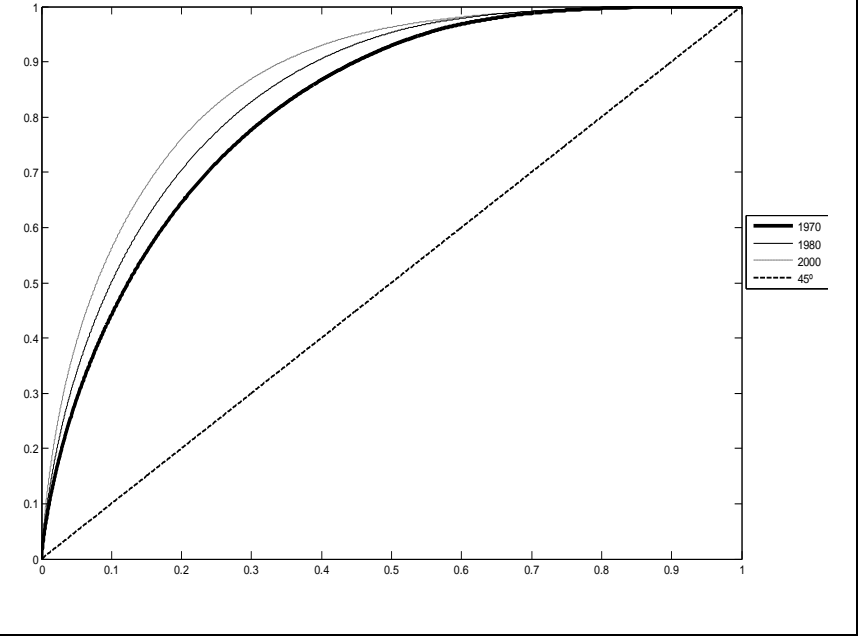

Fonte: Ipeadata e Cálculos do autor

Figura 3.6 - Curva de Lorenz - Educação

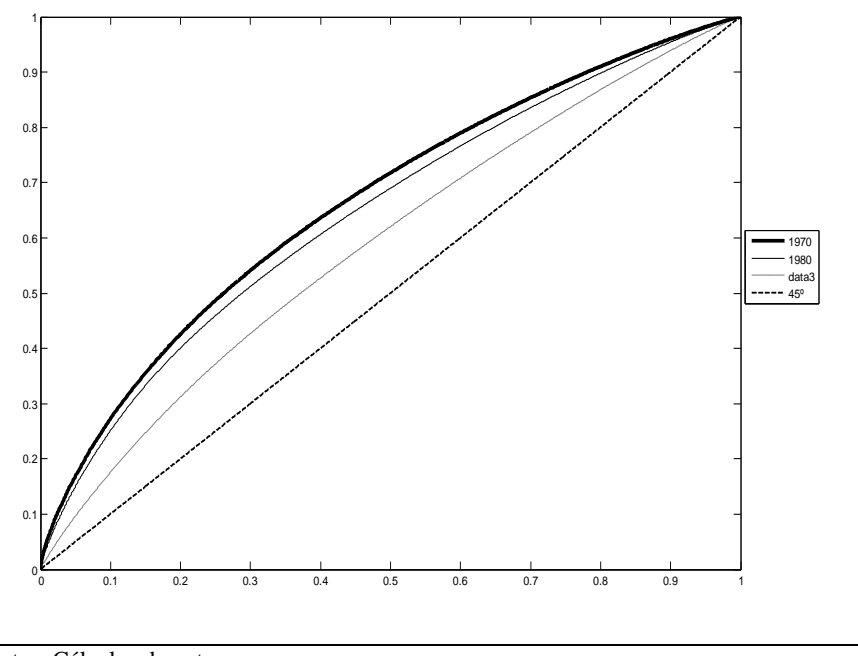


Tabela 3.7 - Evolução do Índice de Gini

\begin{tabular}{lccccc}
\hline \hline & 1970 & 1980 & 1991 & 1996 & 2000 \\
\hline PIB & 0.8675 & 0.8739 & - & 0.888 & 0.8547 \\
População & 0.6367 & 0.6888 & - & 0.7236 & 0.7314 \\
Educação & 0.3285 & 0.2887 & 0.2262 & - & 0.1762 \\
\hline
\end{tabular}

Fonte: IPEDATA e cálculos do autor

Figura 3.7 - Densidade Geográfica do PIB - 1970

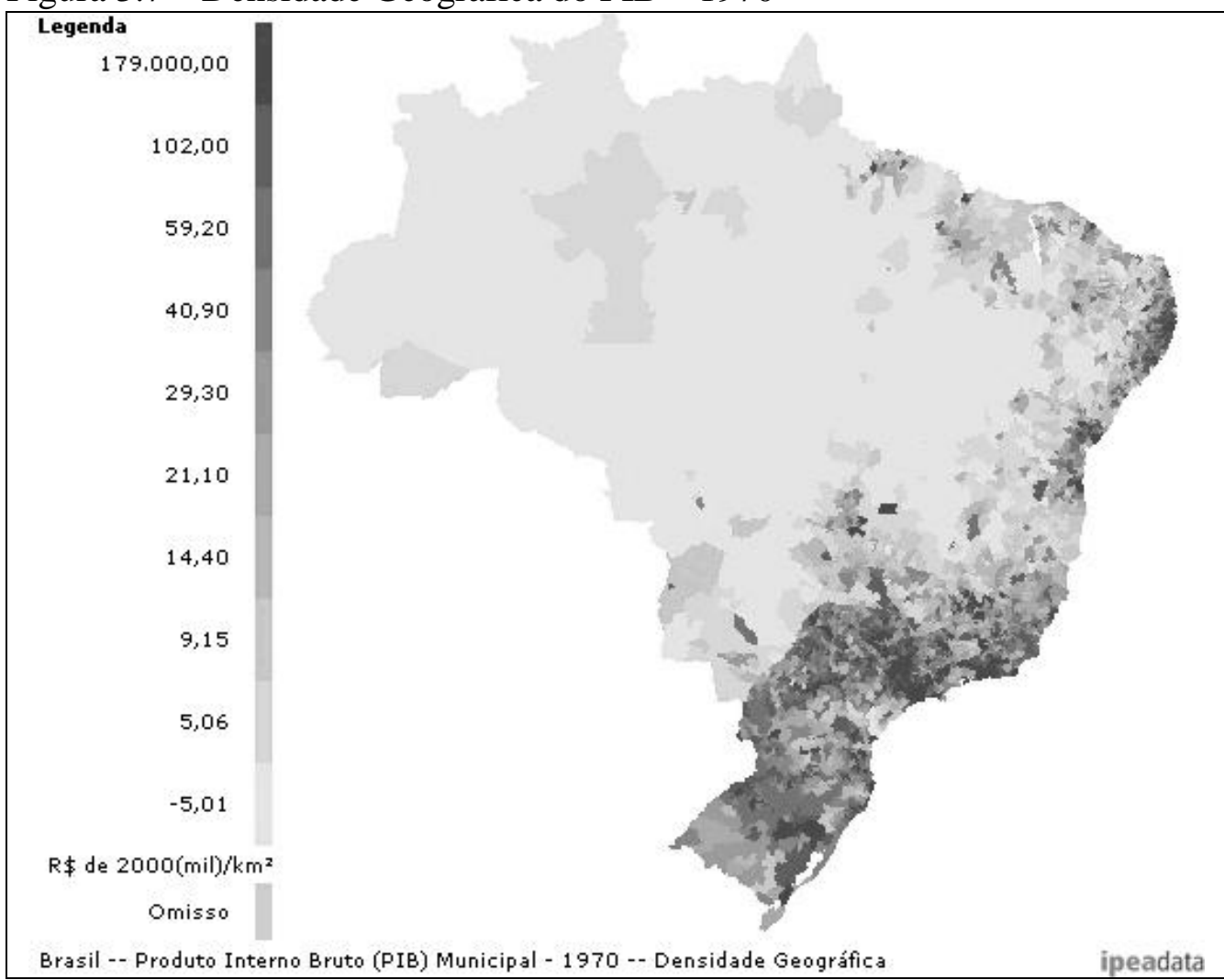


Figura 3.8 - Densidade Geográfica do PIB - 2000

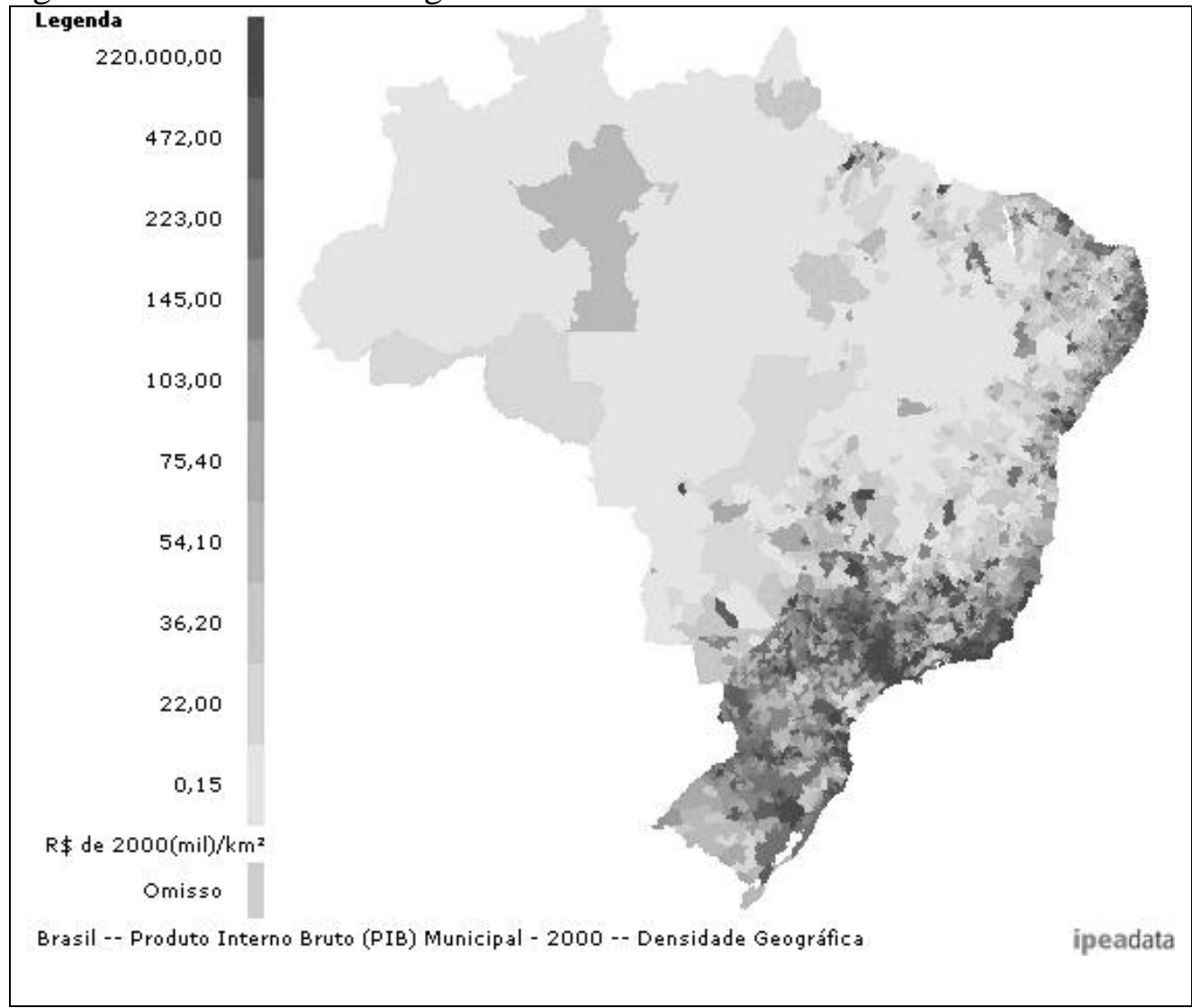

Figura 3.9 - Densidade Populacional - 1970

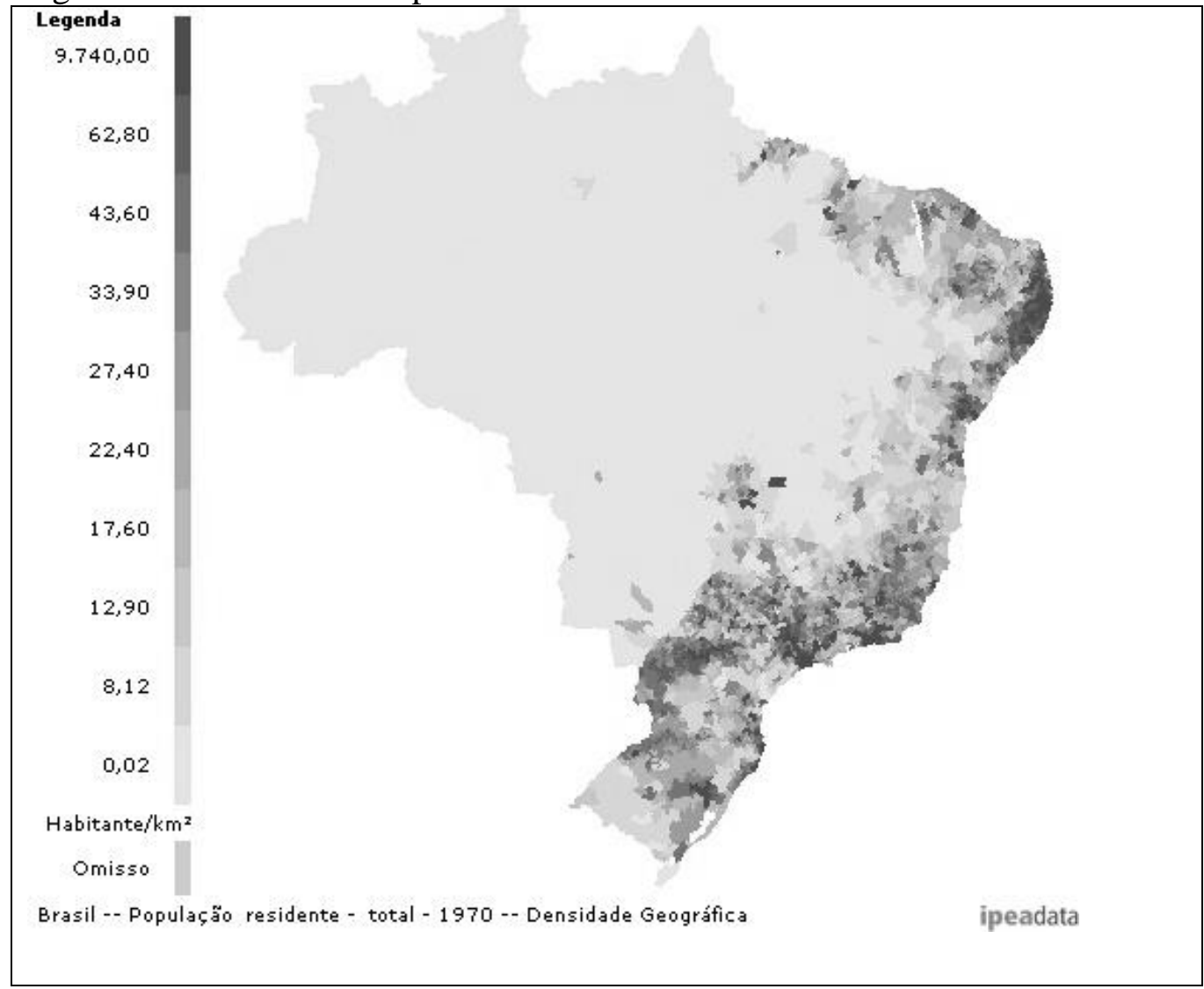


Figura 3.10 - Densidade Populacional - 2000

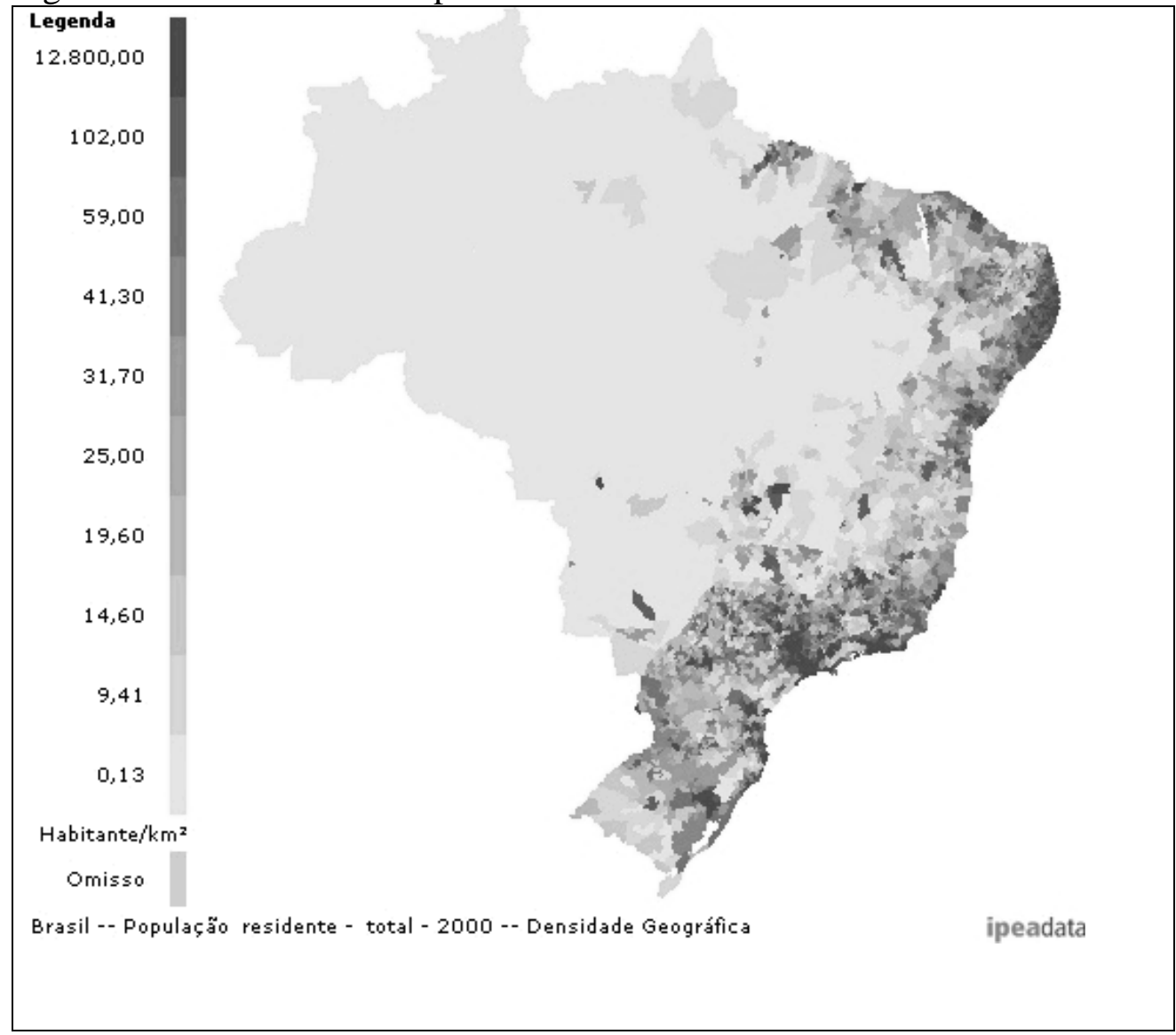

Figura 2.11 - Densidade Educacional - 1970

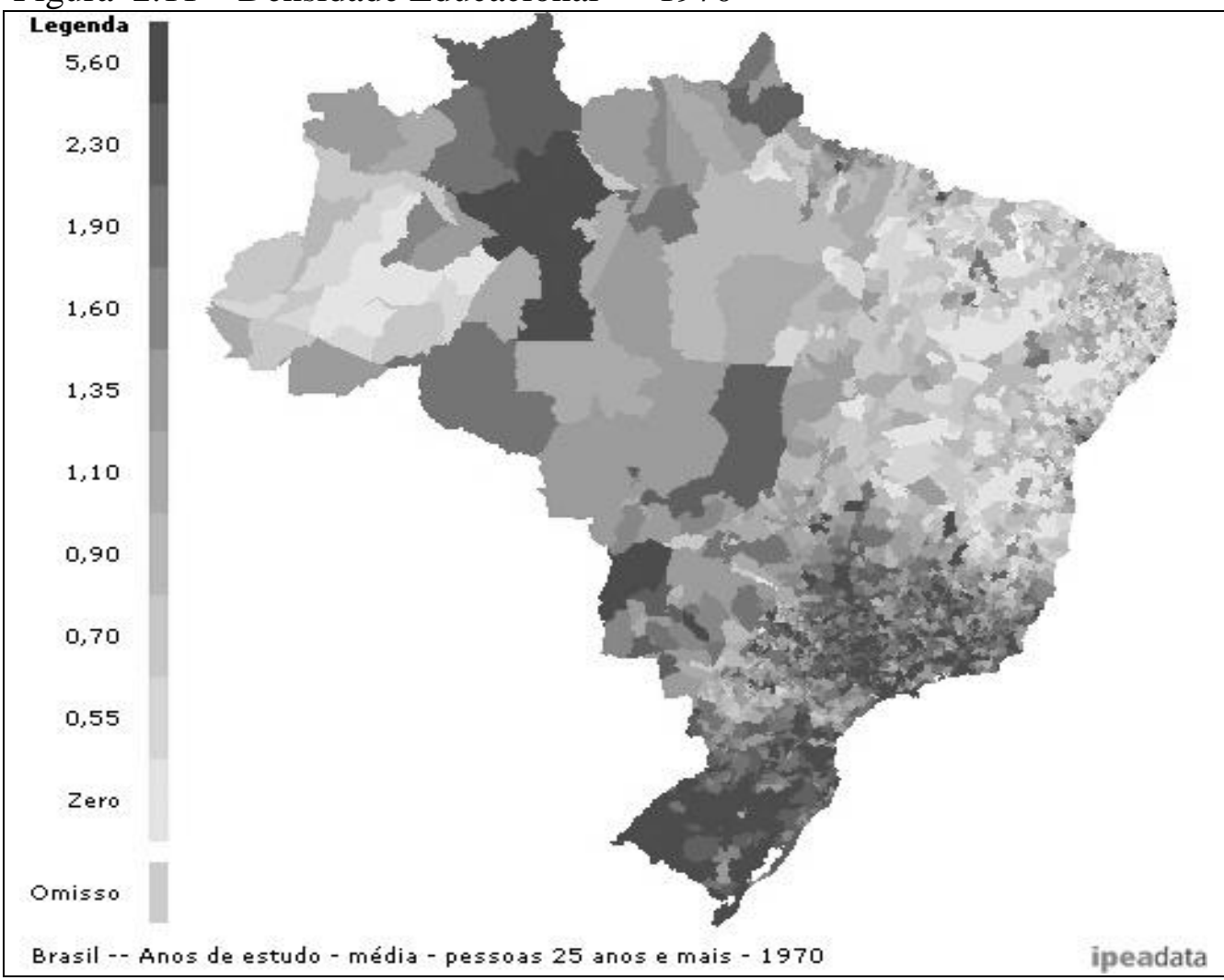


Figura 3.12 - Densidade Educacional - 2000

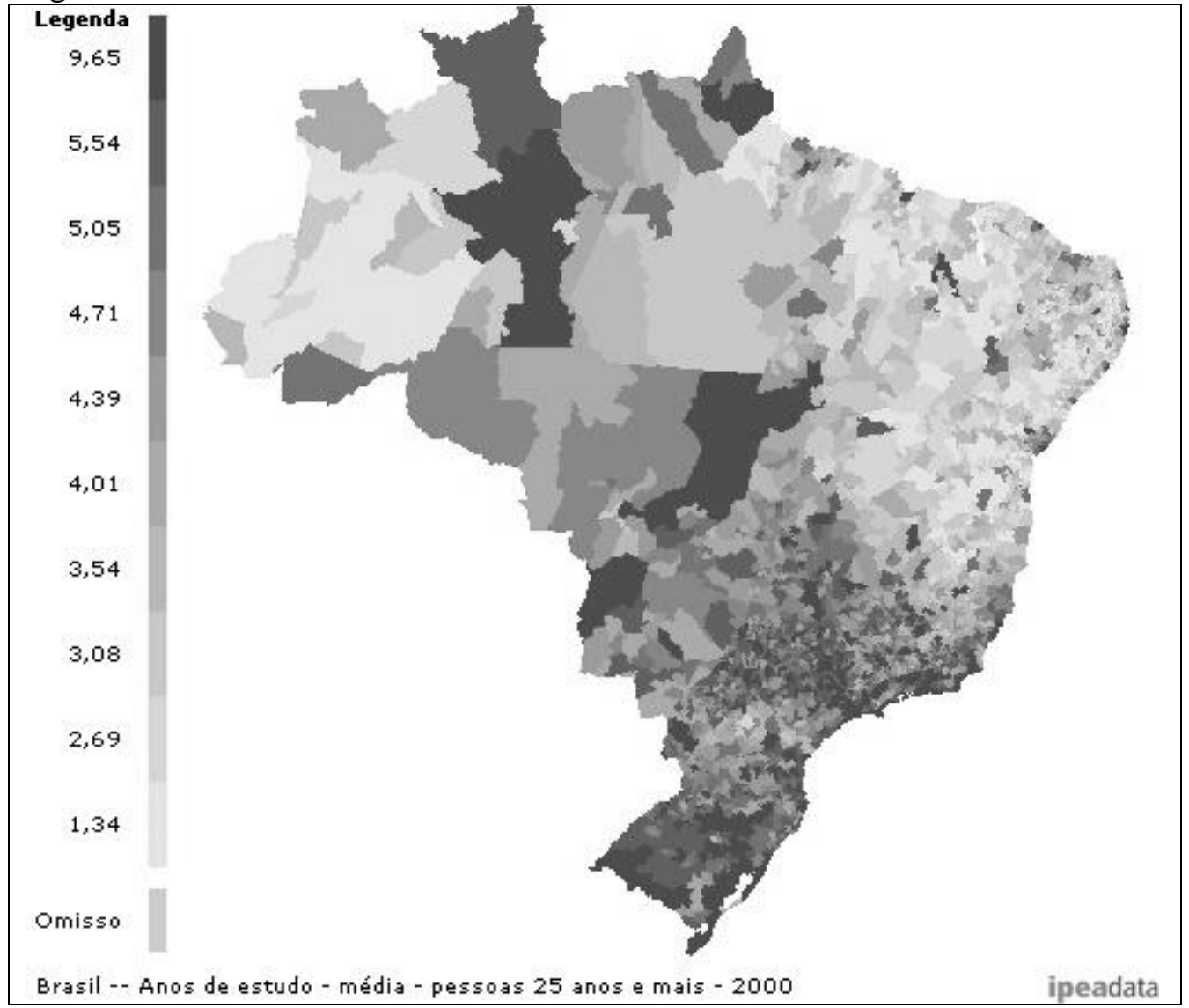

\subsubsection{Indicadores Espaciais}

A análise exploratória de dados Espaciais, conhecida como ESDA (Explanatory Spatial Data Analyses), é um conjunto de técnicas que tem por objetivo descrever e visualizar a distribuição espacial dos dados, de forma a identificar associações espaciais ou clusters (Ertur e Le Gallo, 2003). As ferramentas desse tipo de análise são indicadores capazes mensurar a autocorrelação espacial global e local.

A autocorrelação espacial é definida como a coincidência de valores e localizações similares (Anselin, 2001). Autocorrelação espacial positiva ocorre quando valores altos ou baixos de uma variável aleatória tendem a ser cercados por variáveis com valores similares. De modo contrário, autocorrelação negativa existe quando valores de uma determinada área geográfica tendem a ser cercados por valores muito diferentes (Ertur e Le Gallo, 2003). 
A medida de autocorrelação espacial global mais conhecida e mais utilizada é a estatística I de Moran (Upton and Fingleton, 1985, Ertur e Le Gallo, 2003), definida para um dado ano t como:

$$
I_{t}=\frac{n}{S_{0}}\left\{\frac{\sum_{i} \sum_{j} w_{i j}\left(x_{i, t}-\mu_{t}\right)\left(x_{j, t}-\mu_{t}\right)}{\sum_{t}\left(x_{i, t}-\mu_{t}\right)^{2}}\right\}
$$

Em que $x_{i, t}$ é observação na região i e no ano $t ; \mu_{t}$ é média das observações entre as diversas regiões no ano t; $n$ é o número de regiões; $S_{0}$ é a soma de todos os elementos da matriz de pesos espaciais $\mathrm{W}$, da qual wij é um elemento. Maiores detalhes sobre a matriz de pesos espaciais, e sua importância na econometria espacial, serão dados na seção 4, dedicada à metodologia. No momento, é suficiente dizer que ela contém informações sobre a dependência espacial das $n$ regiões i. Uma vez que essa dependência pode assumir diversas formas, a matriz W não apresenta um formato fixo. Nesta seção, especificamente, utilizamos a matriz definida da seguinte forma:

$$
\left\{\begin{array}{l}
w_{i j}^{*}=0 \quad \text { se } \quad i=j \\
w_{i j}^{*}=1 / d_{i j}^{2} \text { se } i \neq j \quad \text { e } w_{i j}=w_{i j}^{*} / \sum_{j} w_{i j}^{*}
\end{array}\right.
$$

Nota-se que o segundo passo tomado na construção da matriz $\mathrm{W}$ torna a soma dos elementos de cada coluna igual a 1. Esse procedimento, conhecido como padronização, faz com que a fórmula (1) possa ser escrita em notação matricial como:

$$
I_{t}=\left\{\frac{z_{t}{ }^{\prime} W z_{t}}{z_{t}{ }^{\prime} z_{t}}\right\}
$$

Sendo $\mathrm{z}_{\mathrm{t}}$ um vetor de desvios em relação à média.

$\mathrm{O}$ índice de Moran fornece uma indicação formal da associação linear ente o vetor $\mathrm{z}_{\mathrm{t}}$ de valores observados e o vetor $\mathrm{Wz}_{\mathrm{t}}$, que corresponde a média da vizinhança espacialmente 
ponderada (Ertur e Le Gallo, 2003), também conhecida como a defasagem espacial da variável de interesse.

O valor esperado da estatística I é E(I) = -1/(n-1) (Upton and Fingleton, 1985). Estimativas acima desse valor indicam a existência de autocorrelação espacial positiva. Analogamente, valores menores indicam a presença de autocorrelação negativa.

A inferência para a estatística de Moran pode ser feita com base em três diferentes métodos: aproximação pela normal, processo aleatório e o método da permutação proposto por Anselin (1995). O método utilizado nessa dissertação é o processo aleatório, que assume que, sob a hipótese nula, cada valor observado poderia ter ocorrido em cada localização com a mesma probabilidade (Cliff and Ord, 1981). A variância obtida sob essas condições é dada por:

$$
\operatorname{Var}(I)=\frac{n\left\{\left(n^{2}-3 n+3\right) S_{1}-n S_{2}+3 S_{0}^{2}\right\}-k\left\{n(n-1) S_{1}-2 n S_{2}+6 S_{0}^{2}\right\}}{(n-1)^{(3)} S_{0}^{2}}-\frac{1}{(n-1)^{2}}
$$

Sendo:

$$
\begin{gathered}
S_{0}=\text { soma de todos os elementos da Matriz W; } \quad S_{1}=1 / 2 \sum_{i} \sum_{j}\left(w_{i j}+w_{j i}\right)^{2} \\
S_{2}=\sum_{i}\left(w_{i 0}+w_{0 i}\right)^{2} ; \quad w_{i 0}=\sum_{j} w_{i j} ; \quad w_{0 i}=\sum_{j} w_{j i} ; \quad(n-1)^{(3)}=(n-1)(n-2)(n-3) \\
k=m_{4} / m_{2}^{2} \text { e } \quad m_{r}=\sum_{i}\left(x_{i}-\mu\right)^{r}
\end{gathered}
$$

As tabelas 3.8, 3.9, 3.10 mostram, respectivamente, as estatísticas I de Moran para a educação, PIB e população - bem como para o crescimento de cada uma delas - entre os anos de 1970 e 2000. Em todos os anos analisados, a estatística I de Moran mostrou-se positiva e significante, sugerindo que todas as três variáveis apresentam tendência à formação de clusters. Em outras palavras, regiões com escolaridade, PIB e população elevadas são localizadas próximas a regiões com valores também altos dessas variáveis. Nota-se ainda que este padrão se mantém ao longo dos trinta anos de estudo, uma vez que valor da estatística I varia muito pouco. 
A tendência a concentração, indicada pelo índice de Moran, corrobora a análise visual das figuras 3.6 a 3.11, as quais apresentam clara tendência a formação de clusters de valores altos nas regiões Sul e Sudeste e cluster de valores baixos na região Norte, Nordeste e Centro Oeste.

Tabela 3.8 - Teste I de Moran para Autocorrelação Espacial - Educação

\begin{tabular}{lcccc}
\hline \hline & I & Volor Esperado & Desvio Padrão & P-Valor \\
\hline 1970 & 0.65057 & -0.000273748 & 0.006753234 & 0.00 \\
1980 & 0.66815 & -0.000273748 & 0.00675367 & 0.00 \\
1991 & 0.66493 & -0.000273748 & 0.006753899 & 0.00 \\
2000 & 0.66056 & -0.000273748 & 0.006753935 & 0.00 \\
Crescimento 1970-00 & 0.70663 & -0.000273748 & 0.000951658 & 0.00 \\
\hline Fonte: IPEDATA e cálculos do autor & & & &
\end{tabular}

Tabela 3.9 - Teste I de Moran para Autocorrelação Espacial - PIB

\begin{tabular}{lcrrc}
\hline \hline & I & Volor Esperado & Desvio Padrão & P-Valor \\
\hline 1970 & 0.034951 & -0.000273748 & 0.004629736 & 0.00 \\
1980 & 0.041077 & -0.000273748 & 0.004864021 & 0.00 \\
1996 & 0.033729 & -0.000273748 & 0.005397294 & 0.00 \\
2000 & 0.053443 & -0.000273748 & 0.004896654 & 0.00 \\
Crescimento 1970-00 & 0.1203 & -0.000273748 & 0.006605187 & 0.00 \\
\hline
\end{tabular}

Fonte: IPEDATA e cálculos do autor

Tabela 3.10 - Teste I de Moran para Autocorrelação Espacial - População

\begin{tabular}{lcccc}
\hline \hline & I & Volor Esperado & Desvio Padrão & P-Valor \\
\hline 1970 & 0.04697 & -0.000273748 & 0.005380512 & 0.00 \\
1980 & 0.052234 & -0.000273748 & 0.005304457 & 0.00 \\
1991 & 0.059066 & -0.000273748 & 0.005473932 & 0.00 \\
2000 & 0.066689 & -0.000273748 & 0.005620639 & 0.00 \\
Crescimento 1970-00 & 0.16287 & -0.000273748 & 0.006228931 & 0.00 \\
\hline
\end{tabular}

Fonte: IPEDATA e cálculos do autor

Embora o índice I de Moran seja bastante útil na verificação da existência de autocorrelação global, ele não permite acessar a estrutura regional da autocorrelação espacial (Ertur e Le Gallo, 2003). Ou seja, seja não é possível detectar quais as regiões com maior contribuição para a autocorrelação global, ou a existência de clusters de valores altos ou baixos. Para esse tipo de verificação, foram desenvolvidas técnicas de detecção de autocorrelação local. 
Esta análise exploratória de dados utilizou dois métodos de detecçãode autocorrelação local: o gráfico de Moran (Moran Scatterplot) e a versão local do índice I de Moran.

$\mathrm{O}$ gráfico de Moran apresenta os valores do vetor $\mathrm{Wz}_{\mathrm{t}}$ no eixo das ordenadas contra o vetor $\mathrm{z}_{\mathrm{t}}$ no eixo das abscissas (Anselin, 1996). Os quatro quadrantes do plano cartesiano correspondem servem como delimitador das duas possíveis associações espaciais entre as observações. O primeiro e o terceiro quadrantes correspondem a autocorrelação espacial positiva. De modo oposto, o segundo e o quarto quadrantes representam as regiões com autocorrelação espacial negativa. De modo mais objetivo.

Autocorrelação Positiva ( $1^{\circ}$ e $3^{\circ}$ qudrantes):

- HH (high high): primeiro quadrante, região com valores acima da média, cercada por vizinhos com valores acima da média.

- LL (low low): terceiro quadrante, região com valores abaixo da média, cercada por vizinhos com valores abaixo da média.

Autocorrelação Negativa ( $2^{\circ}$ e $4^{\circ}$ qudrantes):

- LH (low low): segundo quadrante, região com valores abaixo da média, cercada por vizinhos com valores acima da média.

- HL (high high): terceiro quadrante, região com valores acima da média, cercada por vizinhos com valores abaixo da média.

As figuras 3.13 a 3.18 mostram os gráficos de Moran das variáveis Escolaridade, PIB e População para os anos iniciais e finais, bem como para os seus respectivos crescimentos. Inicialmente, podemos notar que os gráficos reforçam análise feita anteriormente pela estatística de Moran, uma vez que a inclinação da reta de ajuste dos dados é numericamente igual ao índice I quando se usa uma matriz de pesos padronizada (ver equação 3). Porém, os gráficos mostram uma característica que não pôde ser observada pela análise da autocorrelação global. A tendência a formação de cluster não é tão forte quanto se podia esperar, uma vez que grande parte das observações aparece fora dos quadrantes HH e LL. A única exceção importante é a escolaridade em 2000, o gráfico 3.11 mostra a formação de duas aglomerações, uma de alta e outra de baixa valor, com relativamente poucas observações nos quadrantes LH e HL. 
Figura 3.13 - Gráfico de Moran para a Escolaridade - 1970

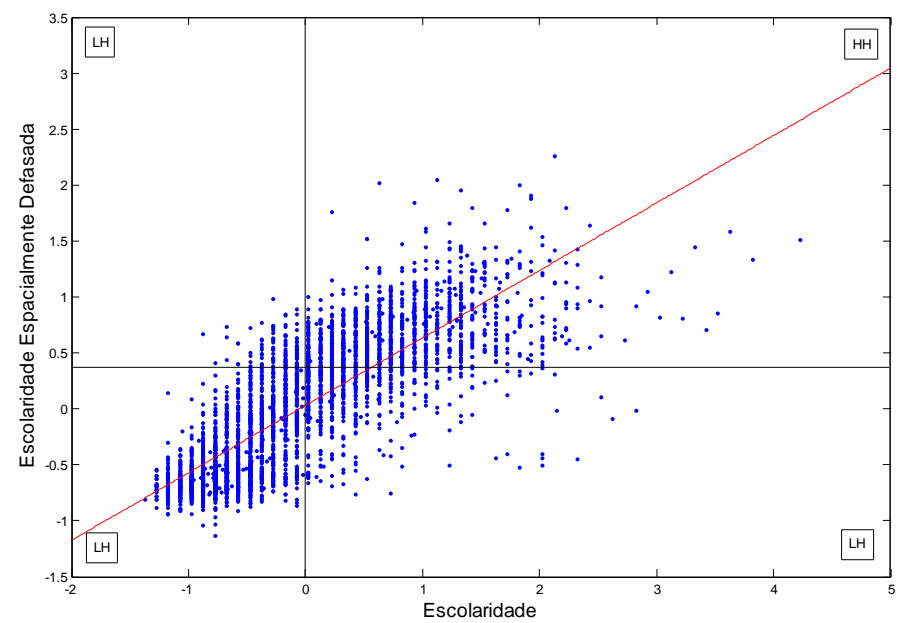

Fonte: IPEDATA e cálculos do autor

Figura 3.14 - Gráfico de Moran para a Escolaridade - 2000

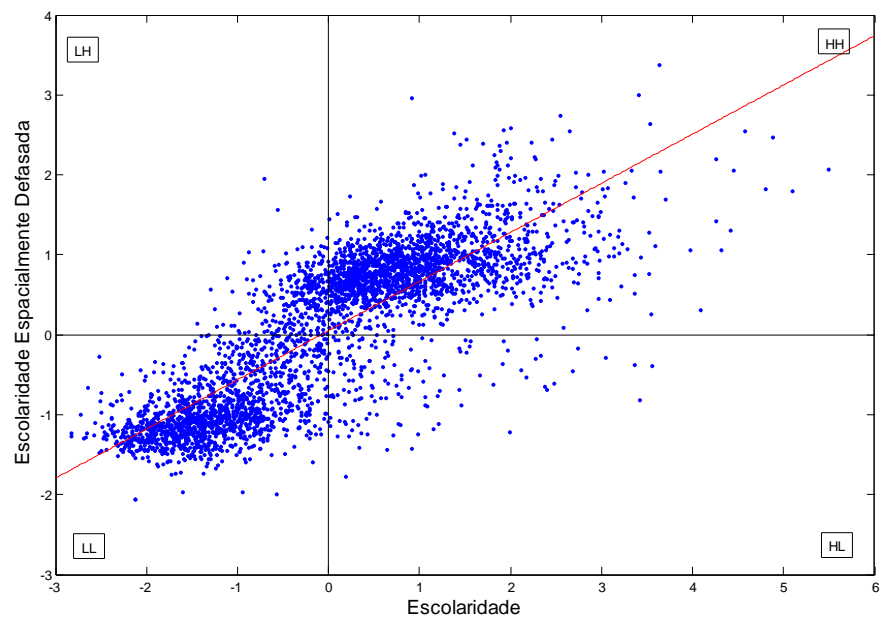

Fonte: IPEDATA e cálculos do autor

Figura 3.15 - Gráfico de Moran para o Crescimento da Escolaridade 1970-2000

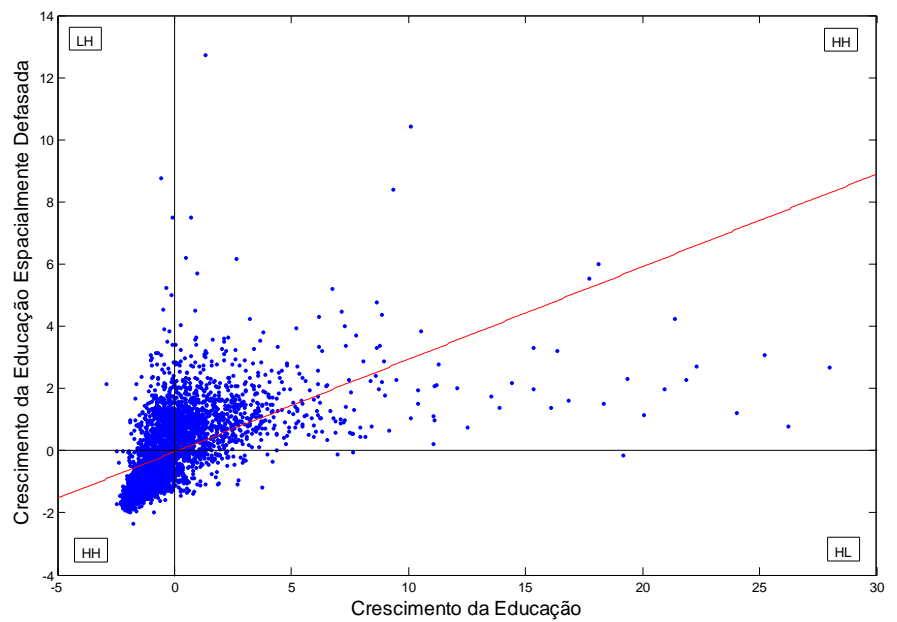

Fonte: IPEDATA e cálculos do autor 
Figura 3.16 - Gráfico de Moran para o PIB - 1970

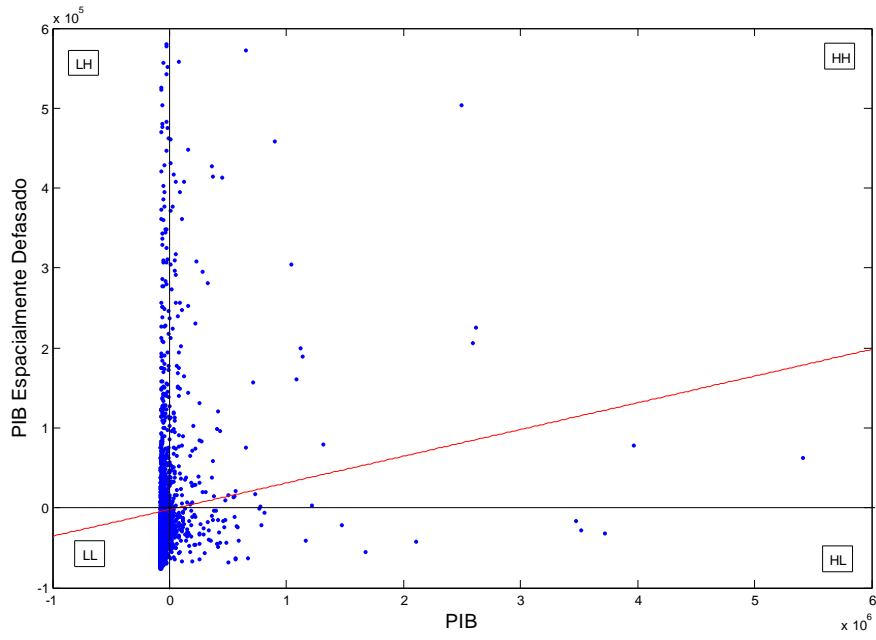

Fonte: IPEDATA e cálculos do autor

Figura 3.17 - Gráfico de Moran para o PIB - 2000

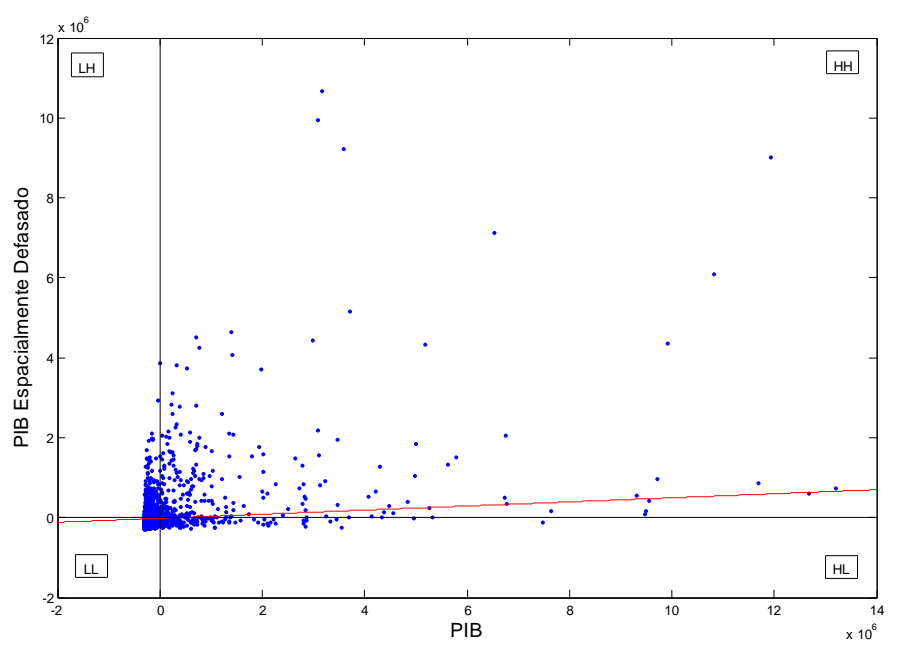

Fonte: IPEDATA e cálculos do autor

Figura 3.18 - Gráfico de Moran para o Crescimento do PIB 1970-2000

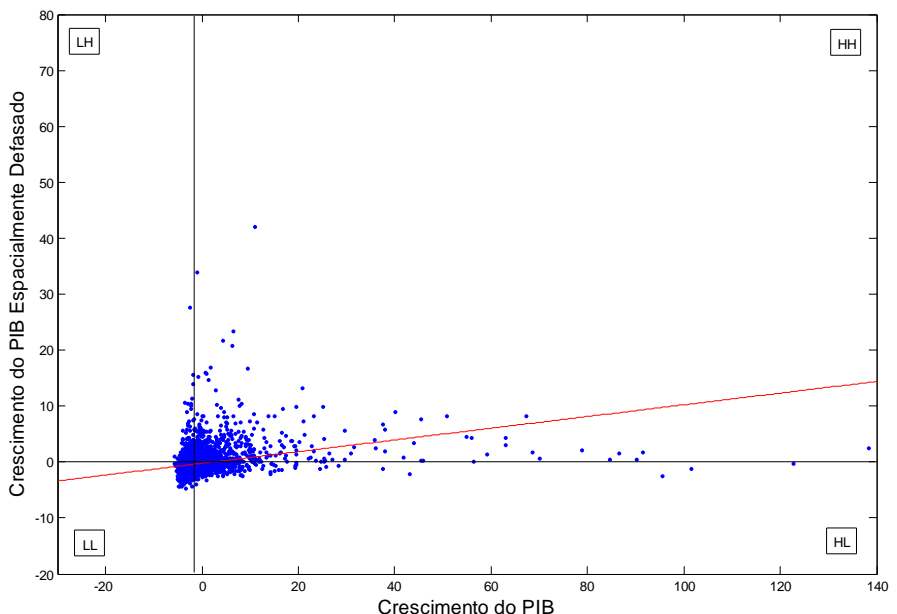

Fonte: IPEDATA e cálculos do autor 
Figura 3.19 - Gráfico de Moran para a População - 1970

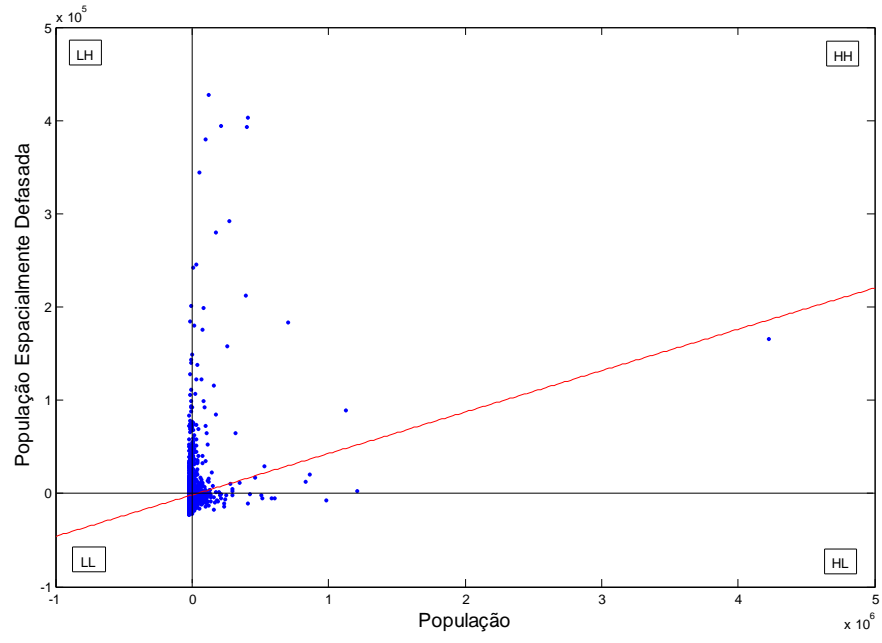

Fonte: IPEDATA e cálculos do autor

Figura 3.20 - Gráfico de Moran para a População - 2000

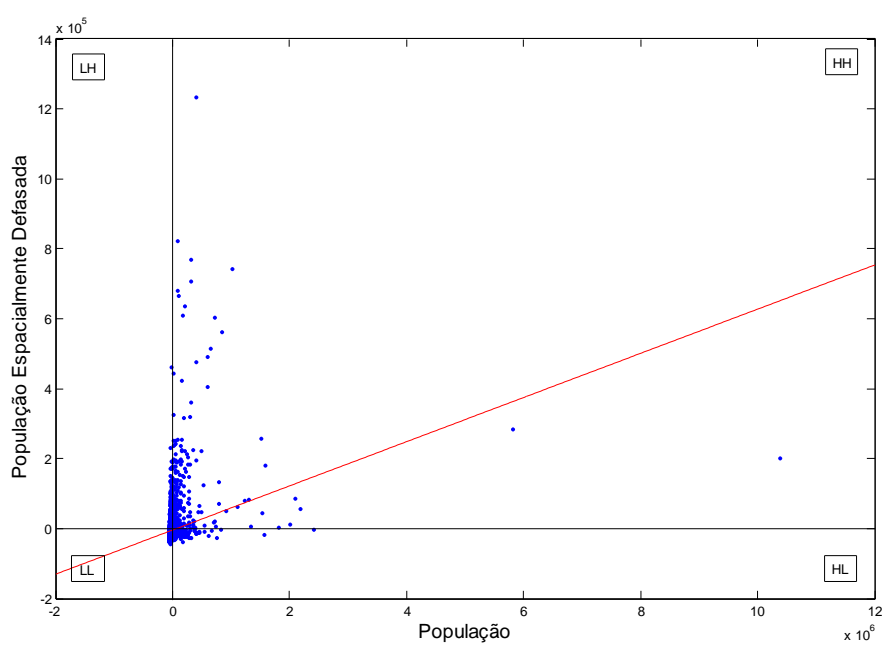

Fonte: IPEDATA e cálculos do autor

Figura 3.21 - Gráfico de Moran para o Crescimento da População 1970-2000

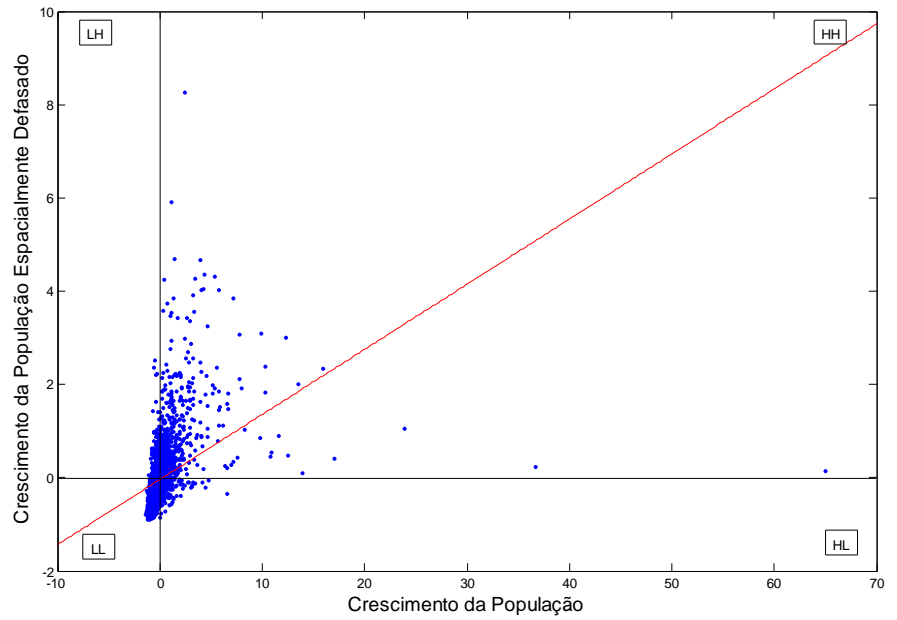

Fonte: IPEDATA e cálculos do autor 
O segundo indicador local utilizado é o índice local de Moran, que obedece a dois critérios que definem, segundo Anselin (1995), um indicador de associação espacial local (LISA Local Indicator of Spatial Autocorrelation): produz, para cada observação, um indicador de aglomeração de valores similares ao redor dessa observação; a soma do indicar local para todas as observações é proporcional ao indicador de associação espacial global. Formalmente, a estatística local de Moran, para cada região i em um dado ano t, é dada pela seguinte definição:

$$
I_{i, t}=\frac{\left(x_{i t}-\mu\right)}{m_{2}} \sum_{j} w_{i j}\left(x_{j, t t}-\mu_{t}\right)
$$

Ertur e Le Gallo (2003) mostram que, para uma matriz de pesos padronizada, o Moran local se relaciona com o Moran global através da relação que se segue,

$$
I_{t}=\frac{\sum_{i} I_{i, t}}{n}
$$

Um valor positivo para $I_{i, t}$ indica a formação de clusters com valores similares, enquanto um valor negativo indica a formação de clusters de valores dissimilares (Ertu e Le Gallo, 2003).

Um modo de condensar a informação disponibilizada pelo índice local de Moran é analisar o comportamento de seus valore extremos. Conforme pode ser visto na tabelas 3.11 a 3.12, os dez valores extremos de todas as variáveis estão localizados nos quadrantes $\mathrm{HH}$ do gráfico de Moran. Esse resultado indica que os clusters de valores altos são os que mais contribuem para o elevado valor positivo da estatística global de Moran ${ }^{15}$.

O padrão de associação entre as variáveis em nível e seus crescimentos apresenta certas peculiaridades que merecem ser destacadas. Em primeiro lugar, as variáveis em nível localizam-se, quase que exclusivamente, nas regiões Sul e Sudeste. Algo esperado, em virtude

\footnotetext{
${ }^{15}$ De fato, para todas as variáveis, todos os cem primeiros resultados pertencem ao primeiro quadrante.
} 
da análise dos mapas apresentados anteriormente. No entanto, o crescimento das variáveis está mais distribuído entre as regiões. Em especial, o dez valores extremos do crescimento da educação estão localizados na região Nordeste. Esse fato pode indicar a formação de clusters de crescimento em algumas regiões com baixo nível das variáveis em estudo. A formação de clusters de crescimento, por sua vez, fornece indícios da existência de spillovers entre as regiões.

Concluímos essa seção afirmando que, embora a análise exploratória espacial de dados forneça algumas informações interessantes, resultados mais contundentes acerca das relações entre o espaço e o crescimento econômico só podem ser realizadas a partir dos testes econometricos expostos nas seções 4 e 5 .

Tabela 3.11 - Valores Extemos do Moran Local - Escolaridade 1970

\begin{tabular}{lcc}
\hline \multicolumn{1}{c}{ AMC } & Moran Local & Quadrante (Gráfico de Moran) \\
\hline Niterói (RJ) & 9.70 & $\mathrm{HH}$ \\
Rio de Janeiro (RJ) & 8.69 & $\mathrm{HH}$ \\
Porto Alegre (RS) & 7.72 & $\mathrm{HH}$ \\
Vila Velha (ES) & 7.28 & $\mathrm{HH}$ \\
Vitória (ES) & 7.27 & $\mathrm{HH}$ \\
Novo Hamburgo (RS) & 6.06 & $\mathrm{HH}$ \\
São Leopoldo (RS) & 6.01 & $\mathrm{HH}$ \\
AMC7097 049 (SP) & 5.78 & $\mathrm{HH}$ \\
Estância Velha (RS) & 5.56 & $\mathrm{HH}$ \\
São Gonçalo (RJ) & 5.55 & $\mathrm{HH}$ \\
\hline
\end{tabular}

Fonte: IPEDATA e cálculos do autor

Tabela 3.12 - Valores Extemos do Moran Local - Escolaridade 2000

\begin{tabular}{lcc}
\multicolumn{1}{c}{ AMC } & Moran & \\
& Local & Quadrante (Gráfico de Moran) \\
\hline Vila Velha (ES) & 7.37 & $\mathrm{HH}$ \\
Vitória (ES) & 7.23 & $\mathrm{HH}$ \\
São Caetano do Sul (SP) & 6.99 & $\mathrm{HH}$ \\
Niterói (RJ) & 6.81 & $\mathrm{HH}$ \\
Santo André (SP) & 6.13 & $\mathrm{HH}$ \\
Rio de Janeiro (RJ) & 5.62 & $\mathrm{HH}$ \\
São Bernardo do Campo (SP) & 5.58 & $\mathrm{HH}$ \\
Florianópolis (SC) & 5.50 & $\mathrm{HH}$ \\
AMC7097 049 (SP) & 5.49 & $\mathrm{HH}$ \\
Porto Alegre (RS) & 5.23 & $\mathrm{HH}$ \\
Fonte: IPEDATA e cálculos do autor & &
\end{tabular}


Tabela 3.13 - Valores Extemos do Moran Local - Crescimento da Escolaridade 1970-2000

\begin{tabular}{lcc}
\hline \hline \multicolumn{1}{c}{ AMC } & Moran & \\
Local & Quadrante (Gráfico de Moran) \\
\hline Tabocas do Brejo Velho (BA) & 18.73 & $\mathrm{HH}$ \\
Serra Dourada (BA) & 18.11 & $\mathrm{HH}$ \\
São José do Piauí (PI) & 16.88 & $\mathrm{HH}$ \\
São Desidério (BA) & 15.59 & $\mathrm{HH}$ \\
Catolândia (BA) & 13.53 & $\mathrm{HH}$ \\
Hugo Napoleão (BA) & 13.41 & $\mathrm{HH}$ \\
Bocaina (PI) & 12.96 & $\mathrm{HH}$ \\
Miguel Leão (PI) & 10.45 & $\mathrm{HH}$ \\
Olho d'Água do Casado (AL) & 9.02 & $\mathrm{HH}$ \\
AMC7097 021 (PI) & 8.73 & $\mathrm{HH}$ \\
\hline
\end{tabular}

Fonte: IPEDATA e cálculos do autor

Tabela 3.14 - Valores Extemos do Moran Local - PIB 1970

\begin{tabular}{lcc}
\multicolumn{1}{c}{ AMC } & Moran & \\
& Local & Quadrante (Gráfico de Moran) \\
\hline São Paulo (SP) & 34.91 & $\mathrm{HH}$ \\
Rio de Janeiro (RJ) & 18.70 & $\mathrm{HH}$ \\
São Bernardo do Campo (SP) & 11.01 & $\mathrm{HH}$ \\
Santo André (SP) & 9.72 & $\mathrm{HH}$ \\
São Caetano do Sul (SP) & 9.53 & $\mathrm{HH}$ \\
Niterói (RJ) & 8.38 & $\mathrm{HH}$ \\
Guarulhos (SP) & 5.81 & $\mathrm{HH}$ \\
Duque de Caxias (RJ) & 3.68 & $\mathrm{HH}$ \\
São Gonçalo (RJ) & 1.92 & $\mathrm{HH}$ \\
Osasco (SP) & 1.65 & $\mathrm{HH}$ \\
\hline
\end{tabular}

Fonte: IPEDATA e cálculos do autor

Tabela 3.15 - Valores Extemos do Moran Local - PIB 2000

\begin{tabular}{lcc}
\hline \multicolumn{1}{c}{ AMC } & Moran & \\
& Local & Quadrante (Gráfico de Moran) \\
\hline São Paulo (SP) & 47.44 & $\mathrm{HH}$ \\
Rio de Janeiro (RJ) & 18.93 & $\mathrm{HH}$ \\
Guarulhos (SP) & 16.55 & $\mathrm{HH}$ \\
São Bernardo do Campo (SP) & 10.13 & $\mathrm{HH}$ \\
Santo André (SP) & 7.15 & $\mathrm{HH}$ \\
Duque de Caxias (RJ) & 6.64 & $\mathrm{HH}$ \\
Niterói (RJ) & 5.20 & $\mathrm{HH}$ \\
Diadema (SP) & 5.10 & $\mathrm{HH}$ \\
São Caetano do Sul (SP) & 4.72 & $\mathrm{HH}$ \\
Osasco (SP) & 3.44 & $\mathrm{HH}$ \\
\hline
\end{tabular}

Fonte: IPEDATA e cálculos do autor 
Tabela 3.16 - Valores Extemos do Moran Local - Crescimento do PIB 1970-2000

\begin{tabular}{lcc}
\hline \hline \multicolumn{1}{c}{ AMC } & Moran Local & Quadrante (Gráfico de Moran) \\
\hline Guamaré (RN) & 89.86 & $\mathrm{HH}$ \\
Galinhos (RN) & 89.07 & $\mathrm{HH}$ \\
Alto do Rodrigues (RN) & 6.48 & $\mathrm{HH}$ \\
Pendências (RN) & 5.36 & $\mathrm{HH}$ \\
Barreiras (BA) & 4.82 & $\mathrm{HH}$ \\
São Desidério (BA) & 4.21 & $\mathrm{HH}$ \\
Anchieta (ES) & 4.03 & $\mathrm{HH}$ \\
AMC7097 006 (RJ) & 3.94 & $\mathrm{HH}$ \\
Barueri (SP) & 3.22 & $\mathrm{HH}$ \\
Piúma (SP) & 3.19 & $\mathrm{HH}$ \\
\hline
\end{tabular}

Fonte: IPEDATA e cálculos do autor

Tabela 3.17 - Valores Extemos do Moran Local - População 1970

\begin{tabular}{lcc}
\hline \multicolumn{1}{c}{ AMC } & Moran Local & Quadrante (Gráfico de Moran) \\
\hline Rio de Janeiro (RJ) & 39.96 & $\mathrm{HH}$ \\
São Paulo (SP) & 20.59 & $\mathrm{HH}$ \\
Niterói (RJ) & 13.92 & $\mathrm{HH}$ \\
Duque de Caxias (RJ) & 9.32 & $\mathrm{HH}$ \\
São Gonçalo (RJ) & 9.07 & $\mathrm{HH}$ \\
AMC7097 012 (RJ) & 7.31 & $\mathrm{HH}$ \\
AMC7097 013 (PE) & 5.71 & $\mathrm{HH}$ \\
Olinda (PE) & 5.21 & $\mathrm{HH}$ \\
Santo André (SP) & 4.76 & $\mathrm{HH}$ \\
Guarulhos (SP) & 4.75 & $\mathrm{HH}$ \\
\hline
\end{tabular}

Fonte: IPEDATA e cálculos do autor

Tabela 3.18 - Valores Extemos do Moran Local - População 2000

\begin{tabular}{lcc}
\hline \multicolumn{1}{c}{ AMC } & Moran & \\
& Local & Quadrante (Gráfico de Moran) \\
\hline São Paulo (SP) & 37.74 & $\mathrm{HH}$ \\
Rio de Janeiro (RJ) & 29.68 & $\mathrm{HH}$ \\
Guarulhos (SP) & 13.72 & $\mathrm{HH}$ \\
Niterói (RJ) & 9.16 & $\mathrm{HH}$ \\
São Gonçalo (RJ) & 8.56 & $\mathrm{HH}$ \\
Duque de Caxias (RJ) & 7.91 & $\mathrm{HH}$ \\
AMC7097 012 (RJ) & 7.03 & $\mathrm{HH}$ \\
São Bernardo do Campo (SP) & 6.09 & $\mathrm{HH}$ \\
Santo André (SP) & 5.32 & $\mathrm{HH}$ \\
AMC7097 013 (PE) & 5.13 & $\mathrm{HH}$ \\
\hline
\end{tabular}

Fonte: IPEDATA e cálculos do autor 
Tabela 3.19 - Valores Extemos do Moran Local - Crescimento da População 2000

\begin{tabular}{lcc}
\hline \hline \multicolumn{1}{c}{ AMC } & Moran & \\
& Local & Quadrante (Gráfico de Moran) \\
\hline Ananindeua (PA) & 11.78 & $\mathrm{HH}$ \\
Santana de Parnaíba (SP) & 11.75 & $\mathrm{HH}$ \\
Embu (SP) & 9.66 & $\mathrm{HH}$ \\
AMC7097 004 (PA) & 8.73 & $\mathrm{HH}$ \\
AMC7097 054 (SP) & 8.57 & $\mathrm{HH}$ \\
Ribeirão das Neves (MG) & 7.90 & $\mathrm{HH}$ \\
Francisco Morato (SP) & 7.79 & $\mathrm{HH}$ \\
Várzea Paulista (SP) & 7.58 & $\mathrm{HH}$ \\
Jandira (SP) & 7.36 & $\mathrm{HH}$ \\
Campo Limpo Paulista (SP) & 7.34 & $\mathrm{HH}$ \\
\hline
\end{tabular}

Fonte: IPEDATA e cálculos do autor 


\section{Metodologia}

\subsection{Modelo Empírico}

Neste capítulo é apresentada uma equação estimável que capta os efeitos de aglomeração sobre o processo de desenvolvimento econômico. O ponto de partida é função de crescimento proposta Glaeser et. al. (1992). Inicialmente, suponha que a função produção agregada de cada município é dada por $A_{t} f\left(l_{t}\right)$, em que $A_{t}$ e $l_{t}$ representam respectivamente o nível geral de tecnologia e a quantidade de trabalho no instante de tempo t.

Glaeser et. al. (1992) utiliza essa função de produção acima para tornar o desenvolvimento tecnológico como uma função de externalidades dinâmicas e de condições iniciais. Especificamente, os autores testam as três possíveis formas de difusão de conhecimento dentro de uma cidade descritas na seção 2. Nesta dissertação, entretanto, utilizamos essa função como forma de fazer do desenvolvimento tecnológico uma função da aglomeração e das condições iniciais, sem procurar especificar de modo preciso a forma de atuação das forças de aglomeração e dispersão.

Evidentemente, a ausência de capital pode parecer um tanto quanto restritiva, porém três razões nos levam a utilizar esse modelo. Primeira, existe escassez de dados de capital para a unidade geográfica estudada ${ }^{16}$. Segunda, seguindo os passos de autores que fizeram uso desse modelo, Glaeser et. al. (1992), Henderson et al. (1995) e Usai e Paci (2003), estamos supondo que a ausência de capital não irá alterar os resultados de modo significativo. Por fim, como as externalidades tecnológicas são geradas por seres humanos que transmitem conhecimento entre si, o capital não é o elemento crucial da hipótese que buscamos testar. Essa justificativa pode ser tomada com base no modelo de Spillovers Locais, se interpretarmos o capital fixo utilizado na manufatura como capital humano incorporado nas pessoas.

Definindo $f(l)=l^{\alpha}, 0<\alpha<1$ e assumindo que cada firma/cidade toma a tecnologia, o preço do produto e os salários, $s_{t}$, como dados, o problema enfrentado pelas empresas torna-se:

\footnotetext{
${ }^{16}$ Apenas uma série de capital residencial, baseada em valor de aluguel obtido através de uma equação hedônica de preços, esta disponível para a AMCs 70-00, dentro o período de analise.
} 


$$
\operatorname{Max} A_{t} l^{\alpha}-s_{t} l_{t}
$$

A condição de maximização de lucro implica que o produto marginal do trabalho deve ser igual ao salário, logo:

$$
l_{t}=\left(\frac{s_{t}}{\alpha A_{t}}\right)^{1 /(\alpha-1)}
$$

Substituindo a quantidade de trabalho na função de produção, temos:

$$
Y_{t}=A_{t}\left(\frac{S_{t}}{\alpha A_{t}}\right)^{\alpha /(\alpha-1)}
$$

Reescrevendo (3) na forma de taxa de crescimento,

$$
\ln \left(Y_{t+1} / Y_{t}\right)=\ln \left(A_{t+1} / A_{t}\right)-\frac{\alpha}{\alpha-1} \ln \left(\frac{s_{t}}{s_{t+1}} \frac{A_{t+1}}{A_{t}}\right)
$$

Simplificando.

$$
\ln \left(Y_{t+1} / Y_{t}\right)=\gamma \ln \left(A_{t+1} / A_{t}\right)+\varphi \ln \left(\frac{s_{t+1}}{s_{t}}\right)
$$

Para tornar o modelo estimável a partir dos dados disponíveis são necessárias duas hipóteses adicionais. Primeira, a taxa de crescimento dos salários é uma constante entre as cidades. Segunda, o nível de tecnologia disponível em uma dada cidade é formado por dois componentes, um local e outro nacional (Glaeser et. al. (1992)).

$$
A=A_{\text {local }} A_{\text {nacional }}
$$


A taxa de crescimento da tecnologia passa então a ser determinada pela soma da taxa de crescimento do componente tecnológico local e da taxa de crescimento da taxa de crescimento nacional.

$$
\ln \left(A_{t+1} / A_{t}\right)=\ln \left(A_{\text {local }, t+1} / A_{\text {local }, t}\right)+\ln \left(A_{\text {nacionalt }+1} / A_{\text {nacionalt }}\right)
$$

Admitindo-se por hipótese que a taxa de crescimento tecnológico nacional também é uma constante entre as firmas, e que a taxa de crescimento local é fruto das condições iniciais, da aglomeração e de um fator aleatório, temos:

$$
\ln \left(A_{\text {local },+1} / A_{\text {local }, t}\right)=g(\text { condições iniciais, aglomeração })+u_{t}
$$

Sendo $g(\bullet)$ uma função linear.

A medida de aglomeração utilizada nesse trabalho é a população residente em 1970, na forma linear e quadrática, controlada pela área. Essa especificação é utilizada para captar de modo acurado os efeitos causados pela concentração das atividades econômicas: em um primeiro instante as externalidades positivas geradas pela aglomeração tem impacto positivo sobre o desenvolvimento, contudo, a partir de um determinado ponto, os custos de congestionamento devem superar os benefícios da aglomeração. Dessa forma, espera-se valor positivo e significante para o coeficiente do termo linear da população, enquanto o termo quadrático dever ter sinal negativo e significante, em outras palavras, espera-se que a relação entre a população e o crescimento econômico tenha o formato de " $U$ " invertido.

A relação não linear entre aglomeração é desenvolvimento é semelhante a utilizada por Henderson (2000) no estudo de crescimento de países. Nesse trabalho, Henderson utiliza como medida de aglomeração a primazia, proposta por Ades e Gleaser (1995) (a parcela da maior área metropolitana no total da população urbana), e a interage com termos linear e quadrático da renda.

Deve-se ressaltar ainda que a medida de aglomeração utilizada nesse trabalho consegue captar duas nuances das economias de aglomeração. Primeira, a importância do número total de 
habitantes em uma região. Quanto maior a população, tudo o mais constante, maior a probabilidade de surgimento de economia de aglomeração, por isso o logaritmo da população é utilizado diretamente no modelo. Segundo, evidentemente uma população grande, dentro de uma ampla área geográfica pode não trazer os benefícios esperados, de tal forma que tornase essencial o uso da área como controle. Outra especificação possível seria a quantidade total de trabalhadores divido pela área - utilizada, por exemplo, por Ciccone e Hall (1996), Ciccone (2002) e Bosker (2007) - que poderia dar o mesmo peso a uma cidade de população e território pequenos e uma cidade com população e territórios grandes.

Substituindo (10) em (9), e a equação resultante em (7), obtém-se a seguinte equação estimável:

$$
\operatorname{cresc}_{i, 70,00}=\alpha+b P_{i, 70}+c P_{i, 70}^{2}+d A_{i}+X_{i, 70} e+u_{i, 00}
$$

A variável $\operatorname{cresc}_{i, 70,00}$ representa o logaritmo da razão entre o PIB de 2000 e 1970 na cidade $i$. $P_{i}$ representa a população no ano de $1970, A_{i}$ a área da cidade e $X_{i 70}$ um vetor de condições iniciais. As variáveis contidas em $X$ são: a escolaridade média dos adultos (pessoas com mais de 25 anos), a porcentagem de municípios com luz elétrica, dummies de estado e o logaritmo do PIB inicial.

A educação média dos adultos, presente no vetor $X$, funciona como proxie para capital humano, considerado como um elemento importante na explicação do crescimento econômico (ver Mankiw et al. 1992 e Barro e Sala-i-Martin 1991, 1992, 1995). A porcentagem de municípios com energia elétrica tem com objetivo captar a infra-estrutura presente na cidade. Espera-se que municípios com melhor infra-estrutura, tudo o mais constante, cresçam a taxas maiores, uma vez que apresentam melhores condições para a abertura de novos negócios e atração de investimentos. Além disso, supõe-se que a variável porcentagem de municípios com energia elétrica seja correlacionada com o investimento público federal e estadual, ajudando assim a mitigar a ausência dessa variável nas estimações. O conjunto de dummies de estado capta características idiossincráticas de cada unidade da federação, como por exemplo, clima e qualidade dos governadores. Por fim, o PIB inicial controla o tamanho inicial da economia, e pode fornecer indícios da existência de convergência, em termos de PIB, entre os municípios brasileiros. 


\subsection{Econometria espacial}

Segundo Anselin (1988), os efeitos espaciais podem ser divididos em duas classes: heterogeneidade espacial e dependência espacial. A primeira delas leva em conta a localização da unidade de estudo em um determinado ponto no espaço, sem considerar possíveis interações com outras unidades, as dummies de estado utilizadas em (X) representam um exemplo desse tipo de efeito. A dependência espacial, ao contrário, está centrada na existência de vínculo, que decai com a distância, entre as diversas observações. Vale destacar que o termo "distância" não está restrito ao conceito euclidiano, ele engloba uma ampla gama de possibilidades tais como o espaço de característica de produto, custo de transporte, etc.

A heterogeneidade espacial tem um papel importante no modelo teórico utilizado neste trabalho, pois as dummies de estado captam efeitos diversos, tais como clima e representação política. Contudo, elas não são capazes de englobar todos os efeitos espaciais existentes entre as cidades. O crescimento de um município em um determinado ano, por exemplo, dificilmente será independente do crescimento dos municípios vizinhos, da mesma forma cidades próximas tendem a ter padrões semelhantes de educação e infra-estrutura. No entanto, a econometria tradicional não consegue captar esse efeito, o que nos leva a utilizar técnicas de econometria espacial com o intuito de inserir a dependência espacial na análise.

O modelo espacial geral (Anselin 1998 e 2003, LeSage 1999), em notação matricial, apresenta a seguinte forma:

$$
\begin{gathered}
\operatorname{cresc}=\rho W \operatorname{cres} c+Z_{t 1} \beta+u \\
u=\lambda W u+e \\
e \sim N\left(0, \sigma^{2} I_{n}\right)
\end{gathered}
$$

Sendo que $Z_{t l}$ reúne todas as variáveis explicativas presentes em (11), $\rho$ é um escalar e W é uma matriz de pesos n por n. Seguindo a notação de LeSage (1999), denominaremos esse modelo de SAC. 
Seguindo a quase totalidade dos trabalhos empíricos, essa dissertação considera dois casos particulares do modelo geral. $O$ primeiro deles considera $\lambda=0$, e é conhecido como modelo de defasagem espacial. Seguindo a notação de LeSage (1999), passaremos a chamar esse modelo de SAR. O segundo modelo considera $\rho=0$, e é conhecido por modelo de erro espacial, ou SEM de acordo com a notação de LeSage (1999).

O modelo SAR pode ser interpretado da seguinte forma: no estudo de crescimento conduzido neste trabalho, o parâmetro $\rho$ representa a influência da média do crescimento da vizinhança sobre o crescimento de um determinado município. Essa característica, no entanto, faz com que o modelo não possa ser estimado de forma consistente pelos estimadores de MQO. Tal fato pode ser facilmente verificado seguindo o exemplo de Anselin (1988), através do uso de um modelo mais simples, sem o vetor de variáveis explicativas $\mathrm{Z}$ :

$$
y=\rho W y+e
$$

O estimador de MQO do parâmetro $\rho$ por é dado por:

$$
r=\left(y_{L}^{\prime} y_{L}\right)^{-1} y_{L}^{\prime} y
$$

Com $y_{L}^{\prime}=W y$. Substituindo (13) em (14) temos:

$$
r=\rho+\left(y_{L}^{\prime} y_{L}\right)^{-1} y_{L}^{\prime} e
$$

A esperança do segundo termo não igual é zero, pois não se pode supor que é $W y$ fixado em amostragem repetida.

A consistência do estimador de MQO depende de duas condições:

$\operatorname{plim} N^{-1}\left(y_{L}^{\prime} y_{L}\right)=Q$

$\operatorname{plim} N^{-1}\left(y_{L}{ }^{\prime} e\right)=0$ 
A primeira condição pode ser satisfeita com base em algumas restrições, contudo, a segunda não será satisfeita no caso de dependência espacial, pois:

$$
\operatorname{plim} N^{-1}\left(y_{L}{ }^{\prime} e\right)=p l i m N^{-1} e^{\prime} W(I-\rho W) e
$$

A presença da matriz de pesos espaciais na expressão acima resulta em uma forma quadrática no erro, que só será igual a zero no caso trivial $\rho=0$ (Anselin 1988).

O Modelo SEM, por outro lado, possui uma interpretação econômica mais sutil. Conforme destacado por Fingleton (2003), esse tipo de especificação procura representar a os efeitos de variáveis omitidas que se manifestam através da autocorrelação dos resíduos. Dessa forma, o modelo SEM pode servir para controlar os efeitos e espaciais e, simultaneamente, mitigar os danos causados por omissão de variáveis.

Ao contrário do que ocorre modelo de defasagem espacial, os estimadores de MQO produzem estimações consistentes do SEM. Porém, tais estimadores apresentam duas deficiências graves: são ineficientes e não estimam $\lambda$ de forma consistente.

Em virtude dos problemas existente no método de MQO, duas técnicas alternativas são propostas para a estimação dos modelos espaciais. A primeira é estimação por Máxima Verossimilhança (MV), que exige normalidade dos resíduos e produz estimações eficientes. $\mathrm{Na}$ verdade, sob condições de regularidade gerais (ver Anselin 1988 para uma derivação completa dos estimadores), os estimadores de MV são consistentes e apresentam a menor variância assintótica entre todos os estimadores existentes, ou seja, atingem o limite inferior de Cramér-Rao (Greene (2000) apresenta uma excelente explicação das propriedades dos estimadores de MV). A segunda alternativa é a estimação pelo Método Generalizado dos Momentos espacial (GMM espacial) proposto por Kelejian e Prucha (1998 e 1999), que não necessita de nenhuma distribuição especifica dos resíduos e produz estimadores consistentes e computacionalmente mais simples.

\subsubsection{A matriz W}

A apresentação do modelo acima torna clara a importância da matriz de pesos W para a analise econométrica, conforme destacado por Abreu et. al. (2004) ela permite sumarizar 
todas as relações de dependência espacial. A estrutura geral da matriz W apresenta a seguinte forma: zeros em sua diagonal principal e os elementos de fora da diagonal principal contêm valores que refletem a proximidade espacial de cada par de áreas. Como a proximidade pode ser medida de vários modos, a matriz W contém uma série de possíveis especificações. Devese destacar ainda que os pesos utilizados na matriz W devem ser exógenos, caso contrário, não existiram graus de liberdade suficiente para a estimação do modelo.

Outro ponto importante na matriz $\mathrm{W}$ diz respeito a disposição dos pesos espaciais. A matriz de pesos é construída de tal forma que vizinhos mais próximos tenham mais peso. Essa disposição de pesos é condizente com a chamada "Lei Geográfica" de Tobler: "Todas as coisas são relacionadas entre si, mas as coisas mais próximas são mais relacionadas" ${ }^{17}$ (Tobler, 1970, p.236).

A matriz de peso mais comum, e também mais simples, é a binária, com valores 1 ou 0 indicando se as áreas são vizinhas ou não. Exemplos de uso desse tipo de matriz são os trabalhos de Lall e Yilmas (2001), que estimaram um modelo de convergência com spillovers de capital humano usando dados americanos e Ávila e Monastério (2004), que analisam o crescimento de 58 áreas estatisticamente comparáveis gaúchas entre 1939 e 2001.

Embora muito utilizada, a matriz binária possui uma séria limitação, conforme destacado por Fingleton et. al.(2005) esse tipo de matriz supõe que a interação espacial é restrita a vizinhança imediata, suposição pouco realista em muitos casos. Para a análise do processo de aglomeração de atividades de alta tecnologia na Inglaterra, estes autores utilizaram uma matriz de peso que levam em consideração o fato de que a influência espacial decai de modo não linear com a distância.

Como forma de testar robustez dos resultados frente as diferentes especificações da matriz W, duas matrizes alternativas foram utilizadas na elaboração desta dissertação. São elas:

\footnotetext{
17 "Everything is related to everything else but nearby things are more related than distant things"
} 


$$
\begin{gathered}
W 1=\left\{\begin{array}{lll}
w_{i j}^{*}=0 & \text { se } & i=j \\
w_{i j}^{*}=1 / d_{i j} & \text { se } & w_{i j}=w_{i j}^{*} / \sum_{j} w_{i j}^{*}
\end{array}\right. \\
W 2=\left\{\begin{array}{lll}
w_{i j}^{*}=0 & \text { se } & i=j \\
w_{i j}^{*}=1 / d_{i j}^{2} & \text { se } & w_{i j}=w_{i j}^{*} / \sum_{j} w_{i j}^{*}
\end{array}\right.
\end{gathered}
$$

Onde $\mathrm{d}_{\mathrm{ij}}$ é distância euclidiana entre os centróides das regiões i e j, obtida através das medidas de latitude e longitude fornecidas pelo Ibge. Em ambas as matrizes considera-se que a influência da vizinhança é decrescente com a distância, sendo que na segunda matriz a queda é mais acentuada.

A normalização feita para que a soma dos elementos de cada linha tenha valor igual a 1 é uma recurso muito útil, conhecido na literatura como padronização, e permite uma interpretação econômica interessante da variável defasada: o valor para a região j de uma variável espacialmente defasada, definida como a j-ésima entrada do vetor WX, é média ponderada dos valores $\mathrm{X}$ da vizinhança de $\mathrm{j}$.

\subsubsection{Testes de Autocorrelação Espacial}

Como dito anteriormente, a presença de autocorrelação espacial - no erro, na variável explicativa ou em ambos - fará com que o modelo (11) seja mal especificado. No entanto, o uso de modelos espaciais na ausência de autocorrelação espacial resulta em perda de eficiência nas estimações. Como forma de obter uma decisão mais precisa acerca da existência ou não de autocorrelação espacial, diversos testes foram desenvolvidos com o intuito de facilitar a tomada de decisão quanto ao modelo mais adequado.

Um teste de dependência espacial amplamente utilizado é a estatística I de Moran, modificada em relação à apresentada na seção 2 para trabalhar com resíduos da regressão por MQO. Formalmente, a estatística apresenta a seguinte forma: 


$$
I=\frac{N}{S}\left\{\frac{e^{\prime} W e}{e^{\prime} e}\right\}
$$

Sendo $e$ o vetor de resíduos da regressão por MQO, $N$ o número total de observações e $S$ um fator de normalização igual a soma de todos os elementos da Matriz $W$. Devido ao padronização mostrada (17) e (18), podemos reescrever o teste como.

$$
I=\left\{\frac{e^{\prime} W e}{e^{\prime} e}\right\}
$$

A inferência do teste é feita com base nos resultados obtidos por Cliff e Ord (1972, 1973 e 1981), que provam que a estatística de Moran segue uma distribuição normal com as seguintes média e variância:

$$
\begin{gathered}
E[I]=\operatorname{tra}(M W) / N-K \\
V[I]=\left\{\operatorname{tra}\left(M W M W^{\prime}\right)+\operatorname{tra}(M W)^{2}+[\operatorname{tra}(M W)]^{2}\right\} /(N-K)(N-K+2)
\end{gathered}
$$

Sendo $M$ uma matriz de projeção, $M=I-X(X X)^{-1} X^{\prime}$, e $K$ o número de parâmetros em uma regressão por OLS.

O teste I de moran é robusto a todas as especificações de autocorrelação espacial (SAR, SAC ou SEM), porém, não fornece indicações de qual modelo se ajusta melhor aos dados. O teste de multiplicadores de lagrange é mais adequado para escolha de modelos alternativos.

O teste de multiplicadores de lagrange consiste na verdade em uma ampla família de testes, sendo freqüentemente em trabalhos empíricos nas mais diferentes áreas. No caso específico da econometria espacial, duas hipóteses são usualmente adotadas para o teste de existência de autocorrelação espacial. A primeira delas testa a hipótese nula de $\lambda=0$ (não existência de erro auto-regressivo espacial) contra o modelo SEM. A segunda, testa a não existência de defasagem espacial $(\rho=0)$ contra o modelo SAR. Na literatura tais testes são conhecidos como LM-erro e LM-lag respectivamente. As estatísticas de teste são dadas por: 


$$
\begin{gathered}
\text { LM-erro }=(1 / T)\left[e^{* * W e} / \sigma^{2}\right]^{2} \sim \chi^{2}(1) \\
\text { LM-lag }=R^{2}[D+T]^{-1} \sim \chi^{2}(1)
\end{gathered}
$$

Sendo: $\mathrm{T}=\operatorname{tra}\left(\left(\mathrm{W}^{\prime}+\mathrm{W}\right) . \mathrm{W}\right), \mathrm{R}=\mathrm{e}^{\prime} \mathrm{Wy} / \sigma^{2}, \mathrm{D}=\sigma^{-2}(\mathrm{WX} \beta)^{\prime} \mathrm{M}(\mathrm{WX} \beta), \sigma=$ desvio padrão da regressão por MQO e $\beta$ o vetor de parâmetros estimados por MQ.

Florax et al. (2003) sugere que se ambos os teste de LM forem significativos, deve ser usado o modelo com maior valor do teste LM (menor $\mathrm{p}$ valor).

\subsubsection{Abordagem Alternativa da Autocorrelação Espacial}

Uma abordagem alternativa à modelagem econometria espacial tradicional apresentada acima é proposta por Conley (1999), que sugere um método não paramétrico para a estimação da matriz de variância em estimações por MQO e por método generalizado dos momentos (GMM). Basicamente, o método parte de uma condição de momento que permite a estimação consistente dos parâmetros de interesse:

$$
E[Z(Y-X \beta)]=0
$$

Sendo $\mathrm{Z}$ um vetor $n \mathrm{X} v$ de instrumentos; $\mathrm{X}$ o vetor das variáveis explicativas $n \mathrm{X} k$; Y o vetor $n \times 1$ da variável dependente e $\beta$ um vetor de parâmetros $k X 1$. Assume-se que $v \geq k$ para que o sistema (25) seja identificável.

O estimador de GMM do vetor de parâmetros $\beta$, b, é aquele que resolve o problema abaixo:

$$
\operatorname{Min}_{b}\left[Z^{\prime}(Y-X b)\right]^{\wedge} \Phi\left[Z^{\prime}(Y-X b)\right]
$$

Sendo $\Phi$ uma matriz de ponderação positivamente definida.

Em princípio, qualquer matriz positiva definida produz estimadores consistentes dos parâmetros $\beta$. No entanto, sendo $C$ a variância de $Z(Y-X \beta)$, se escolhermos $\Phi$ igual ao seu 
inverso, teremos um estimador de GMM eficiente ${ }^{18}$. Evidentemente, o verdadeiro C não é observável, o que implica no uso de um estimador Ĉ. A contribuição de Conley (1999) é um método de estimação da matriz $\mathrm{C}$ em situações em que a autocorrelação espacial é presente. De modo mais especifico ${ }^{19}$ :

$$
\hat{C}=\frac{1}{N} \sum_{i=1}^{N} \sum_{j=1}^{N} k(i, j)\left[\left(y_{i}-x_{i}^{\prime} b\right) z_{i}\right]\left[\left(y_{i}-x_{i}^{\prime} b^{*}\right) z_{i}\right]^{\prime}
$$

Sendo $k(i, j)$ um fator de peso entre as regiões $\mathrm{i}$ e j, e $\mathrm{b}^{*}$ um estimativa dos parâmetros $\beta$ realizada com uma matriz semi-positiva definida qualquer.

Baseado em Newey e West (1987), Conley (1999) propõe o seguinte sistema de peso espacial $^{20}$ :

$k(i, j)=\left(\begin{array}{lrl}\left(1-D_{H}(i, j) / L_{H}\right)\left(1-D_{V}(i, j) / L_{V}\right) & \text { para } \quad D_{H}(i, j)<L_{H} \quad \text { e } \quad D_{H}(i, j)<L_{V} \\ 0 & \text { caso contrário }\end{array}\right.$

Em que $D_{H}(i, j)$ e $D_{V}(i, j)$ correspondem, respectivamente as distâncias vertical e horizontal entre as unidade $\mathrm{i}$ e $\mathrm{j}$, e $\mathrm{L}_{\mathrm{H}}$ e $\mathrm{L}_{\mathrm{V}}$ a máxima distância horizontal e vertical, para qual as localidades i e j apresentam algum tipo de correlação espacial. Dessa forma, a correlação espacial decai linearmente com a distância e torna-se nula a partir de parâmetros de corte (cutoff) escolhido pelo pesquisador.

O modelo proposto por Conley apresenta três vantagens em relação a modelagem tradicional. Em primeiro lugar, não é necessário a formulação de hipóteses sobre a estrutura de dependência espacial entre os agentes. Outra vantagem é a robustez dos resultados frente a erros de media da distância econômica. Experimentos de Monte Carlo conduzidos por

\footnotetext{
${ }^{18}$ Para maiores detalhes a respeito do estimador de GMM ver Wooldrige (2002).

${ }^{19}$ Como forma de tornar a exposição mais clara, seguimos a simplificação do modelo realizada por Carvalho et al. (2005). O leitor interessado poderá encontrar um tratamento mais formal do modelo em Conley (1999).

${ }^{20}$ De fato, esse não é o único sistema possível de pesos no estimador de Conley. Qualquer estimador que obedeça as condições apresentadas em Conley (1999) também produz estimações consistentes da matriz C. Tais condições são omitidas nesta dissertação por necessitarem de conhecimento prévio em processos estocásticos, de tal forma que sua inclusão tornaria o trabalho acessível a poucos, além de demasiado extenso.
} 
Molinari e Conley (2007) sugerem que o estimador não paramétrico é mais robusto a erros de medida da distância/posição que os estimadores paramétricos tradicionais de MV ou GMM espacial. Adicionalmente, este estimador é computacionalmente mais simples que as demais modelos de econometria espacial.

Porém, o estimador de GMM proposto por Conley apresenta algumas limitações. Em primeiro lugar, o processo gerador de dados deve ser estacionário, caso contrário a consistência dos estimadores não é garantida. No entanto, deve-se destacar que em experimentos de Monte Carlo realizados por Carvalho et al.(2005), os estimadores de Conley permaneceram robustos mesmo sob uma estrutura heterogênea dos resíduos. Um segundo problema é a inexistência de um guia para a escolha dos cutoffs ótimos, o que torna a escolha dos parâmetros de corte arbitrária.

Por fim, deve-se notar que quantos as variáveis explicativas de uma determinada regressão são exógenas, o método de GMM reduz-se ao estimador de MQO. Isso implica que em regressões em que a endogeneidade não seja um problema, o estimador de Conley irá alterar apenas a inferência, não influenciando a estimação dos parâmetros de interesse $\beta$.

Com base na discussão acima, pode-se dizer que a estratégia empírica utilizada neste trabalho consiste em estimar o modelo básico por OLS, testar a autocorrelação espacial dos resíduos, e se necessário utilizar os métodos paramétrico (SAR e SEM) e não paramétricos para correção do problema. 


\section{$5 \quad$ Resultados}

Frente às diversas abordagens econometricas empregues nesse trabalho, optou-se por dividir essa seção em quatro partes, de forma a expor os resultados com maior clareza. A primeira parte esta concentrada nas estimações por OLS, MV e GMM, tendo a matriz W1 como a representação das relações espaciais presentes na amostra. Na parte seguinte, replicamos essas estimações com outra matriz de pesos - W2. A terceira seção aborda a correção não paramétrica da autocorrelação espacial proposta por Conley (1999). Por fim, enceramos a seção refazendo a análise anterior com a amostra restrita às regiões Sul, Sudeste e Nordeste.

\subsection{Matriz W1}

A tabela 6.1 mostra o resultado da estimação de cinco diferentes modelos. O primeiro é o modelo (11), estimado por MQO. O segundo modelo é uma expansão do primeiro através da inclusão de duas variáveis explicativas: "escolaridade da vizinhança" (escvzi) e "população da vizinhança" (popviz), que consistem da defasagem espacial da escolaridade e do logaritmo da população. A estimação desse modelo também é feita por MQO, uma vez que as defasagens espaciais não alteram as propriedades ótimas desse estimador. Em seguida, temos os modelos SEM e SAR, ambos estimados por MV, que contém todas as variáveis explicativas do modelo anterior. Por fim, apresentamos os modelos SEM e SAR estimados por GMM.

A inclusão de variáveis espacialmente defasadas produz modelos econométricos conhecidos na literatura como modelos de regressão cruzada (cross regressive model). Abreu et. al. (2004) destaca que esse tipo de modelo tem a vantagem de confinar a dependência espacial à vizinhança de cada observação e de manter uma forte ligação com a teoria. Além disso, esse tipo de variável pode fornecer indícios a respeito da existência de spillovers (Ansellin(2003), Florax e Folmer (1992)). De modo mais especifico, a inclusão da escolaridade e da população espacialmente defasadas permite testar dois aspectos levantados pela economia regional. Primeiro, a escolaridade defasada pode indicar se a educação atravessa as fronteiras municipais e causa algum tipo de impacto na vizinhança. Segundo, pode-se argumentar que a proximidade em relação a um município de população grande pode ser benéfica para o desenvolvimento de uma dada cidade, devido a facilidade de acesso a um grande mercado ou 
a presença de externalidades. A especificação contendo a variável população da vizinhança defasada pode fornecer evidência da existência ou não desse fenômeno.

Os resultados da estimação do primeiro modelo mostram um valor negativo e significante para o coeficiente do logaritmo do PIB inicial, o que indica que municípios com maior PIB nos anos 70, tudo o mais constantes, apresentaram menor taxa de crescimento, sugerindo a existência convergência entre as economias. A educação apresentou o resultado esperado, coeficiente positivo e significante. Do mesmo modo, o resultado positivo e significante captado pela energia elétrica também se mostrou condizente a teoria: uma melhor infraestrutura implica em maior taxa de crescimento. Os valores estimados do coeficiente do logaritmo da população e do quadrado de logaritmo da população tiveram os sinais esperados, o termo linear apresenta sinal positivo, indicando a existência de efeitos benéficos da aglomeração e o termo quadrático apresentou sinal negativo, o que capta os custos de congestionamento. Porém, apenas a parte linear da aglomeração é significante, o que pode indicar que as externaliades negativas causadas pela aglomeração foram irrelevantes para o crescimento dos municípios brasileiros entre 1970 e 2000. Mas, ainda assim, os coeficientes indicam a existência de uma curva em forma de "U" invertido em relação ao crescimento do pib e a população, quando controlado pela área.

Os resultados dos testes I de Moran, LM-erro e LM-lag do primeiro modelo, contudo, mostram-se altamente significativos, indicando a presença de autocorrelação espacial nos resíduos. Com base nesse resultado, pode-se argumentar que os modelos 1 apresentam erros de especificação.

Os resultados da segunda regressão são muito próximos, em termos de magnitude e significância dos parâmetros, aos obtidos no primeiro modelo. Evidentemente, as variáveis defasadas, ausentes na primeira regressão, constituem-se exceções. Ambas mostraram-se positivas e significantes, indicando a existência de spillovers entre as regiões. Além da significância, merece destaque a magnitude dos coeficientes, a educação da vizinhança apresenta um valor mais de dez vezes superior ao da escolaridade do próprio município. A população da vizinhança também segue essa linha, embora de forma bem menos expressiva, com um coeficiente cerca de duas vezes maior que o coeficiente da população. Deve-se ressaltar, contudo, que a inclusão de variáveis explicativas espacialmente defasadas não 
resolveu o problema de autocorrelação nos resíduos, conforme pode ser visto nos teste I de moran, LM-erro e LM-lag.

A terceira e quarta coluna da tabela 6.1 mostram o resultado das regressões por MV dos modelos SEM e SAR respectivamente. Os resultados das variáveis explicativas são semelhantes aos obtidos na regressão anterior, o que indica robustez dos resultados. Porém, esses modelo apresentam novos parâmetros associados a modelagem do fenômeno espacial, que não aparecem nos modelos obtidos por OLS. O primeiro deles é o $\lambda$, cujo resultado positivo e significante sugere que um choque positivo em um município tem um efeito também positivo sobre a vizinhança devido à ação de variáveis não observadas. O segundo deles, o $\rho$, tem uma interpretação mais intuitiva. Seu valor positivo mostra que a média do crescimento dos municípios vizinhos a uma determinada cidade tem efeito positivo sobre o seu crescimento. O valor desses parâmetros, entretanto, merece atenção, pois ambos estão próximos a 1, valor que indicaria a existência de raiz unitária espacial, um evento extremante raro em aplicações práticas.

A sugestão de Florax et al. (2003) nos levaria a adotar o modelo SEM, pois o valor da estatística do teste LM-erro das regressões por MQO é maior que o valor da estatística LMlag. Porém, os resultados dos testes Jarque-Bera nos quatro primeiros modelos mostram que a hipótese de normalidade dos resíduos não é plausível para essas regressões. O que torna as estimações por MV inválidas.

As duas últimas entradas da tabela 6.1 são reservadas as estimações dos modelos SEM e SAR pelo método de GMM proposto por Kelejian e Prucha (1998 e 1999). Os resultados relacionados ao SEM mostram pouca alteração nas variáveis explicativas em relação a estimação por MV, porém o valor do parâmetro espacial sofre uma grande mudança. O valor do $\lambda$ pula para 2,6, sendo dessa forma incompatível com os resultados normalmente encontrados na literatura (teórica e empírica), além de difícil explicação em termos econômicos. Da mesma forma, o modelo SAR estimado por GMM espacial também sofre pouca alteração em relação ao seu par estimado por MV, com exceção do parâmetro $\rho$, que sofre uma forte redução, ficando próximo de zero $(0,001)$ em termos numéricos, embora seja estatisticamente significante. 
Tabela 5.1 - Crescimento do PIB Municipal Total - W1

\begin{tabular}{|c|c|c|c|c|c|c|}
\hline & \multicolumn{6}{|c|}{ Ln(PIB em 2000/PIB em 1970) } \\
\hline & OLS 1 & OLS 2 & Sem1 (pop) & Sar1 (pop) & Sem GMM & Sar GMM \\
\hline Constante & $\begin{array}{l}0.8158 \\
(0.17)\end{array}$ & $\begin{array}{c}12.8695 \\
(0,00)\end{array}$ & $\begin{array}{c}-11.7099 \\
(0,00)\end{array}$ & $\begin{array}{c}-12.9846 \\
(0,00)\end{array}$ & $\begin{array}{c}-6.7903 \\
(0,00)\end{array}$ & $\begin{array}{c}-12.8696 \\
(0,00)\end{array}$ \\
\hline $\operatorname{Ln}($ pib70) & $\begin{array}{c}-0.6572 \\
(0,00)\end{array}$ & $\begin{array}{c}-0.7088 \\
(0,00)\end{array}$ & $\begin{array}{c}-0.7194 \\
(0,00)\end{array}$ & $\begin{array}{c}-0.6985 \\
(0,00)\end{array}$ & $\begin{array}{c}-0.7226 \\
(0,00)\end{array}$ & $\begin{array}{c}-0.7088 \\
(0,00)\end{array}$ \\
\hline $\operatorname{Ln}($ pop) & $\begin{array}{c}0.6971 \\
(0,00)\end{array}$ & $\begin{array}{c}0.7485 \\
(0,00)\end{array}$ & $\begin{array}{c}0.7634 \\
(0,00)\end{array}$ & $\begin{array}{c}0.7433 \\
(0,00)\end{array}$ & $\begin{array}{c}0.7584 \\
(0,00)\end{array}$ & $\begin{array}{c}0.7484 \\
(0,00)\end{array}$ \\
\hline $\operatorname{Ln}(p o p)^{\wedge} 2$ & $\begin{array}{c}-0.0036 \\
(0.56)\end{array}$ & $\begin{array}{c}-0.0029 \\
(0.64)\end{array}$ & $\begin{array}{c}-0.0032 \\
(0.58)\end{array}$ & $\begin{array}{c}-0.0033 \\
(0.58)\end{array}$ & $\begin{array}{c}-0.0030 \\
(0.59)\end{array}$ & $\begin{array}{c}-0.0029 \\
(0.63)\end{array}$ \\
\hline Esc & $\begin{array}{c}0.2258 \\
(0,00)\end{array}$ & $\begin{array}{c}0.1260 \\
(0,00)\end{array}$ & $\begin{array}{c}0.1156 \\
(0,00)\end{array}$ & $\begin{array}{c}0.1164 \\
(0,00)\end{array}$ & $\begin{array}{c}0.0931 \\
(0,00)\end{array}$ & $\begin{array}{c}0.1260 \\
(0,00)\end{array}$ \\
\hline Area & $\begin{array}{c}8.0 \mathrm{E}-06 \\
(0,00)\end{array}$ & $\begin{array}{c}\text { 8.0E-06 } \\
(0,00)\end{array}$ & $\begin{array}{c}8.0 \mathrm{E}-06 \\
(0,00)\end{array}$ & $\begin{array}{c}8.0 \mathrm{E}-06 \\
(0,00)\end{array}$ & $\begin{array}{c}8.0 \mathrm{E}-06 \\
(0,00)\end{array}$ & $\begin{array}{c}8.0 \mathrm{E}-06 \\
(0,00)\end{array}$ \\
\hline Eletricidade & $\begin{array}{c}0.9836 \\
(0,00)\end{array}$ & $\begin{array}{c}1.0226 \\
(0,00)\end{array}$ & $\begin{array}{c}1.0834 \\
(0,00)\end{array}$ & $\begin{array}{l}1.0453 \\
(0,00)\end{array}$ & $\begin{array}{l}1.1861 \\
(0,00)\end{array}$ & $\begin{array}{l}1.0227 \\
(0,00)\end{array}$ \\
\hline dumies de estado & SIM & SIM & SIM & SIM & SIM & SIM \\
\hline Escviz & - & $\begin{array}{c}1.4078 \\
(0,00)\end{array}$ & $\begin{array}{l}1.4615 \\
(0,00)\end{array}$ & $\begin{array}{c}1.2148 \\
(0,00)\end{array}$ & $\begin{array}{c}1.1518 \\
(0,00)\end{array}$ & $\begin{array}{l}1.4076 \\
(0,00)\end{array}$ \\
\hline Popviz & - & $\begin{array}{c}1.2719 \\
(0,00)\end{array}$ & $\begin{array}{l}1.2248 \\
(0,00)\end{array}$ & $\begin{array}{l}1.1544 \\
(0,00)\end{array}$ & $\begin{array}{c}0.6346 \\
(0,00)\end{array}$ & $\begin{array}{c}1.2718 \\
(0,00)\end{array}$ \\
\hline$P$ & - & - & . & $\begin{array}{c}0.9990 \\
(0,00)\end{array}$ & - & $\begin{array}{c}0.0010 \\
(0,00)\end{array}$ \\
\hline$\Lambda$ & - & - & $\begin{array}{c}0.9899 \\
(0,00)\end{array}$ & - & $\begin{array}{c}3.0559 \\
(0,00)\end{array}$ & - \\
\hline $\mathrm{R}^{2}$ & 0.2716 & 0.3089 & 0.3500 & -55.6326 & 0.4000 & 0.3024 \\
\hline Moran & $\begin{array}{c}0.0380 \\
(0,00)\end{array}$ & $\begin{array}{c}0.0313 \\
(0,00)\end{array}$ & - & - & - & - \\
\hline LM-erro & $\begin{array}{c}1345.54 \\
(0,00)\end{array}$ & $\begin{array}{l}911.90 \\
(0,00)\end{array}$ & - & - & - & - \\
\hline LM-lag & $\begin{array}{c}673.84 \\
(0,00)\end{array}$ & $\begin{array}{c}352.47 \\
(0,00)\end{array}$ & - & - & - & - \\
\hline Jarque-Bera & $\begin{array}{c}3781.50 \\
(0,00)\end{array}$ & $\begin{array}{c}3779.20 \\
(0,00)\end{array}$ & $\begin{array}{c}3508.80 \\
(0,00)\end{array}$ & $\begin{array}{c}25852.00 \\
(0,00)\end{array}$ & - & - \\
\hline $\mathrm{N}$ & 3654 & 3654 & 3654 & 3654 & 3654 & 3654 \\
\hline
\end{tabular}

Nota:Valor $p$ entre parênteses

\subsection{Matriz W2}

A tabela 6.2 apresenta estrutura similar a da tabela 6.1, diferenciando-se apenas pelo emprego da matriz W2 para a realização dos testes de autocorrelação espacial e estimação dos modelos espaciais.

A semelhança entre as tabelas não está restrita apenas a estrutura, os resultados obtidos também são próximos. Assim como na subseção anterior, os testes de autocorrelação sobre os 
resíduos das regressões por MQO acusaram forte presença de dependência espacial - testes I de Moran, LM-erro e LM-lag altamente significativos. Além disso, os coeficientes das variáveis explicativas nas regressões dos modelos SEM e SAR estimados como uso da matriz W2 são parecidos aos obtidos anteriormente - com exceção das variáveis defasadas que diminuíram de modo considerável a sua magnitude. Outra semelhança é a ausência de normalidade nos resíduos das regressões por MQO e por MV.

Porém, duas modificações decorrentes do uso de outra matriz de pesos merecem destaque. Primeiro, embora o valor do coeficiente do quadrado do logaritmo da população tenha sofrida pouca alteração, a significância desse parâmetro sofreu forte mudança. O termo quadrático da população, antes insignificante em todos os modelos, agora aparece como significante nas estimações por MV. Segundo, os valore dos parâmetros $\lambda$ e $\rho$ são condizentes com o esperado tanto do ponto vista teórico quanto empírico - valores positivos e menores que 1. A única exceção ocorre o $\rho$ obtido por GMM espacial, que embora seja positivo, apresenta um valor superior a 1 . 
Tabela 5.2 - Crescimento do PIB Municipal Total - W2

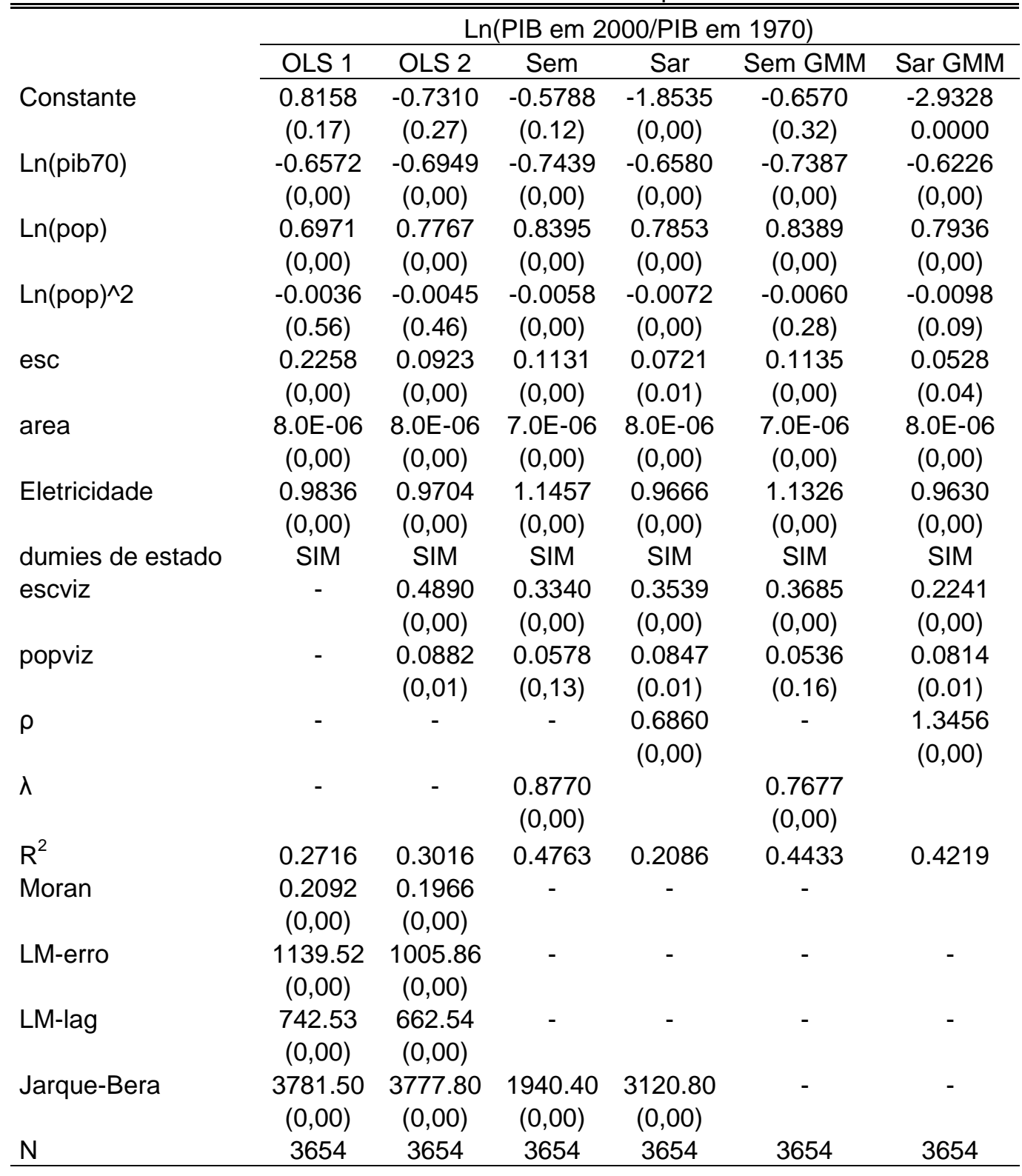

Nota:Valor $p$ entre parênteses

\subsection{Correção não Paramétrica da Variância}

Três especificações usadas anteriormente são novamente testadas nessa subseção. A primeira corresponde ao modelo (11) - primeira entrada das tabelas 6.1 e 6.2. A segunda acrescenta as variáveis escolaridade e população defasadas espacialmente através do uso da matriz W1 (segunda entrada da tabela 6.2). A terceira especificação possui as mesmas variáveis explicativas que a especificação anterior, porém utiliza a matriz W2 para realização das defasagens espaciais (segunda entrada da tabela 6.3). 
Para testar a robustez dos resultados, utilizamos seis valores para os cortes: $0,0.3,1,2,3$ e 5 - o zero corresponde a situação em que não há autocorrelação no espaço. Tais valores representam a distância, ao Norte e ao Sul do centróide de cada município, a partir da qual o espaço não exerce mais influência ${ }^{21}$. Estes valores de cutoff coincidem com os usados por Carvalho et al. (2005) em simulações de Monte Carlo - tendo como base os municípios brasileiros - com o intuito de verificar as propriedades assintóticas do estimador de Conley.

Os resultados das estimações podem ser vistos nas tabelas 6.3, 6.4 e 6.5, que apresentam novamente as estimações dos parâmetros $\beta$, além dos desvios padrões corrigidos pela dependência espacial de acordo com cada valor de corte. Uma vez que a metodologia de Conley (1999) não interfere nas estimações dos parâmetros por OLS, as únicas alterações ocorrem na significância dos parâmetros, em virtude da correção efetuada nos erros padrão. Nota-se que os desvios padrão, com poucas exceções, aumentam conforme o parâmetro de corte aumenta. Isso implica que quanto maior o nível de dependência espacial escolhido, menor a significância dos parâmetros.

Mesmo com o aumento no erro padrão, as variáveis logaritmo do PIB inicial, porcentagem de residência com energia elétrica, logaritmo da população, área e logaritmo da vizinhança são significativamente diferentes de zero a $1 \%$, para todos os cortes utilizados. De modo contrário, o termo quadrático da população permanece insignificante em todas as regressões.

Quanto às demais variáveis, a significância dos parâmetros é mais sensível ao nível de dependência espacial utilizado. A escolaridade é sempre significante a $1 \%$ se considerarmos apenas o modelo 1 Contudo, no modelo com variáveis espacialmente defasadas, a escolaridade deixa de ser significante a esse nível nos cutoffs 2, 3 e 5, na regressão com variáveis defasadas com W1, e nos cortes 3 e 5 na regressão com variáveis defasadas com W2 - embora sempre ela seja significante a 5\%. A população da vizinhança é sempre significante a $1 \%$ na regressão com $\mathrm{W} 1$. Na regressão com W2, no entanto, ela só significativa a $1 \%$ quanto não se considera a dependência espacial, em todos os outros casos, ela é insignificante a $5 \%$.

\footnotetext{
${ }^{21}$ Cada grau de latitude equivale a 110 quilômetros, enquanto para a longitude isso varia de acordo com a distância em relação ao equador (cerca de 110 quilômetros próximo a linha do equador).
} 
Tabela 5.3 - Crescimento do PIB Municipal Total

\begin{tabular}{|c|c|c|c|c|c|c|c|}
\hline \multirow[b]{4}{*}{ Constante } & \multicolumn{7}{|c|}{ Ln(PIB em 2000/PIB em 1970) } \\
\hline & \multirow[b]{2}{*}{ Parâmetro } & \multicolumn{6}{|c|}{ Valor dos Erros Padrões de acordo com o Corte } \\
\hline & & 0 & 0.3 & 1 & 2 & 3 & 5 \\
\hline & 0.815794 & 6.00E-01 & 0.74061435 & 0.90956795 & 1.058657 & 1.1350338 & 1.292489 \\
\hline $\operatorname{Ln}($ pib70) & -0.65722 & $(0.0223)^{\star \star \star}$ & $(0.041)^{\star \star \star}$ & $(0.048)^{\star \star \star}$ & $(0.053)^{\star \star \star}$ & $(0.057)^{\star \star \star}$ & $(0.063)^{\star \star \star}$ \\
\hline $\operatorname{Ln}($ pop) & 0.697097 & $(0.123)^{* * *}$ & $(0.156)^{\star * \star}$ & $(0.183)^{\star * *}$ & $(0.207)^{* * *}$ & $(0.218)^{* * *}$ & $(0.240)^{\star * *}$ \\
\hline $\operatorname{Ln}(p o p)^{\wedge} 2$ & -0.003597 & $6.21 \mathrm{E}-03$ & 0.00762385 & 0.00945346 & 0.010868 & 0.01144276 & 0.012975 \\
\hline Esc & 0.225761 & $(0.026)^{\star * *}$ & $(0.032)^{* * *}$ & $(0.047)^{\star * *}$ & $(0.062)^{* * *}$ & $(0.075)^{* * *}$ & $(0.090)^{* *}$ \\
\hline Area & 8.0E-06 & $(8.5 \mathrm{E}-07)^{\star \star \star}$ & $(1.8 \mathrm{E}-06)^{\star \star *}$ & $(1.9 \mathrm{E}-06)^{\star \star *}$ & $(1.8 \mathrm{E}-06)^{\star * *}$ & $(1.8 \mathrm{E}-06)^{\star \star \star}$ & $(1.8 \mathrm{E}-06)^{\star * *}$ \\
\hline Eletricidade & 0.983589 & $(0.080)^{* * *}$ & $(0.0978)^{* * *}$ & $(0.126)^{\star * \star}$ & $(0.159)^{\star \star \star}$ & $(0.187)^{* \star *}$ & $(0.225)^{* * *}$ \\
\hline $\begin{array}{l}\text { dummies de } \\
\text { estado }\end{array}$ & SIM & - & - & - & - & - & - \\
\hline $\mathrm{R}^{2}$ & 0.2716 & - & - & - & - & - & - \\
\hline
\end{tabular}

${ }^{\star * *}$ significante a $1 \%,{ }^{* *}$ significante a $5 \%$ e *significante a $10 \%$

Tabela 5.4 - Crescimento do PIB Municipal Total - W1

\begin{tabular}{|c|c|c|c|c|c|c|c|}
\hline & \multicolumn{7}{|c|}{ Ln(PIB em 2000/PIB em 1970) } \\
\hline & \multirow[b]{2}{*}{ Parâmetro } & \multicolumn{6}{|c|}{ Valor dos Erros Padrões de acordo com o Corte } \\
\hline & & 0 & 0.3 & 1 & 2 & 3 & 5 \\
\hline Constante & -12.869 & $(1.693)^{* * *}$ & $(2.566)^{\star \star \star}$ & $(3.697)^{\star * *}$ & $(4.247)^{\star \star \star}$ & $(4.402)^{* * *}$ & $(4.512)^{\star \star \star}$ \\
\hline Ln(pib70) & -0.709 & $(0.022)^{\star \star \star}$ & $(0.040)^{\star \star \star}$ & $(0.045)^{\star \star \star}$ & $(0.048)^{\star \star \star}$ & $(0.051)^{\star \star \star}$ & $(0.054)^{\star \star \star}$ \\
\hline $\operatorname{Ln}($ pop) & 0.748 & $(0.112)^{* * *}$ & $(0.163)^{* * *}$ & $(0.199)^{* * *}$ & $(0.230)^{* * *}$ & $(0.244)^{* * *}$ & $(0.279)^{\star * *}$ \\
\hline $\operatorname{Ln}(p o p)^{\wedge} 2$ & -0.003 & 0.006 & 0.008 & 0.010 & 0.012 & 0.013 & 0.015 \\
\hline Esc & 0.126 & $(0.028)^{* * *}$ & $(0.032)^{\star \star *}$ & $(0.039)^{\star \star \star}$ & $(0.045)^{\star \star \star}$ & $(0.050)^{\star *}$ & $(0.056)^{\star \star}$ \\
\hline Area & 8.0E-06 & $(8.2 \mathrm{E}-07)^{\star * *}$ & $(1.9 \mathrm{E}-06)^{\star \star *}$ & $(1.9 \mathrm{E}-06)^{\star \star *}$ & $(1.8 \mathrm{E}-06)^{\star \star \star}$ & $(1.8 \mathrm{E}-06)^{\star \star \star}$ & $(1.9 \mathrm{E}-06)^{\star * *}$ \\
\hline Eletricidade & 1.023 & $(0.078)^{* * *}$ & $(0.093)^{* * *}$ & $(0.115)^{* * *}$ & $(0.133)^{* * *}$ & $(0.144)^{* \star *}$ & $(0.164)^{* * \star}$ \\
\hline escviz (W1) & 1.408 & $(0.122)^{\star * *}$ & $(0.153)^{\star \star \star}$ & $(0.237)^{\star \star \star}$ & $(0.304)^{* \star *}$ & $(0.333)^{* * *}$ & $(0.357)^{\star \star \star}$ \\
\hline popviz (W1) & 1.272 & $(0.169)^{\star \star \star}$ & $(0.256)^{\star \star \star}$ & $(0.357)^{\star \star \star}$ & $(0.403)^{\star \star \star *}$ & $(0.413)^{\star \star \star}$ & $(0.404)^{\star \star \star}$ \\
\hline $\begin{array}{l}\text { dumies de } \\
\text { estado }\end{array}$ & SIM & - & - & - & - & - & - \\
\hline $\mathrm{R}^{2}$ & 0.309 & - & - & - & - & - & - \\
\hline
\end{tabular}

${ }^{* * *}$ significante a $1 \%$, ${ }^{* *}$ significante a $5 \%$ e ${ }^{*}$ significante a $10 \%$ 
Tabela 5.5 - Crescimento do PIB Municipal Total - W2

\begin{tabular}{|c|c|c|c|c|c|c|c|}
\hline & \multicolumn{7}{|c|}{ "Ln(PIB em 2000/PIB em 1970) } \\
\hline & \multirow[b]{2}{*}{ Parâmetro } & \multicolumn{6}{|c|}{ Valor dos Erros Padrões de acordo com o Corte } \\
\hline & & 0 & 0.3 & 1 & 2 & 3 & 5 \\
\hline Constante & -0.731 & 0.667 & 0.915 & 1.207 & 1.419 & 1.515 & 1.697 \\
\hline Ln(pib70) & -0.695 & $(0.022)^{\star \star *}$ & $(0.038)^{\star \star \star}$ & $(0.043)^{\star \star \star}$ & $(0.047)^{\star \star \star}$ & $(0.050)^{\star \star \star}$ & $(0.054)^{\star * *}$ \\
\hline $\operatorname{Ln}(p o p)$ & 0.777 & $(0.121)^{\star * *}$ & $(0.169)^{* * *}$ & $(0.206)^{\star \star *}$ & $(0.237)^{\star * \star}$ & $(0.248)^{* * *}$ & $(0.281)^{\star * *}$ \\
\hline $\operatorname{Ln}(p o p)^{\wedge} 2$ & -0.004 & 0.006 & 0.009 & 0.011 & 0.013 & 0.013 & 0.015 \\
\hline Esc & 0.092 & $(0.030)^{* * *}$ & $(0.032)^{* * *}$ & $(0.037)^{\star * *}$ & $(0.042)^{\star \star *}$ & $(0.047)^{\star *}$ & $(0.053)^{*}$ \\
\hline Area & 8.0E-06 & $(8.4 \mathrm{E}-07)^{\star \star \star}$ & $(1.9 \mathrm{E}-06)^{\star \star \star}$ & $(1.9 \mathrm{E}-06)^{\star \star *}$ & $(1.8 \mathrm{E}-06)^{\star * *}$ & $(1.8 \mathrm{E}-06)^{\star \star \star}$ & $(1.8 \mathrm{E}-06)^{\star \star \star}$ \\
\hline Eletricidade & 0.970 & $(0.078)^{\star \star \star}$ & $(0.093)^{* * *}$ & $(0.113)^{\star \star \star}$ & $(0.134)^{* * *}$ & $(0.153)^{* * \star}$ & $(0.180)^{\star \star *}$ \\
\hline escviz (W2) & 0.489 & $(0.046)^{\star \star \star}$ & $(0.059)^{* \star *}$ & $(0.080)^{\star \star \star}$ & $(0.098)^{\star \star \star}$ & $(0.107)^{\star \star \star}$ & $(0.116)^{\star \star \star}$ \\
\hline popviz (W2) & 0.088 & $(0.034)^{* * \star}$ & $(0.053)^{\star}$ & 0.069 & 0.075 & 0.076 & 0.073 \\
\hline $\begin{array}{l}\text { dumies de } \\
\text { estado }\end{array}$ & SIM & - & - & - & - & - & - \\
\hline$R^{2}$ & 0.302 & - & - & - & - & - & - \\
\hline
\end{tabular}

${ }^{* * *}$ significante a $1 \%,{ }^{* *}$ significante a $5 \%$ e ${ }^{*}$ significante a $10 \%$ 


\subsection{A Exclusão das Regiões Norte e Centro Oeste}

Conforme visto na tabela 2.2, o tamanho médio das AMCs nas regiões Norte e Centro Oeste é muito superior a média das demais regiões. Aliado a isso, temos uma baixa densidade populacional nessas regiões no início dos anos 70 e o fato de que as regiões Norte e Centro Oeste apresentaram o maior crescimento no número de municípios durante os anos 80 e 90 . Tais fatores podem ser apontados como eventuais causadores de distorções nos resultados obtidos anteriormente. Para testar essa hipótese, refizemos as estimações anteriores, excluindo as regiões Norte e Centro Oeste da Amostra.

As tabelas 6.6, 6.7, 6.8, 6.9 e 6.10 são, respectivamente, réplicas das tabelas 6.1, 6.2, 6.3, 6.4 e 6.5, nas quais foram retirados os municípios das regiões Norte e Centro Oeste. Evidentemente, ocorrem mudanças na magnitude dos parâmetros devido a alteração de amostra, porém as características mais importantes das regressões permanecem inalteradas.

Em relação aos modelos nas tabelas 6.6 e 6.7, pode-se observar que os parâmetros diferem pouco entre as diferentes especificações e são numericamente parecidos aos apresentados nas tabelas 6.1 e 6.2. Além disso, o padrão da significância é praticamente o mesmo apresentado na subseção anterior. Os problemas pós estimação, presentes na amostra irrestrita, também são notados nas regressões sem a região Norte e Centro Oeste: não normalidade dos resíduos, autocorrelação espacial e parâmetros espaciais, $\lambda$ e $\rho$, acima do valor unitário.

Ao considerarmos a correção da autocorrelação feita de acordo com a abordagem de Conley (1999), também verificamos que a restrição imposta a amostra não resultou em mudança nas principais conclusões. A robustez da significância apontada acima continua presente, agora se estendendo a população da vizinhança, de tal forma que a única variável que continuou sensível a mudança no cutoff foi a educação do município sob presença de variáveis espacialmente defasadas. 
Tabela 5.6 - Crescimento do PIB Municipal Total - W1

\begin{tabular}{|c|c|c|c|c|c|c|}
\hline & \multicolumn{6}{|c|}{ Ln(PIB em 2000/PIB em 1970) } \\
\hline & OLS 1 & OLS 2 & Sem1 (pop) & Sar1 (pop) & Sem GMM & $\begin{array}{c}\text { Sar } \\
\text { GMM }\end{array}$ \\
\hline Constante & $\begin{array}{c}0.5328 \\
(0.38)\end{array}$ & $\begin{array}{c}17.1663 \\
(0.00)\end{array}$ & $\begin{array}{c}-15.8120 \\
(0.00)\end{array}$ & $\begin{array}{c}-16.7577 \\
(0.00)\end{array}$ & $\begin{array}{c}-9.6362 \\
(0.00)\end{array}$ & $\begin{array}{c}-16.7528 \\
(0.00)\end{array}$ \\
\hline $\operatorname{Ln}($ pib70) & $\begin{array}{c}-0.6588 \\
(0,00)\end{array}$ & $\begin{array}{c}-0.7181 \\
(0,00)\end{array}$ & $\begin{array}{c}-0.7283 \\
(0,00)\end{array}$ & $\begin{array}{c}-0.7062 \\
(0,00)\end{array}$ & $\begin{array}{c}-0.7283 \\
(0,00)\end{array}$ & $\begin{array}{c}-0.7060 \\
(0,00)\end{array}$ \\
\hline $\operatorname{Ln}($ pop) & $\begin{array}{c}0.7361 \\
(0,00)\end{array}$ & $\begin{array}{c}0.8254 \\
(0,00)\end{array}$ & $\begin{array}{l}0.8165 \\
(0,00)\end{array}$ & $\begin{array}{l}0.8013 \\
(0,00)\end{array}$ & $\begin{array}{c}0.7673 \\
(0,00)\end{array}$ & $\begin{array}{l}0.8010 \\
(0,00)\end{array}$ \\
\hline $\operatorname{Ln}(p o p)^{\wedge} 2$ & $\begin{array}{c}-0.0076 \\
(0.23)\end{array}$ & $\begin{array}{c}-0.0092 \\
(0.13)\end{array}$ & $\begin{array}{c}-0.0081 \\
(0.19)\end{array}$ & $\begin{array}{c}-0.0086 \\
(0.12)\end{array}$ & $\begin{array}{c}-0.0053 \\
(0.36)\end{array}$ & $\begin{array}{c}-0.0086 \\
(0.14)\end{array}$ \\
\hline esc & $\begin{array}{c}0.2625 \\
(0,00)\end{array}$ & $\begin{array}{c}0.1695 \\
(0,00)\end{array}$ & $\begin{array}{l}0.1545 \\
(0,00)\end{array}$ & $\begin{array}{l}0.1577 \\
(0,00)\end{array}$ & $\begin{array}{c}0.1271 \\
(0,00)\end{array}$ & $\begin{array}{c}0.1576 \\
(0,00)\end{array}$ \\
\hline area & $\begin{array}{c}5.8 \mathrm{E}-05 \\
(0,00)\end{array}$ & $\begin{array}{c}6.5 \mathrm{E}-05 \\
(0,00)\end{array}$ & $\begin{array}{c}6.0 \mathrm{E}-05 \\
(0,00)\end{array}$ & $\begin{array}{c}6.1 \mathrm{E}-05 \\
(0,00)\end{array}$ & $\begin{array}{c}5.3 \mathrm{E}-05 \\
(0,00)\end{array}$ & $\begin{array}{c}6.1 \mathrm{E}-05 \\
(0,00)\end{array}$ \\
\hline Eletricidade & $\begin{array}{l}1.0559 \\
(0,00)\end{array}$ & $\begin{array}{c}1.1268 \\
(0,00)\end{array}$ & $\begin{array}{l}1.1735 \\
(0,00)\end{array}$ & $\begin{array}{l}1.1388 \\
(0,00)\end{array}$ & $\begin{array}{l}1.2440 \\
(0,00)\end{array}$ & $\begin{array}{l}1.1389 \\
(0,00)\end{array}$ \\
\hline dumies de estado & SIM & SIM & SIM & SIM & SIM & SIM \\
\hline escviz & & $\begin{array}{l}1.3604 \\
(0,00)\end{array}$ & $\begin{array}{l}1.4508 \\
(0,00)\end{array}$ & $\begin{array}{l}1.1461 \\
(0,00)\end{array}$ & $\begin{array}{c}1.2242 \\
(0,00)\end{array}$ & $\begin{array}{c}1.1435 \\
(0,00)\end{array}$ \\
\hline popviz & - & $\begin{array}{l}1.6452 \\
(0,00)\end{array}$ & $\begin{array}{l}1.5718 \\
(0,00)\end{array}$ & $\begin{array}{l}1.4990 \\
(0,00)\end{array}$ & $\begin{array}{l}0.8871 \\
(0,00)\end{array}$ & $\begin{array}{l}1.4973 \\
(0,00)\end{array}$ \\
\hline$\rho$ & - & - & & $\begin{array}{c}0.9990 \\
(0,00)\end{array}$ & & $\begin{array}{l}1.0107 \\
(0,00)\end{array}$ \\
\hline$\lambda$ & - & - & $\begin{array}{c}0.9900 \\
(0,00)\end{array}$ & & 2.7264 & \\
\hline$R^{2}$ & 0.2834 & 0.3341 & 0.3770 & -17.5025 & 0.4201 & 0.3722 \\
\hline Moran & $\begin{array}{c}0.0438 \\
(0,00)\end{array}$ & $\begin{array}{c}0.0342 \\
(0,00)\end{array}$ & - & - & & \\
\hline LM-erro & $\begin{array}{c}1445.09 \\
(0,00)\end{array}$ & $\begin{array}{l}882.12 \\
(0,00)\end{array}$ & - & - & & \\
\hline LM-lag & $\begin{array}{c}696.86 \\
(0,00)\end{array}$ & $\begin{array}{c}312.38 \\
(0,00)\end{array}$ & - & - & & \\
\hline Jarque-Bera & $\begin{array}{c}3864.50 \\
(0,00)\end{array}$ & $\begin{array}{c}3983.00 \\
(0,00)\end{array}$ & $\begin{array}{c}3698.40 \\
(0,00)\end{array}$ & $\begin{array}{c}83016.00 \\
(0,00)\end{array}$ & & \\
\hline $\mathrm{N}$ & 3289 & 3289 & 3289 & 3289 & 3289 & 3289 \\
\hline
\end{tabular}

Nota:Valor $p$ entre parênteses 
Tabela 5.7 - Crescimento do PIB Municipal Total - W2

\begin{tabular}{|c|c|c|c|c|c|c|}
\hline & \multicolumn{6}{|c|}{ Ln(PIB em 2000/PIB em 1970) } \\
\hline & OLS 1 & OLS 2 & Sem & Sar & Sem GMM & Sar GMM \\
\hline Constante & $\begin{array}{c}0.5328 \\
(0.38)\end{array}$ & $\begin{array}{c}-2.0901 \\
(0,00)\end{array}$ & $\begin{array}{c}-0.3713 \\
(0.32)\end{array}$ & $\begin{array}{c}-2.5375 \\
(0,00)\end{array}$ & $\begin{array}{c}-0.5089 \\
(0.32)\end{array}$ & $\begin{array}{c}-2.7590 \\
(0.00)\end{array}$ \\
\hline Ln(pib70) & $\begin{array}{c}-0.6588 \\
(0,00)\end{array}$ & $\begin{array}{c}-0.7036 \\
(0,00)\end{array}$ & $\begin{array}{c}-0.7450 \\
(0,00)\end{array}$ & $\begin{array}{c}-0.6603 \\
(0,00)\end{array}$ & $\begin{array}{c}-0.7422 \\
(0,00)\end{array}$ & $\begin{array}{c}-0.6388 \\
(0,00)\end{array}$ \\
\hline $\operatorname{Ln}($ pop) & $\begin{array}{c}0.7361 \\
(0,00)\end{array}$ & $\begin{array}{c}0.8682 \\
(0,00)\end{array}$ & $\begin{array}{c}0.7678 \\
(0,00)\end{array}$ & $\begin{array}{c}0.7962 \\
(0,00)\end{array}$ & $\begin{array}{c}0.7751 \\
(0,00)\end{array}$ & $\begin{array}{c}0.7606 \\
(0,00)\end{array}$ \\
\hline $\operatorname{Ln}(p o p)^{\wedge} 2$ & $\begin{array}{c}-0.0076 \\
(0.23)\end{array}$ & $\begin{array}{c}-0.0113 \\
(0.06)\end{array}$ & $\begin{array}{c}-0.0041 \\
(0,00)\end{array}$ & $\begin{array}{c}-0.0097 \\
(0,00)\end{array}$ & $\begin{array}{c}-0.0046 \\
(0.41)\end{array}$ & $\begin{array}{c}-0.0089 \\
(0.10)\end{array}$ \\
\hline esc & $\begin{array}{c}0.2625 \\
(0,00)\end{array}$ & $\begin{array}{c}0.1288 \\
(0,00)\end{array}$ & $\begin{array}{c}0.1392 \\
(0,00)\end{array}$ & $\begin{array}{c}0.1041 \\
(0.01)\end{array}$ & $\begin{array}{c}0.1417 \\
(0,00)\end{array}$ & $\begin{array}{l}0.0919 \\
(0.00)\end{array}$ \\
\hline area & $\begin{array}{c}5.8 \mathrm{E}-05 \\
(0,00)\end{array}$ & $\begin{array}{c}\text { 6.2E-05 } \\
(0,00)\end{array}$ & $\begin{array}{c}4.8 \mathrm{E}-05 \\
(0,00)\end{array}$ & $\begin{array}{c}4.8 \mathrm{E}-05 \\
(0,00)\end{array}$ & $\begin{array}{c}4.8 \mathrm{E}-05 \\
(0,00)\end{array}$ & $\begin{array}{c}4.1 \mathrm{E}-05 \\
(0,00)\end{array}$ \\
\hline Eletricidade & $\begin{array}{l}1.0559 \\
(0,00)\end{array}$ & $\begin{array}{l}1.0495 \\
(0,00)\end{array}$ & $\begin{array}{c}1.1942 \\
(0,00)\end{array}$ & $\begin{array}{l}1.0086 \\
(0,00)\end{array}$ & $\begin{array}{l}1.1844 \\
(0,00)\end{array}$ & $\begin{array}{c}0.9630 \\
(0,00)\end{array}$ \\
\hline dumies de estado & SIM & SIM & SIM & SIM & SIM & SIM \\
\hline escviz & 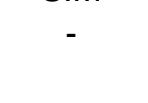 & $\begin{array}{c}0.6187 \\
(0,00)\end{array}$ & $\begin{array}{c}0.3020 \\
(0,00)\end{array}$ & $\begin{array}{c}0.3469 \\
(0,00)\end{array}$ & $\begin{array}{c}0.3338 \\
(0,00)\end{array}$ & $\begin{array}{c}0.2686 \\
(0,00)\end{array}$ \\
\hline popviz & - & $\begin{array}{c}0.5051 \\
(0,01)\end{array}$ & $\begin{array}{c}0.0737 \\
(0,07)\end{array}$ & $\begin{array}{c}0.1501 \\
(0.01)\end{array}$ & $\begin{array}{l}0.0761 \\
(0.16)\end{array}$ & $\begin{array}{l}0.1456 \\
(0.01)\end{array}$ \\
\hline$\rho$ & - & - & - & $\begin{array}{c}0.7170 \\
(0,00)\end{array}$ & - & $\begin{array}{l}1.0719 \\
(0,00)\end{array}$ \\
\hline$\lambda$ & - & - & $\begin{array}{c}0.8790 \\
(0,00)\end{array}$ & & $\begin{array}{c}0.8137 \\
(0,00)\end{array}$ & \\
\hline $\mathrm{R}^{2}$ & 0.2834 & 0.3240 & 0.4968 & 0.2312 & 0.4730 & 0.4219 \\
\hline Moran & $\begin{array}{c}0.2244 \\
(0,00)\end{array}$ & $\begin{array}{c}0.2029 \\
(0,00)\end{array}$ & - & - & - & \\
\hline LM-erro & $\begin{array}{c}1212.03 \\
(0,00)\end{array}$ & $\begin{array}{l}991.37 \\
(0,00)\end{array}$ & - & - & - & - \\
\hline LM-lag & $\begin{array}{c}793.25 \\
(0,00)\end{array}$ & $\begin{array}{l}687.47 \\
(0,00)\end{array}$ & - & - & - & - \\
\hline Jarque-Bera & $\begin{array}{c}3781.50 \\
(0,00)\end{array}$ & $\begin{array}{c}3864.50 \\
(0,00)\end{array}$ & $\begin{array}{c}2656.10 \\
(0,00)\end{array}$ & $(0,00)$ & - & - \\
\hline $\mathrm{N}$ & 3289 & 3289 & 3289 & 3289 & 3289 & 3289 \\
\hline
\end{tabular}

Nota:Valor $p$ entre parênteses 
Tabela 5.8 - Crescimento do PIB Municipal Total

\begin{tabular}{|c|c|c|c|c|c|c|c|}
\hline & \multicolumn{7}{|c|}{ Ln(PIB em 2000/PIB em 1970) } \\
\hline & \multirow[b]{2}{*}{ Parâmetro } & \multicolumn{6}{|c|}{ Valor dos Erros Padrões de acordo com o Corte } \\
\hline & & 0 & 0.3 & 1 & 2 & 3 & 5 \\
\hline Constante & 0.53281 & 6.03E-01 & 0.74379414 & 0.89189178 & 1.031374 & 1.124063 & 1.291173 \\
\hline $\operatorname{Ln}($ pib70) & -0.658791 & $(0.0228)^{\star \star \star}$ & $(0.045)^{\star \star \star}$ & $(0.051)^{\star * *}$ & $(0.057)^{\star * *}$ & $(0.061)^{\star \star *}$ & $(0.067)^{\star \star \star}$ \\
\hline $\operatorname{Ln}(p o p)$ & 0.736064 & $(0.125)^{\star * *}$ & $(0.158)^{* * *}$ & $(0.182)^{\star * *}$ & $(0.206)^{\star \star \star}$ & $(0.221)^{\star * *}$ & $(0.245)^{\star \star \star}$ \\
\hline $\operatorname{Ln}(\text { pop })^{\wedge} 2$ & -0.007572 & 6.31E-03 & 0.00760217 & 0.00922066 & 0.010597 & 0.01131858 & 0.01285 \\
\hline Esc & 0.262479 & $(0.027)^{\star * *}$ & $(0.033)^{\star * *}$ & $(0.049)^{\star * *}$ & $(0.065)^{\star * *}$ & $(0.080)^{* * *}$ & $(0.097)^{* * *}$ \\
\hline Area & $5.8 \mathrm{E}-05$ & $(6.3 \mathrm{E}-06)^{\star \star *}$ & $(9.7 \mathrm{E}-06)^{\star \star *}$ & $(1.1 \mathrm{E}-05)^{\star * *}$ & $(1.2 \mathrm{E}-05)^{\star \star \star}$ & $(1.2 \mathrm{E}-05)^{\star \star \star}$ & $(1.3 \mathrm{E}-05)^{\star \star *}$ \\
\hline \multirow{2}{*}{$\begin{array}{l}\text { Eletricidade } \\
\text { dummies de } \\
\text { estado }\end{array}$} & 1.055906 & $8.10 \mathrm{E}-02$ & 0.10173777 & 0.12866144 & 0.159097 & 0.18562719 & 0.221675 \\
\hline & SIM & - & - & - & - & - & - \\
\hline$R^{2}$ & 0.2834 & - & - & - & - & - & - \\
\hline
\end{tabular}

${ }^{* * *}$ significante a $1 \%,{ }^{* *}$ significante a $5 \%$ e *significante a $10 \%$

Tabela 5.9 - Crescimento do PIB Municipal Total - W1

\begin{tabular}{|c|c|c|c|c|c|c|c|}
\hline & \multicolumn{7}{|c|}{ Ln(PIB em 2000/PIB em 1970) } \\
\hline & \multirow[b]{2}{*}{ Parâmetro } & \multicolumn{6}{|c|}{ Valor dos Erros Padrões de acordo com o Corte } \\
\hline & & 0 & 0.3 & 1 & 2 & 3 & 5 \\
\hline Constante & -17.16626 & $(1.638)^{* * *}$ & $(2.505)^{\star * *}$ & $(3.522)^{\star \star \star}$ & $(3.980)^{\star * *}$ & $(4.100)^{\star * \star}$ & $(4.231)^{\star \star \star}$ \\
\hline Ln(pib70) & -0.718071 & $(0.022)^{\star * *}$ & 0.04320882 & 0.04802912 & 0.051252 & 0.05416988 & 0.056223 \\
\hline $\operatorname{Ln}(p o p)$ & 0.825356 & $(0.120)^{* * *}$ & $(0.160)^{* * *}$ & $(0.192)^{* * *}$ & $(0.224)^{\star * *}$ & $(0.242)^{\star * *}$ & $(0.280)^{* * *}$ \\
\hline $\operatorname{Ln}(p o p)^{\wedge} 2$ & -0.009189 & 0.006 & 0.00791516 & 0.0098971 & 0.011762 & 0.01286849 & 0.015223 \\
\hline Esc & 0.169541 & $(0.028)^{\star \star \star}$ & $(0.033)^{* * *}$ & $(0.040)^{\star \star \star}$ & $(0.046)^{\star \star \star}$ & $(0.052)^{\star * *}$ & $(0.058)^{* * *}$ \\
\hline Area & 6.5E-05 & $(6.2 \mathrm{E}-06)^{\star \star \star}$ & $(1.1 \mathrm{E}-05)^{\star \star *}$ & $(1.1 \mathrm{E}-05)^{\star \star \star}$ & $(1.2 \mathrm{E}-05)^{\star \star *}$ & $(1.3 \mathrm{E}-05)^{\star \star \star}$ & $(1.4 \mathrm{E}-05)^{\star \star \star}$ \\
\hline Eletricidade & 1.126814 & $(0.078)^{\star \star \star}$ & $(0.097)^{\star * *}$ & $(0.116)^{\star \star \star}$ & $(0.129)^{\star \star \star}$ & $(0.135)^{\star * \star}$ & $(0.143)^{\star \star *}$ \\
\hline escviz (W1) & 1.360386 & $(0.116)^{\star \star \star}$ & $(0.149)^{\star * *}$ & $(0.222)^{\star \star \star}$ & $(0.277)^{\star * *}$ & $(0.299)^{\star * \star}$ & $(0.317)^{\star * *}$ \\
\hline popviz (W1) & 1.645248 & $(0.162)^{\star \star \star}$ & $(0.248)^{\star * *}$ & $(0.340)^{\star \star \star}$ & $(0.376)^{\star \star \star}$ & $(0.379)^{\star \star \star}$ & $(0.368)^{\star \star \star}$ \\
\hline $\begin{array}{l}\text { dumies de } \\
\text { estado }\end{array}$ & SIM & - & - & - & - & - & - \\
\hline $\mathrm{R}^{2}$ & 0.3341 & - & - & - & - & - & - \\
\hline
\end{tabular}

${ }^{* * *}$ significante a $1 \%,{ }^{* *}$ significante a $5 \%$ e * significante a $10 \%$ 
Tabela 5.10 - Crescimento do PIB Municipal Total - W2

\begin{tabular}{|c|c|c|c|c|c|c|c|}
\hline & \multicolumn{7}{|c|}{ L Ln(PIB em 2000/PIB em 1970) } \\
\hline & \multirow[b]{2}{*}{ Parâmetro } & \multicolumn{6}{|c|}{ Valor dos Erros Padrões de acordo com o Corte } \\
\hline & & 0 & 0.3 & 1 & 2 & 3 & 5 \\
\hline Constante & -2.090062 & $(0.672)^{\star \star \star}$ & $(0.922)^{\star *}$ & $(1.182)^{*}$ & 1.376641 & 1.4697371 & 1.62905 \\
\hline $\operatorname{Ln}($ pib70) & -0.703568 & $(0.022)^{\star \star \star}$ & $(0.041)^{\star \star *}$ & $(0.046)^{\star * *}$ & $(0.050)^{\star \star \star}$ & $(0.053)^{\star \star \star}$ & $(0.056)^{\star \star \star}$ \\
\hline $\operatorname{Ln}(p o p)$ & 0.868234 & $(0.122)^{\star * *}$ & $(0.171)^{\star * *}$ & $(0.205)^{\star * *}$ & $(0.237)^{\star * *}$ & $(0.251)^{* * *}$ & $(0.283)^{\star * *}$ \\
\hline $\operatorname{Ln}(p o p)^{\wedge} 2$ & -0.011272 & 0.006 & 0.00855919 & 0.01063895 & 0.012485 & 0.01331436 & 0.015333 \\
\hline Esc & 0.128771 & $(0.030)^{* * *}$ & $(0.034)^{\star * *}$ & $(0.037)^{\star * *}$ & $(0.044)^{* * *}$ & $(0.045)^{* * *}$ & $(0.056)^{\star *}$ \\
\hline Area & $6.2 \mathrm{E}-05$ & $(6.3 \mathrm{E}-06)^{\star \star \star}$ & $(1.1 \mathrm{E}-05)^{\star \star \star}$ & $(1.1 \mathrm{E}-05)^{\star \star \star}$ & $(1.2 \mathrm{E}-05)^{\star \star *}$ & $(1.3 \mathrm{E}-05)^{\star \star *}$ & $(1.4 \mathrm{E}-05)^{\star * *}$ \\
\hline Eletricidade & 1.049546 & $(0.079)^{\star \star *}$ & $(0.096)^{\star * \star}$ & $(0.114)^{\star * \star}$ & $(0.132)^{\star * \star}$ & $(0.146)^{* * *}$ & $(0.167)^{\star * \star}$ \\
\hline escviz (W2) & 0.618707 & $(0.046)^{\star \star \star}$ & $(0.060)^{\star \star \star}$ & $(0.080)^{\star \star \star}$ & $(0.098)^{\star \star \star}$ & $(0.106)^{\star \star \star}$ & $(0.114)^{\star * \star}$ \\
\hline popviz (W2) & 0.505084 & $(0.035)^{\star * *}$ & $(0.055)^{\star \star *}$ & $(0.073)^{\star * *}$ & $(0.077)^{\star * *}$ & $(0.078)^{* * *}$ & $(0.074)^{\star * *}$ \\
\hline $\begin{array}{l}\text { dumies de } \\
\text { estado }\end{array}$ & SIM & - & - & - & - & - & - \\
\hline $\mathrm{R}^{2}$ & 0.324 & - & - & - & - & - & - \\
\hline
\end{tabular}

${ }^{* * *}$ significante a $1 \%,{ }^{* *}$ significante a $5 \%$ e "significante a $10 \%$ 


\section{Considerações Finais}

Esta dissertação procurou analisar empiricamente a influência do espaço, ou de modo mais especifico da aglomeração, sobre o processo de desenvolvimento econômico dos municípios brasileiros entre 1970 e 2000. Os conceitos econômicos de externalidades e retornos crescentes, especialmente através dos trabalhos da NGE, forneceram a base teórica sobre a qual se estabeleceram os testes econométricos.

Os testes empíricos realizados levaram em conta a discussão atual sobre a forma mais correta de tratar o problema espacial, utilizando tanto métodos paramétricos quanto não paramétricos de correção da dependência espacial. Sem aprofundar a questão de qual é o melhor método em termos estatísticos, apenas podemos afirmar que os resultados não diferem substancialmente com a alteração da forma de estimação.

No tocante a amostra, utilizamos uma base de dados pouco explorada, composta por unidades geográficas que levam em conta a aumento do número de municípios ocorridos entre 1970 e 2000, permitindo a comparação de áreas fixas ao longo dos anos. No entanto, como fruto dessa possibilidade de comparação, ocorre o super-dimensionamento de algumas áreas, especialmente nas Regiões Norte e Centro Oeste, o que no levou a realizar estimações com a amostra irrestrita (total de municípios) e restrita (sem as regiões Norte e Nordeste). Tal divisão mostrou-se, posteriormente, desnecessária, pois não modificou significativamente as estimações.

Como principal conclusão, pode-se dizer que o espaço, exerce forte influência sobre o processo de desenvolvimento econômico. Porém, tal relação é um tanto quanto diferente da esperada inicialmente. Em primeiro lugar, os resultados mostram que a aglomeração exerce influência positiva sobre o crescimento econômico. Encontramos um coeficiente positivo e significante para o logaritmo da população residente no município em todas as especificações utilizadas. Tal resultado era de fato esperado, em virtude da existência de externalidades tecnológicas abordadas na revisão de literatura. Porém, o termo quadrático da população, responsável por captar efeitos de congestionamento, não pode ser considerado estatisticamente diferente zero na maior parte das regressões realizadas na dissertação - 
embora o seu sinal seja negativo. Uma implicação forte, decorrente desse resultado, é a constatação de que os efeitos de congestionamento parecem irrelevantes no processo de desenvolvimento econômico das cidades brasileiras nas últimas três décadas. Sobrando apenas os efeitos benéficos originados pelas economias de aglomeração.

No entanto, esse resultado merece uma análise mais acurada. Afinal, baixa concentração econômica e populacional não parece condizer com a situação encontrada nas grandes cidades brasileiras, as quais convivem diariamente com congestionamentos, filas e violência. Porém, em pequenas e médias cidades, um maior adensamento da população pode aumentar a taxa de crescimento econômico. Como as grandes cidades representam um baixo percentual do total de municípios e as regressões refletem apenas o comportamento médio da amostra, os resultados podem exprimir a realidade das pequenas cidades. Essa discussão, embora especulativa, pode indicar a existência de ilhas de alta densidade cercadas por grandes espaços com baixa concentração populacional.

A inclusão das variáveis educação e população defasadas espacialmente possibilitou a detecção de spillovers, mostrando outro canal pelo qual o espaço impacta o desempenho econômico. O sinal positivo e significante, em todas as especificações, da educação vizinhança mostrou que o desempenho econômico de uma cidade não depende só da forma como esse município administra a sua educação, mas também do modo como o fazem as demais cidades da região. De modo semelhante, a população da vizinhança também apareceu positiva e significante. Embora tal resultado possa abrir espaço para outras interpretações, pode-se argumentar que ser vizinho de grandes cidades, em termos populacionais, significa acesso a grandes mercados, gerando dessa forma o sinal positivo observado.

As limitações dos dados, no entanto, mostram que algumas considerações devem ser levadas em conta na análise destes resultados. Em primeiro lugar, o pequeno número de controles presentes nas estimações releva a escassez de dados municipais brasileiros para estudos de crescimento de longo prazo. Além disso, o baixo número de pontos no tempo impede o uso de técnicas de painel para estudar os fatores de crescimento. Por fim, o aumento no número de municípios brasileiros nos últimos limita a interpretação das AMCs como entidades autônomas. 
Além dos dados, a possível endogeneidade presente no modelo é outro fator que torna os resultados limitados. Pode-se argumentar que a população inicial é correlacionada com o termo de erro presente no modelo. Isso ocorre pela possibilidade de antecipação, por parte dos agentes econômicos, de um maior crescimento em uma determinada região. Dessa forma, um possível evento não observável na amostra, capaz de gerar crescimento econômico, levaria a população a se concentrar em uma dada cidade, superestimando o efeito da aglomeração. A falta de instrumentos para a população impediu a correção desse problema nesta dissertação. No entanto, desdobramentos desta pesquisa devem conter formas de mitigar, ou mesmo eliminar, esse problema de endogeneidade.

Como conclusão desse trabalho, gostaríamos de apontar algumas possíveis linhas de pesquisa acerca das relações ente economia e espaço a ser realizadas em trabalhos futuros. Primeiramente, estudos futuros poderão contar com períodos mais extensos de tempo, garantindo maior consistência aos resultados encontrados. Essa maior disponibilidade de dados deverá ser acompanha de técnicas de painel capazes de lidar com a questão do espaço. Nesse sentido, Baltagi e Li (2006) e Kapoor et al. (2006) aparecem como pioneiros no desenvolvimento de estimadores com essas características. Em segundo lugar, a obtenção de equações de crescimento regional diretamente a partir de modelos teóricos ainda é um desafio a ser superado. Pesquisas futuras devem procurar ultrapassar essa barreira, produzindo testes que avaliem de modo mais acurado a validade das hipóteses econômicas desenvolvidas nos últimos anos. Por fim, novos modelos teóricos precisam ser desenvolvidos de forma a captar certas nuances da realidade - em especial a importância das interações sociais - ausentes nos modelos atuais. 


\section{Referências}

ABREU, Maria et al. Space and Growth. Timberg Working Paper $\mathbf{n}^{\circ}$ 129/3, 2004.

ADES, Alberto; GLAESER, Edward. Trade and Circuses: Explaining Urban Giants. The Quarterly Journal of Economics. v.110 n.1, fevereiro 1995.

ANDERSEN, Lykke. et al. The Dynamics of Deforestation and Economic Growth in the Brazilian Amazon. Cambridge: Cambridge University Press, 2002.

ANDRADE, Eduardo et al. Convergence clubs among Brazilian municipalities. Economics Letters, n.83, fevereiro 2004.

ANSELIN, Luc. Spatial Econometrics: Methods and Models. Dordrecht: Kluwer, 1988.

ANSELIN, LuC. Local Indicators of Spatial Association - LISA. Geographical Analyses, 1995.

ANSELIN, Luc. Spatial Econometrics. In: BALTAGI, Badi. Companion to Econometrics. Oxford: Basil Blackwell, 2001.

ANSELIN, Luc. Spatial Externalities, Spatial Multipliers, and Spatial Econometrics. International Regional Science Review, v. 26 n.2, 2003.

ARROW, Kenneth. The economic Implications of learning by doing. Review of Economic Studies, v. 29 n.3, junho, 1962.

AU, Chun-Chung; HENDERSON, John Vernon. Are Chinese Cities Too Small. Review of Economic Studies, v. 73 n.3, setembro, 2006.

ÁVILA, Rodrigo Peres de; MONASTÉRIO, Leonardo. Uma Análise do Crescimento Econômico do Rio Grande do Sul (1939- 2001). Economia, n.2 v.5, 2. sem. 2004.

AZZONI, Carlos Roberto. Concentração Regional e Dispersão das Rendas Per Capita estaduais: Análise a partir de Séries Históricas Estaduais de PIB, 1939-1995. Estudos Econômicos. v. 27 n. 2, set-dez, 1997.

BAIROCH, Paul. De Jéricho à Mexico. Villes et économie dans l'histoire. Paris: Gallimard, 1985. Tradução para o inglês (1988): Cities and Economic Development: From the Dawn of History to the Present. Chicago: University of Chicago Press. 
BALDWIN, Richard et al. Global Income Divergence, Trade and Industrialization: The Geography of Growth Take-Off. Journal of Economic Growth, v.6 n.1, março, 2001

BALDWIN, Richard et al. Economic Geography and Public Policy. New Jersey: Princeton University Press, 2003.

BALDWIN, Richard; MARTIN, Philippe. Agglomeration and regional growth. In: HENDERSON, Vernon; THISSE, Jacques-François (Org.). Handbook of Regional and Urban Economics. Amsterdam: Elsevier Science Publishers, 2004.

BALTAGI, BALDI, LI, Dong. Prediction in the panel data model with spatial correlation: the case of liquor, Spatial Economic Analysis, v.1 n.2, 2006.

BARRO, Robert J.; SALA-I-MARTIN, Xavier. Convergence across States and Regions. Brookings Papers on Economic Activity. v. 1991 n.1, 1991.

. Convergence. Journal of Political Economy. v. 100 n.1, 1992.

Economic Growth. New York: MacGraw-Hill, 1995.

BAUMONT, Catherine; HURIOT, Jean-Marie. Urban Economics in Retrospect: Continuity or Change? In: HURIOT, Jean-Marie; THISSE, Jacques-François (Org.). Economics of Cities: theoretical perspectives. Cambridge: Cambridge University Press, 2000.

BECKER, Randy; HENDERSON, John Vernon. Intra-industry Specialization and Urban Development. In: HURIOT, Jean-Marie; THISSE, Jacques-François (Org.). Economics of Cities: theoretical perspectives. Cambridge: Cambridge University Press, 2000.

BOSKER, Maarten. Growth, Agglomeration and Convergence, a Space Time Analysis for European Regions. Spatial Economic Analyses, v. 2 n.1, fevereiro, 2007.

CANTILLON, Richard. Essai sur la Aature du Commerce em General, 1755. London: Fletcher Tradução para o inglês (1964): Essay on the Nature of Trade in Genereal, New York: A. M. Kelley.

CARVALHO, Alexandre et al. Estimation of Multiequation Cross-Section Models in the Presence of Spatial Autocorrelation. IPEA: Texto para discussão $\mathrm{n}^{\circ} 1064$. Rio de Janeiro, 2005.

CICCONE, Antonio; HALL, Robert. Productivity and the Density of Economic Activity. American Economic Review. v. 87 n. 1, março, 1996. 
CICCONE, Antonio. Agglomeration-Effects in Europe. European Economic Review. v. 46 n.2, fevereiro, 2002.

CLIFF, Andrew; ORD, J. Keith. Testing the for Spatial Autocorrelation Among Regressions Residuals. Geographical Analyses, n.4, 1972.

Spatial Autocorrelation, London: Pion, 1973.

Spatial Processes: Models and Applications. London: Pion, 1981.

COE, David; HELPMAN, Elhanan. International $R \& D$ Spillovers. European Economic Review. V.39 n.5, maio, 1995.

COE, David et al. North-South R\&D Spillovers. The Economic Journal, v.107 n.440, janeiro, 1997.

CONLEY, Timothy G. GMM estimation with cross sectional dependence. Journal of Econometrics, v.92 n.1, setembro, 1999.

CONLEY, Timothy G.; MOLINARI, Francesca. Spatial correlation robust inference with errors in location or distance. Journal of Econometrics, 2007.

Da MATA, Daniel et al. Determinants of City Growth in Brazil. NBER Working Paper, n. 11585, 2005.

DIXIT, Avinash Krishna; e STIGLITZ, Joseph. Monopolistic Competition and Optimum Product Diversity. American Economic Review, v. 111 n.2, junho, 1977.

DURANTON, Gilles; PUGA, Diego. Nursery Cities: Urban Diversity, Process Innovation, and the Life Cycle of Products. The American Economic Review, v.91 n.5, 2001.

ERTUR, Cem; LE GALLO, Julie. An Exploratory Spatial Data Analysis of European Regional Disparities, 1980-1995. In: FINGLETON, Bernard (org.). European Regional Growth. New York: Springer Verlag, 2003.

FELDMAN, Maryann P. The Geography of Innovation. Dordrecht: Kluwer, 1994.

FINGLETON, Bernard. Models and Simulations of GDP per Inhabitant Across Europe's Regions: A Preliminary View. In: FINGLETON, Bernard (org.). European Regional Growth. New York: Springer Verlag, 2003.

FINGLETON, Bernard, et al. Employment Growth of Small High-technology Firms and the Role of Horizontal Clustering: Evidence from Computing Services and R\&D in Great Britain 
1991-2000. In: FINGLETON, Bernard (org.). European Regional Growth. New York: Springer Verlag, 2003.

FINGLETON, Bernard, et al. Cluster Dynamics: New Evidence and Projections for

Computing Services in Great Britain. Journal of Regional Science, v. 45 n. 2, 2005.

FLORAX, Raymond et al. Specification searches in spatial econometrics: The relevance of Hendry's methodology. Regional Science and Urban Economics, v. 33 n.5, setembro, 2003.

FLORAX, Raymond; FOLMER, Henk. Specification and Estimation of Spatial and Linear Regression Models: Monte Carlo Evaluation of Pre-Test Estimators. Regional Science and Urban Economics. v. 22 n.3, setembro, 1992.

FUJITA, Masahisa et al. The Spatial Economy: Cities, Regions and International Trade. Cambridge (Mass.): MIT Press, 1999.

FUJITA, Masahisa; THISSE, Jacques-François. The Formation of Economic Agglomeration. In: HURIOT, Jean-Marie; THISSE, Jacques-François (Org.). Economics of Cities: theoretical perspectives. Cambridge: Cambridge University Press, 2000.

FUJITA, Masahisa; THISSE, Jacques-François. Economics of Agglomeration. Cambridge: Cambridge university press, 2002.

FERREIRA, Pedro; ELLERY, Roberto. Convergência entre Renda Per Capita dos Estados Brasileiros. Revista de Econometria, v.15 n.1, 1996.

GLAESER, Edward, et al. Growth in Cities. Journal of Political Economy, v.100 n.6, 1992.

GREENE, William H. Introduction to Econometric Analysis. Upper Saddle River: Prentice Hall, 2000.

GROSSMAN, Gene M.; HELPMAN, Elhanan. Innovation and Growth in the World Economy. Cambridge MA: MIT Press, 1991.

HENDERSON, John Vernon. The Sizes and Types of Cities. American Economic Review, v.64 n. 4, dezembro, 1974.

HENDERSON, John Vernon. Urban Development: Theory, Fact and Illusion. Oxford: Oxford University Press, 1988. 
HENDERSON, John Vernon. The effects of Urban Concentration on Economic Growth. NBER Working Paper, n. 7503, 2000.

HENDERSON, John Vernon et al. Industrial Development in Cities. Journal of Political Economy. v. 103 n.5, outubro, 1995.

HURIOT, Jean-Marie; THISSE, Jacques-François. Introduction. In: HURIOT, Jean-Marie; THISSE, Jacques-François (Org.). Economics of Cities: theoretical perspectives. Cambridge: Cambridge University Press, 2000.

IGLIORI, Danilo Camargo. Economia dos Clusters Industriais. São Paulo: Editora Iglu, 2001.

JAFFE Adam et al. Geographic Localization of Knowledge Spillovers as Evidenced by Patent Citations, Quarterly Journal of Economics, v.108 n.3, Augusto, 1993.

KALEJIAN, Harry; PRUCHA, Ingmar. A Generalized Spatial Two-Stage Least Squares Procedure for Estimating a Spatial Autoregressive Model With Autoregressive Disturbances. Journal of Real Estate Finance and Economics, v. 17, 1998.

KALEJIAN, Harry; PRUCHA, Ingmar. A Generalized Moments Estimator for the Autoregressive Parameter in a Spatial Model. International Economic Review, v. 40 n.2, maio, 1999.

Keller W. Geographic Localization of International Technology Diffusion. American Economic Review, 92, 2002.

Kapoor, Mudit; et al. Panel data models with spatially correlated error components. Journal of Econometrics , v.140 n.1, setembro, 2007.

KOOPMANS T. C. Three Essays on the State of Economics Science. New York: McGrawHill, 1957.

KRUGMAN, Paul. Increasing Returns and Economics Geography. Journal of Political Economy, 99, 1991(a).

Geography and Trade. Cambridge (Mass): MIT Press, 1991(b).

KELLER Wolfgang. Geographic Localization of International Technology Diffusion. American Economic Review, v.92 n.1, março, 2002.

LALL, Somik; YILMAZ, Serdar. Regional Economic Convergence: Do Policy Instruments Make a Difference? Annals of Regional Science, 35, pp. 153-166 2001. 
LESAGE, James. Spatial Econometrics. Manuscrito não publicado disponível em http://rri.wvu.edu/regscweb.htm, 1999.

LUCAS, Robert Emerson. On the Mechanics of Economic Development. Journal of Monetary Economics. v. 22, n.1. Julho, 1998.

MAGAlHÃES, André et al. Spatial Dependence and Regional Convergence in Brazil. Real Working Paper. Urbana: September, 2000.

MANKIW, Gregory N. et al. A Contribution to the Empirics of Economic Growth. The Quarterly Journal of Economics, v. 107 n. 2, maio, 1992.

MARSHALL, Alfred. Principles of economics. Macmilan, London, 1920.

MARTIN, Philippe; OTTAVIANO, Gianmarco. Growing Locations: Industry Location in a Model of Endogenous Growth. European Economic Review, v.43 n.2, 1999.

MAS-COLLEL, Andreu et al. Microeconomic Theory. New York: Oxford University Press, 1995.

MOSSI, M. et al. Growth Dynamics and Space in Brazil. International Regional Science Review. v. 26 n.3, julho, 2003.

NEWEY, W Whitney; WEST, Kenneth. A simple, positive semi-definite, heteroskedasticity and autocorrelation consistent covariance matrix. Econometrica 55, 703 \}708, 1987.

O'FLAHERTY, Brenda. City Economics. Cambridge (Mas): Harvard University Press, 2005.

OTTAVIANO, Gianmarco; THISSE, Jacques-François. On economic geography in economic theory: increasing returns and pecuniary externalities. Journal of Economic Geography, v.1, n.2, abril 2001.

QUAH, Danny. Regional Convergence Cluster across Europe. European Economic Review, v. 40, 1996.

PACI, Raffaele; USAI, Stefano. Externalities and Local Economic Growth in Manufacturing Industries. In: FINGLETON, Bernard (org.). European Regional Growth. New York: Springer Verlag, 2003.

RAMSEY, Frank Plumpton. A Mathematical Theory of Saving. The Economic Journal, v. 38, n.152, dezembro, 1928. 
REIS, Eustáquio et al. O PIB dos Municípios Brasileiros : Metodologia e Estimativas, 1970-1996. IPEA: Texto para discussão nº1064. Rio de Janeiro, 2005.

RENAUD, Bertrand. National Urbanization Policy in Developing Countries. New York: Oxford University Press, 1981.

ROBERT-NICOUD, Frederic. The Structure of Simple 'New Economic Geography Models'. Mimeo, LSE.

ROMER, Paul M. Increasing Returns and Long Run Growth. Journal of Political Economy. v. 94 n.5, outubro, 1986.

.Endogenous Technological Change. Journal of Political Economy. v.98 n.5. Part2: The problem of Development: A Conference of the Institute for the Study of Free Enterprise System, outubro, 1990.

SAMUELSON, Paul Anthony. The transfer problem and transport costs: the terms of trade when impediments are absent. Economic Journal, v.62 n.246, junho, 1952.

SCITOVSKY, Tibor. Two concepts of external economies. Journal of Political Economy, v. 62, n.2, Abril 1954.

Solow, Robert Merton. Congestion Cost and the Use of Land for Streets. The Bell Journal of Economics and Management Science, v. 4 n.2, 1973.

SOLOW, Robert Merton. A Contribution to the Theory of Economic Growth. Quarterly Journal of Economics, v.70 n.1, fevereiro, 1956.

STARRET, David. Market Allocations of Location Choices in a Model with Free Mobility. Journal of Economic Theory, v.17 n.1, fevereiro, 1978.

Congestion Cost and the Use of Land for Streets. The Bell Journal of Economics and Management Science, v. 4 n.2, 1973.

TOBLER, Waldo. computer model simulation of urban growth in the Detroit region. Economic Geography, 46:234-240, 1970.

UNITED NATIONS. World Urbanization Prospects: the 1994 Revision. New York: United Nations, Population Division, 1994. 
UPTON, Graham J. G.; FINGLETON, Bernard. Spatial Data Analyses by Example. New York: Wiley.

WORLD WATCH INSTITUTE. State of the World 2007: Our Urban Future. New York: W. W. Norton 2007.

WOOLDRIGE, Jeffrey. Econometric Analysis of Cross Section and Panel Data. Cambridge (MA): MIT press, 2002.

ZINI JR, Alvaro Antonio. Regional Income Convergence in Brazil and Its Socioeconomic Determinants. Economia Aplicada, v.2 n.4, 1998. 